\title{
Comparing proxy and model estimates of hydroclimate variability and change over the Common Era
}

\section{PAGES Hydro2k Consortium}

A full list of authors and their affiliations appears at the end of the paper.

Correspondence: Jason E. Smerdon (jsmerdon@ldeo.columbia.edu)

Received: 8 March 2017 - Discussion started: 7 April 2017

Revised: 24 August 2017 - Accepted: 11 September 2017 - Published: 20 December 2017

\begin{abstract}
Water availability is fundamental to societies and ecosystems, but our understanding of variations in hydroclimate (including extreme events, flooding, and decadal periods of drought) is limited because of a paucity of modern instrumental observations that are distributed unevenly across the globe and only span parts of the 20th and 21st centuries. Such data coverage is insufficient for characterizing hydroclimate and its associated dynamics because of its multidecadal to centennial variability and highly regionalized spatial signature. High-resolution (seasonal to decadal) hydroclimatic proxies that span all or parts of the Common Era (CE) and paleoclimate simulations from climate models are therefore important tools for augmenting our understanding of hydroclimate variability. In particular, the comparison of the two sources of information is critical for addressing the uncertainties and limitations of both while enriching each of their interpretations. We review the principal proxy data available for hydroclimatic reconstructions over the $\mathrm{CE}$ and highlight the contemporary understanding of how these proxies are interpreted as hydroclimate indicators. We also review the available last-millennium simulations from fully coupled climate models and discuss several outstanding challenges associated with simulating hydroclimate variability and change over the CE. A specific review of simulated hydroclimatic changes forced by volcanic events is provided, as is a discussion of expected improvements in estimated radiative forcings, models, and their implementation in the future. Our review of hydroclimatic proxies and last-millennium model simulations is used as the basis for articulating a variety of considerations and best practices for how to perform proxy-model comparisons of CE hydroclimate. This discussion provides a framework for how best to evaluate hydroclimate variability and its associated dynam-
\end{abstract}

ics using these comparisons and how they can better inform interpretations of both proxy data and model simulations. We subsequently explore means of using proxy-model comparisons to better constrain and characterize future hydroclimate risks. This is explored specifically in the context of several examples that demonstrate how proxy-model comparisons can be used to quantitatively constrain future hydroclimatic risks as estimated from climate model projections.

\section{Introduction}

Research on the climate of the Common Era (CE) has exploded in scope and extent over the last 2 decades (e.g., Jones et al., 2009; Masson-Delmotte et al., 2013; PAGES 2k Consortium, 2013; Schmidt et al., 2014; Luterbacher et al., 2016; Smerdon and Pollack, 2016; Christiansen and Ljungqvist, 2017; PAGES2k Consortium, 2017). Multiple developments have driven this expansion:

1. improved interpretations of high-resolution proxies (e.g., tree rings, corals, lake sediments, documentary evidence, and speleothems; Masson-Delmotte et al., 2013);

2. the development of proxy and multi-proxy networks to extend over the full CE and into poorly sampled regions such as the oceans and tropics, Africa, and the Southern Hemisphere (e.g., Cook et al., 2010a; PAGES 2k Consortium, 2013; Tierney et al., 2013, 2015a; Neukom et al., 2014; Piovano et al., 2014; Cook et al., 2015b; McGregor et al., 2015; Palmer et al., 2015; Gergis et al., 2016; Luterbacher et al., 2016; Nash et al., 2016; PAGES2k Consortium, 2017); 
3. improved statistical methods for synthesizing proxy networks into index or gridded climate reconstructions that span all or parts of the globe (e.g., Smerdon, 2012; Tingley et al., 2012; Anchukaitis and Tierney, 2013; Dannenberg and Wise, 2013; Emile-Geay et al., 2013a, b; Steiger et al., 2014; Guillot et al., 2015; Hakim et al., 2016; Steiger and Smerdon, 2017);

4. enhanced understanding of the forcings that have operated on the climate system during the CE (e.g., Schmidt et al., 2012; Sigl et al., 2015; Jungclaus et al., 2017);

5. increased numbers of forced last-millennium simulations and simulation ensembles from fully coupled climate models (e.g., Jungclaus et al., 2010; FernandezDonado et al., 2013; Schmidt et al., 2014; Otto-Bliesner et al., 2016; Jungclaus et al., 2017);

6. comparisons between climate reconstructions and climate model simulations of the CE (e.g., Mann et al., 2009; Anchukaitis et al., 2010; Goosse et al., 2012b; Schmidt et al., 2014; Coats et al., 2015a, b; Cook et al., 2015a; Neukom et al., 2015; PAGES 2k-PMIP3 Group, 2015; Luterbacher et al., 2016; Li et al., 2017);

7. the development of new tools and techniques for proxymodel comparisons, in particular proxy system models (PSMs; Evans et al., 2013) and data assimilation techniques (Goosse et al., 2010, 2012b; Widmann et al., 2010; Bhend et al., 2012; Steiger et al., 2014; Hakim et al., 2016; Steiger and Smerdon, 2017).

These efforts are being combined to describe how and why climate varied over the $\mathrm{CE}$, with critical implications for how we model climate and anticipate the risks associated with anthropogenic climate change in the 21st century.

An important advance underlying several of the developments listed above was the inclusion of the lastmillennium (past1000; 850-1850 CE) experiment into the Coupled Model Intercomparison Project Phase 5 (CMIP5) and Paleoclimate Modelling Intercomparison Project Phase 3 (PMIP3) experimental protocol (e.g., Schmidt et al., 2011, 2014; Masson-Delmotte et al., 2013). For most of the last decade and a half, modeling CE climate relied primarily on computationally efficient energy balance models or Earth system models of intermediate complexity (e.g., Bertrand et al., 2002; Bauer et al., 2003; Crowley et al., 2003; Gerber et al., 2003; Goosse et al., 2010); only a few fully coupled climate models were initially used to derive forced transient simulations of CE climate (González-Rouco et al., 2003, 2006; Ammann et al., 2007; Hofer et al., 2011) or control simulations spanning several millennia (Raible et al., 2006; Wittenberg, 2009). More recently, however, and aided by the inclusion of the last-millennium simulation in the PMIP3 protocol, a large and growing ensemble of lastmillennium simulations is available (Masson-Delmotte et al., 2013). Critically, the last-millennium simulations associated with PMIP3 were performed with a constrained set of boundary conditions and the same model resolutions and configurations as those completed for the historical and future projection experiments in CMIP5. This latter characteristic, which will also apply to PMIP4/CMIP6 simulations (Jungclaus et al., 2017), makes evaluations of the last-millennium simulations directly comparable to the CMIP5 simulations and therefore offers the opportunity to use proxy-model comparisons over the $\mathrm{CE}$ as truly quantitative constraints on future projections (e.g., Schmidt et al., 2014).

Relative to comparisons over other paleoclimatic time periods that have a longer history of research, proxy-model comparisons specifically over the $\mathrm{CE}$ are a relatively new endeavor and involve unique considerations because of the seasonal to annual resolution of many CE proxies and the spatially resolved reconstructions that are possible because of their broad spatial sampling (e.g., Pinot et al., 1999; Braconnot et al., 2007; Otto-Bliesner et al., 2007; Braconnot et al., 2012; Schmidt et al., 2014). Initial efforts to compare proxies and models over the CE largely focused on temperature (e.g., Mann et al., 2009; Widmann et al., 2010; Goosse et al., 2012a; Fernandez-Donado et al., 2013; Masson-Delmotte et al., 2013; Phipps et al., 2013; Lehner et al., 2015; PAGES 2k-PMIP3 Group, 2015; Luterbacher et al., 2016), but more recent efforts have considered aspects of hydroclimate (e.g., Anchukaitis et al., 2010; Coats et al., 2013b, 2015a-c; Landrum et al., 2013; Tierney et al., 2013; Gómez-Navarro et al., 2015; Smerdon et al., 2015; Ljungqvist et al., 2016; OttoBliesner et al., 2016; Stevenson et al., 2016; Li et al., 2017). These hydroclimate proxy-model comparisons have been made possible not only by the growing ensemble of lastmillennium simulations, but also by the expanding number of hydroclimate proxies and their syntheses into largescale gridded hydroclimate reconstructions (e.g., Cook et al., 2004, 2010a, 2015b; Pauling et al., 2006; Jones et al., 2009; Neukom et al., 2010; Masson-Delmotte et al., 2013; Palmer et al., 2015; Brewer et al., 2007; Carro-Calvo et al., 2013).

Many of the same technical details associated with proxymodel comparisons of temperature (PAGES 2k-PMIP3 Group, 2015) are also applicable to hydroclimate. The latter nevertheless requires unique considerations before meaningful comparisons can be made, in part because of the many different processes and variables that are related to hydroclimate and because the spatial coherence of hydroclimate is more limited than temperature (e.g., Diaz et al., 2011; Graham et al., 2011; Chen et al., 2015; Swann et al., 2016; Xu et al., 2016; Mankin et al., 2017). Addressing these and other issues is an aim of contemporary research. This review is therefore motivated by the emerging efforts to compare hydroclimate variability and change over the $\mathrm{CE}$ as estimated from proxies and models in order to (1) better understand characteristics of hydroclimate over decades to centuries, (2) jointly evaluate proxies and models over these timescales, and (3) ultimately constrain projections of risk in the 21 st century associated with increasing anthropogenic emissions 
of greenhouse gases. We review the principal proxy data available for hydroclimatic reconstructions over the $\mathrm{CE}$ and highlight the contemporary understanding of how these proxies are interpreted as hydroclimate indicators in Sect. 2. In Sect. 3, we review available last-millennium simulations and discuss several outstanding challenges associated with simulating hydroclimate variability and change over the CE using fully coupled climate models. A variety of considerations and best practices related to proxy-model comparisons of CE hydroclimate are discussed in Sect. 4, and Sect. 5 explores the possibility of using these comparisons to better constrain and characterize future hydroclimate risks. Each of these sections is summarized in Sect. 6 along with the important recommendations of our review.

\section{High-resolution hydroclimate archives for the Common Era}

The following subsections review the principal proxies available for hydroclimatic studies over the CE. We survey recent advances in the development and characterization of the proxy systems and the contemporary understanding of the uncertainties associated with their interpretation.

\subsection{Corals}

Shallow-water corals of the tropical and subtropical oceans provide an archive of environmental conditions near the sea surface. Isotopic and elemental tracers incorporated into their massive carbonate skeletons during growth enable the construction of temperature- and salinity-related proxy records (e.g., Lough, 2010). When analyzed at sub-seasonal resolution to reveal annual cycles, and supported by distinct annual density bands, corals can provide accurately dated nearmonthly resolved reconstructions of seasonal, interannual, and decadal climate variability (e.g., Cobb et al., 2001; Linsley et al., 2004; Felis et al., 2009b; DeLong et al., 2012). Because they only grow for a few centuries, corals are particularly important for documenting ocean-atmosphere variability and change during the observational period back into the Little Ice Age. On rare occasions, modern and young fossil corals can be spliced together when supported by radiometric dating, which provides proxy records that cover time intervals spanning the last millennium (Cobb et al., 2003).

The most commonly analyzed variable in coral skeletons is $\delta^{18} \mathrm{O}$, which reflects a combination of both the temperature and the $\delta^{18} \mathrm{O}$ of the seawater near the ocean surface. Seawater $\delta^{18} \mathrm{O}\left(\delta^{18} \mathrm{O}_{\text {sw }}\right)$ can be influenced by atmospheric processes, such as the precipitation-evaporation (P-E) balance at the sea surface and the isotopic signature of precipitation, as well as oceanic processes such as the advection of surface currents and the upwelling of deeper water masses (Fairbanks et al., 1997; Conroy et al., 2014). Interpretations of coral records can therefore be complicated by sampling factors such as water depth and the temperature and $\delta^{18} \mathrm{O}_{\mathrm{sw}}$ of specific mi- croenvironments. In general, $\delta^{18} \mathrm{O}_{\mathrm{sw}}$ is highly correlated with ocean salinity because they are both governed by the same fundamental processes, but surface $\delta^{18} \mathrm{O}_{\mathrm{sw}}$ salinity slopes vary appreciably through space and time where they have been studied (LeGrande and Schmidt, 2011; Conroy et al., 2014). Importantly, the relative contributions of temperature and $\delta^{18} \mathrm{O}_{\mathrm{sw}}$ to the coral $\delta^{18} \mathrm{O}$ signal may vary through time, as the ratio of temperature vs. $\delta^{18} \mathrm{O}_{\mathrm{sw}}$ in the ocean likely varies on different timescales. Calibration efforts that rely on in situ observations of temperature and $\delta^{18} \mathrm{O}_{\mathrm{sw}}$ contributions to coral $\delta^{18} \mathrm{O}$ over a period of several years cannot therefore be applied to constrain decadal- to centennial-scale changes in ocean temperature from coral $\delta^{18} \mathrm{O}$. Tools such as the isotope-equipped Regional Ocean Modeling System (isoROMS; Stevenson et al., 2015a) hold great promise in probing the spatiotemporal variability of $\delta^{18} \mathrm{O}_{\mathrm{sw}}$ and its dynamical drivers; they remain under active development.

The coral $\mathrm{Sr} / \mathrm{Ca}$ temperature proxy has the potential to decouple the temperature and $\delta^{18} \mathrm{O}_{\mathrm{sw}}$ signals from coral $\delta^{18} \mathrm{O}$ records in order to deliver reconstructions of $\delta^{18} \mathrm{O}_{\mathrm{sw}}-$ a hydrologically relevant climate variable - but only a handful of centuries-long coral $\mathrm{Sr} / \mathrm{Ca}$ records currently exist (e.g., Linsley et al., 2000, 2004; Hendy et al., 2002; Felis et al., 2009b; Nurhati et al., 2011b; DeLong et al., 2012). While many studies suggest a high degree of reproducibility of coral $\mathrm{Sr} / \mathrm{Ca}$ variations for corals of the most commonly used genus Porites (Stephans et al., 2004; Nurhati et al., 2009; DeLong et al., 2013), some studies find poor reproducibility of the $\mathrm{Sr} / \mathrm{Ca}$ sea surface temperature (SST) proxy among contemporaneous Porites colonies recovered from the same reef (Linsley et al., 2006; Alpert et al., 2016). Other temperature proxies in corals include U/Ca (e.g., Hendy et al., 2002; Felis et al., 2009b), Li/Ca (e.g., Hathorne et al., 2013), and Sr-U (DeCarlo et al., 2016).

When paired with coral $\delta^{18} \mathrm{O}$ measurements, the measurement of temperature-sensitive proxies such as coral $\mathrm{Sr} / \mathrm{Ca}$ provides a tool for reconstructing $\delta^{18} \mathrm{O}_{\mathrm{sw}}$ changes of the surface ocean on seasonal, interannual, and decadal timescales (e.g., Gagan et al., 2000; Hendy et al., 2002; Ren et al., 2003; Cahyarini et al., 2008; Felis et al., 2009b; Nurhati et al., $2011 \mathrm{~b})$. The calculation of paleo- $\delta^{18} \mathrm{O}_{\mathrm{sw}}$ changes nevertheless requires careful assessment of the associated errors (e.g., Schmidt, 1999; Cahyarini et al., 2008; Nurhati et al., 2011a; Giry et al., 2013), including quantitative estimates of the analytical error of both coral $\delta^{18} \mathrm{O}$ and the paleo-temperature proxy in question (i.e., coral $\mathrm{Sr} / \mathrm{Ca}$ ), as well as the uncertainties associated with the coral temperature proxy-SST relationship that are typically estimated via in situ calibration.

Early approaches to reconstruct Pacific SST fields and the associated leading modes of large-scale variability over the last several centuries used a sparse network (11 sites) of coral $\delta^{18} \mathrm{O}$ records available at the time (Evans et al., 2002). Subsequently, the growing number of coral records has contributed to multi-proxy reconstructions of tropical temperature (D'Arrigo et al., 2009) and central equatorial Pacific 


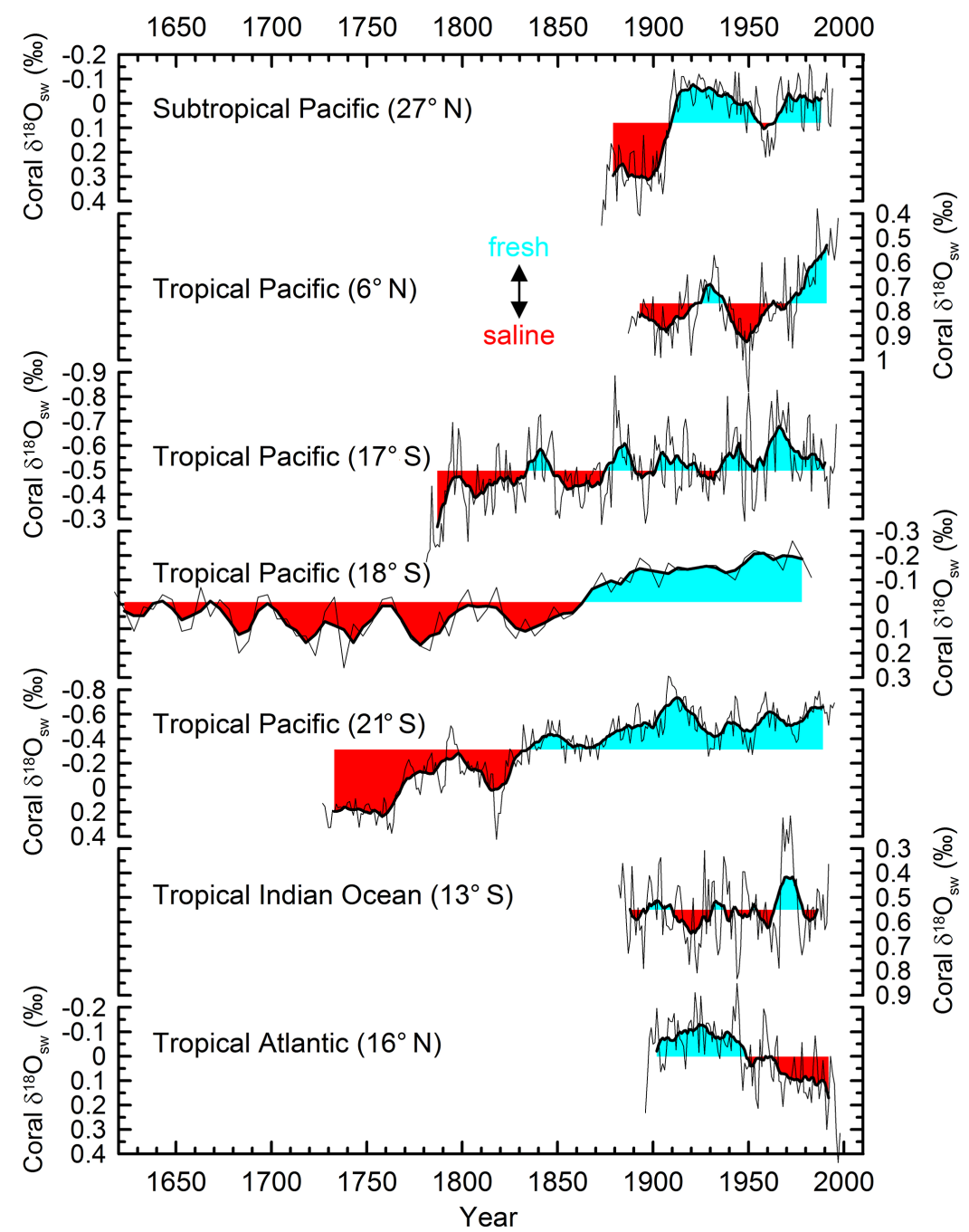

Figure 1. Annual reconstructions of seawater $\delta^{18} \mathrm{O}\left(\delta^{18} \mathrm{O}_{\mathrm{sw}}\right)$ near the ocean surface derived from sub-seasonal $\mathrm{Sr} / \mathrm{Ca}$ and $\delta^{18} \mathrm{O}$ measurements in shallow-water corals. Top to bottom: Ogasawara (Felis et al., 2009a, b) (average of Sr/Ca- $\delta^{18} \mathrm{O}_{\mathrm{sw}}$ and $\mathrm{U} / \mathrm{Ca}-\delta^{18} \mathrm{O}_{\mathrm{sw}} \mathrm{reconstruc}-$ tion), Palmyra (Nurhati et al., 2011b, 2016), Fiji (Linsley et al., 2004, 2006; Linsley, 2017a), Great Barrier Reef (Hendy et al., 2002, 2017) (pentannual resolution), Rarotonga (Linsley et al., 2000; Ren et al., 2003; Linsley, 2017b), Mayotte (Zinke et al., 2008, 2016), and Guadeloupe (Hetzinger et al., 2010, 2017). Calculated $\delta^{18} \mathrm{O}_{\mathrm{sw}}$ is derived from original publications. Note that the absolute magnitude of changes in reconstructed $\delta^{18} \mathrm{O}_{\mathrm{sw}}$ is dependent on the selected proxy-temperature relationships. Bold lines: 13-year running averages (Great Barrier Reef: three-point running average). The red and blue shading is centered on the mean of each record.

SST over the last millennium (Emile-Geay et al., 2013a). More recently, the PAGES (PAst Global ChangES) Ocean2k project has used available coral $\delta^{18} \mathrm{O}$ and $\mathrm{Sr} / \mathrm{Ca}$ records (39 sites) to reconstruct regional tropical SST for the past 4 centuries at annual resolution (Tierney et al., 2015a), and further efforts are underway to address reconstructions of the spatiotemporal patterns of $\delta^{18} \mathrm{O}_{\mathrm{sw}}$ (McGregor et al., 2016).

With regard to hydroclimate variability and change during the CE, the few available $\delta^{18} \mathrm{O}_{\text {sw }}$ reconstructions derived from paired coral $\mathrm{Sr} / \mathrm{Ca}$ and $\delta^{18} \mathrm{O}$ that extend back for a century or more suggest freshening in the southwestern tropical Pacific around the mid-19th century (Hendy et al., 2002; Ren et al., 2003; Linsley et al., 2004), in the northwestern subtropical Pacific after 1910 CE (Felis et al., 2009b), and in the central tropical Pacific after 1970 CE (Nurhati et al., 2011b) (Fig. 1). No $\delta^{18} \mathrm{O}_{\mathrm{sw}}$ trend is observed in the southwestern tropical Indian Ocean during the 20th century (Zinke et al., 2008), whereas saltier surface waters are inferred in the northwestern tropical Atlantic after 1950 CE (Hetzinger et al., 2010). In all cases, the reconstructions reveal pronounced interannual and decadal to multidecadal variability in $\delta^{18} \mathrm{O}_{\text {sw }}$. While some reconstructed changes in $\delta^{18} \mathrm{O}_{\text {sw }}$ can be definitively linked to changes in the surface freshwater balance related to El Niño-Southern Oscillation (ENSO) extremes (e.g., Nurhati et al., 2011b), the dynamical drivers of inferred lower-frequency changes in $\delta^{18} \mathrm{O}_{\mathrm{sw}}$ remain unclear 
in most cases. Efforts to quantify and describe variations in $\delta^{18} \mathrm{O}_{\mathrm{sw}}$ have thus far relied on scant observational data available from limited monitoring campaigns (Fairbanks et al., 1997; Benway and Mix, 2004; McConnell et al., 2009; Conroy et al., 2014) compiled into a global database (Schmidt et al., 1999; LeGrande and Schmidt, 2006).

Despite existing uncertainties and challenges, $\delta^{18} \mathrm{O}_{\mathrm{sw}}$ is closely related to ocean salinity, which has been referred to as "nature's rain gauge" for the data-sparse expanses of the ocean (Terray et al., 2011). Unlocking the full potential of coral $\delta^{18} \mathrm{O}_{\text {sw }}$ reconstructions would perhaps enable researchers to resolve natural vs. anthropogenic trends in the hydrological cycle. The marine hydrological cycle and the terrestrial hydrological cycle are also importantly linked through atmospheric moisture transport and continental runoff (e.g., Gordon, 2016). Moisture evaporating from the ocean feeds terrestrial precipitation, and recent studies indicate that interannual changes in the ocean-to-land moisture transport leave an imprint on sea surface salinity, establishing the potential to improve seasonal rainfall predictions in regions such as the Sahel and the Midwestern United States (Li et al., 2016a, b). Coral $\delta^{18} \mathrm{O}_{\text {sw }}$ reconstructions can also provide marine perspectives on past ocean-atmosphereland interactions and on terrestrial hydroclimate variability and change observed in continental-scale tree-ring networks (e.g., Cook et al., 2015b). The ultimate potential of these applications is further enhanced by a new generation of ocean, atmosphere, and fully coupled climate models equipped with water isotope tracer modules (see Sects. 3 and 4) that promise to deliver additional insights into the dynamical controls both oceanic and atmospheric - on $\delta^{18} \mathrm{O}_{\mathrm{sw}}$ variations.

\subsection{Tree rings}

Tree-ring proxies are an important source of high-resolution, absolutely dated information about the hydroclimate of the CE. They are widespread and well replicated, and they can be statistically calibrated against overlapping instrumental records to produce validated reconstructions and associated estimates of uncertainty in past climate variability at an annual resolution. Annual ring width is the most common proxy measurement, but sub-annual increments (Griffin et al., 2013; Knapp et al., 2016), wood density (Briffa et al., 1992b), the blue intensity proxy of wood density obtained from high-resolution images (McCarroll et al., 2002; Campbell et al., 2007; Wilson et al., 2014), and stable and radiogenic isotopes (Suess, 1980; McCarroll and Loader, 2004; Gagen et al., 2011a) also provide information from tree-ring archives about past environmental conditions. The process of developing tree-ring proxy time series begins with collecting multiple increment cores from multiple trees at a site. The annual rings are exactly dated using a process of visual and statistical cross-comparison and correlation called cross dating (Douglass, 1941; Stokes and Smiley, 1968; Fritts, 1976; Holmes, 1983). All dating issues are resolved prior to mea- surement, which is at high resolution $(0.01$ or $0.001 \mathrm{~mm})$ and with high precision. Statistical validation of the dating is performed using the software COFECHA (Holmes, 1983). Tree-ring width, sub-annual increment, and density series typically consist of dozens of trees with multiple cores per tree. More labor-intensive or costly methods using isotopes may be derived from fewer series. Proxy measurements on individual cores are combined into mean time series called "chronologies". The similarity among individual series is assessed using the inter-series correlation (the mean correlation between individual series and the other series) and the expressed population signal (EPS), which estimates how well a sample reflects the signal of a hypothetical population based on the number of samples and the inter-series correlation (Wigley et al., 1984; Cook and Kairiukstis, 1990).

Tree-ring proxy measurements reflect a combination of internal and external influences on tree growth that include climate, but also tree age and geometry and disturbance. Cook (1987) proposed a linear aggregate model of tree growth, a heuristic model to describe the different influences on the growth of annual rings:

$R_{\mathrm{t}}=A_{\mathrm{t}}+C_{\mathrm{t}}+D_{\mathrm{t}}^{\mathrm{i}}+D_{\mathrm{t}}^{\mathrm{e}}+\varepsilon_{\mathrm{t}}$,

where $R_{\mathrm{t}}$ is the width of the ring in year $t, A_{\mathrm{t}}$ is growth imposed by tree age and geometry, $C_{\mathrm{t}}$ is the influence of climate, $D_{\mathrm{t}}$ represents the impact of tree-level $\left({ }^{\mathrm{i}}\right)$ and sitelevel disturbance $\left({ }^{\mathrm{e}}\right)$, respectively, and $\varepsilon_{\mathrm{t}}$ is variability not captured by the other terms, including random error. The influence of climate is not necessarily limited to the year or growing season associated with the ring, as prior-year climate and growth can influence subsequent ring formation (Fritts, 1966). For the application of tree-ring proxies to paleoclimatology, the objective is to isolate the climatic influence on tree-ring growth, remove age-related growth trends, and minimize the influence of disturbance such that past climate as a function of ring width can be estimated.

The global network of tree-ring chronologies records a diverse set of seasonal climate signals (Meko et al., 1993; Williams et al., 2010; Breitenmoser et al., 2014; St. George, 2014; St. George and Ault, 2014; Wise and Dannenberg, 2014; Anchukaitis et al., 2017; Baek et al., 2017). The network itself is biased toward terrestrial middle and high latitudes in the Northern Hemisphere $(\mathrm{NH})$, reflecting a mix of historical focus, continental forest regions, and the abundance of trees that form unambiguous annual growth rings. Tropical regions in particular (Stahle, 1999) and the Southern Hemisphere (SH) remain underrepresented, as does subSaharan Africa (Jones et al., 2009). High-latitude and highelevation trees near the limit of their thermal tolerance are more likely to record variations in growing season temperature, while trees located in dry and semiarid sites predominantly reflect moisture availability. Wood density proxies typically have high correlations with summer temperatures at high-latitude sites (Briffa et al., 2002a, b; Wilson et al., 
2016; Anchukaitis et al., 2017), although high-latitude locations away from the tree line may also reflect precipitation and moisture (Hughes et al., 1994). Tree-ring growth within temperate mesic forests of the midlatitudes often reflects species-specific or mixed environmental signals including both moisture and temperature (Cook and Jacoby, 1977; Graumlich, 1993; Meko et al., 1993; Pederson et al., 2004; Babst et al., 2013), with some notable exceptions (e.g., Stahle et al., 1998).

The majority of tree-ring proxies reflect seasonal rather than annual climate variability. For moisture-sensitive trees, the climate response can vary across regional and continental scales. In Mediterranean regions and the American Southwest, winter, spring, and water-year (October-September) precipitation usually dominate moisture variability and treering formation, whereas continental and mesic forests reflect summer or growing season precipitation (Meko et al., 1993; Touchan et al., 2005, 2014; Esper et al., 2007; Buentgen et al., 2010, 2011; St. George et al., 2010, 2014). Treering proxies may also record winter snow accumulation, either via the subsequent influence of spring melt on growing season water balance or more directly via limitations on the initiation of growth (Pederson et al., 2011; Coulthard and Smith, 2016). Tree rings have also been used with considerable success to reconstruct river flow (e.g., Stockton and Jacoby, 1976; Woodhouse et al., 2006; Meko et al., 2007; Maxwell et al., 2011; Cook et al., 2013b; Harley et al., 2017) and runoff ratio (Lehner et al., 2017), as tree growth can reflect an integrated seasonal moisture balance signal in a fashion similar to watersheds. Sub-annual chronologies isolating earlywood and latewood width can provide differential seasonal resolution. In the North American monsoon region, for instance, earlywood width reflects winter-spring precipitation, while latewood width can more strongly reflect the summer rains associated with the monsoon (Meko and Baisan, 2001; Stahle et al., 2009; Griffin et al., 2013). Stable carbon and isotope chronologies are less common than ring width or wood density series, but can reflect a host of hydroclimatic processes, including drought (Treydte et al., 2007; AndreuHayles et al., 2016), cloud cover (Young et al., 2010; Gagen et al., 2011b), relative humidity (Edwards and Fritz, 1986; Anchukaitis and Evans, 2010), rainfall amount (Evans and Schrag, 2004), snow (Treydte et al., 2006), vapor pressure (Voelker et al., 2014), and moisture source and atmospheric circulation (Saurer et al., 2012; Williams et al., 2012).

Ring width proxies of hydroclimate in many cases reflect soil moisture as opposed to rainfall directly. Metrics that model the integrated effect of precipitation, evapotranspiration, and soil water processes on moisture balance may account for more variability in ring width than precipitation alone (e.g., Kempes et al., 2008). More importantly, the use of these metrics as climate reconstruction targets, including the Palmer Drought Severity Index (PDSI) and the Standardized Precipitation Evapotranspiration Index (SPEI), also permits large-scale uniform field reconstructions of droughts and pluvials even in the presence of a seasonality in rainfall sensitivity or mixed climate response (Cook et al., 1999). Franke et al. (2013) and Bunde et al. (2013) raised concerns about the spectral fidelity of tree-ring proxies, observing that the slope of their frequency continuum resembled neither that of temperature nor precipitation; however, a reexamination of the coeval spectra of a global network of tree-ring chronologies presented here in Fig. 2 suggests that this apparent discrepancy is because hydroclimate tree-ring proxies reflect soil moisture, which displays greater power at decadal to centennial frequencies. In a related example, Wahl et al. (2017) developed spatially explicit annual precipitation reconstructions for the western United States, which exhibit the same spectral characteristics as the corresponding instrumental data. The approach used existing river flow reconstructions as the predictor data to explicitly take advantage of the integrated moisture balance signal reflected in river flow.

Isolating the climate signal itself from the tree-ring proxy measurements also requires removing or accounting for agerelated or geometric growth trends and minimizing the influence of disturbance or other ecological processes - a method known as detrending and standardization. As Cook (1987) noted, the age-related component of tree-ring width series is "a non-stationary, stochastic process which may, as a special case, be modeled as a deterministic process". In practice, this means that although geometric curves can be fit to tree-ring series and used to remove these trends, in most cases the true shape of the curve remains uncertain. Of concern for climate reconstruction is the removal of low-frequency climate information or the potential for systematic non-climatic biases to persist or be imparted due to detrending and standardization. The choice of growth curve for removing the effects of tree age and geometry may have considerable influence on the low-frequency component of the chronology. Detrending by means of using individual curves fit to measured treering width series unavoidably results in the "segment length curse" (Cook et al., 1995), which mathematically constrains the resolved frequency range of the resulting chronology to be no lower than that corresponding to the mean length of the individual series. In order to exorcise this curse, dendroclimatologists have increasingly used regional curve standardization (RCS), which detrends each series using an estimated common growth curve for all individual trees (Briffa et al., 1992a; Esper et al., 2002) and can preserve variance at periods longer than the detrended measurement series. Nevertheless, the RCS method may impart its own biases (Briffa and Melvin, 2011; Anchukaitis et al., 2013). Similar concerns may exist for newer "signal-free" detrending methods that attempt to avoid bias in trends due to medium-frequency variance (Melvin and Briffa, 2008). Whichever method is used, detrending and the removal of non-climatic influences continues to represent one of the most important "known unknowns" (Logan, 2009) in the reconstruction of past hydroclimate from tree-ring proxies. 


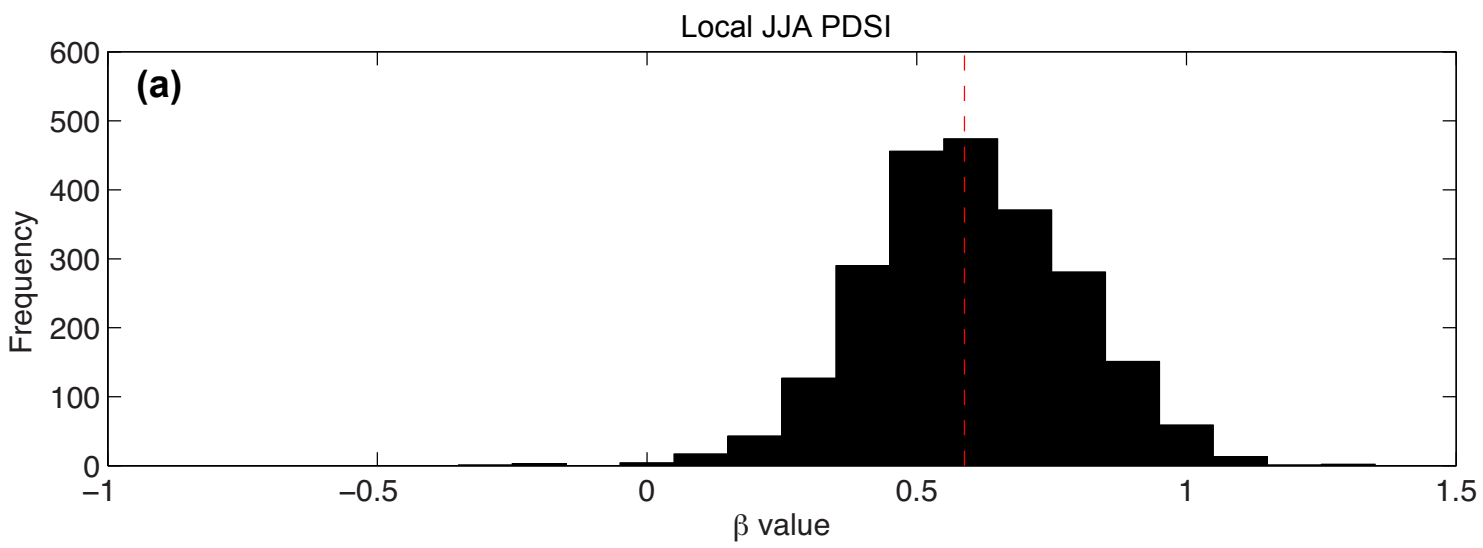

Local DJF precipitation

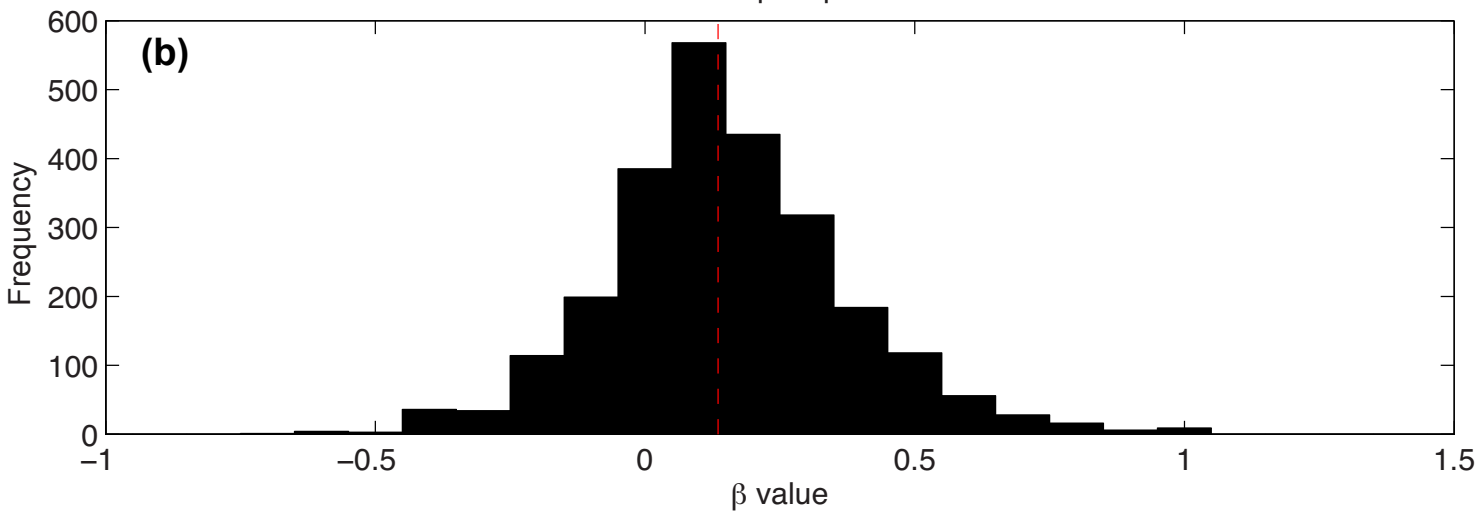

Chronology

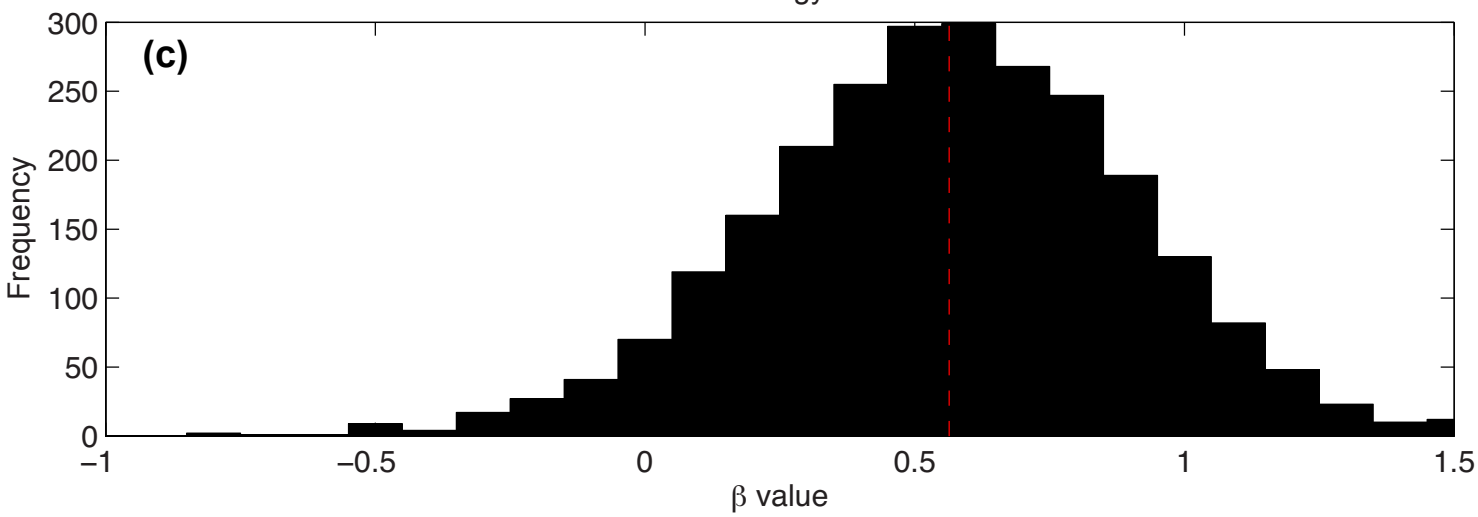

Figure 2. The slope of the multitaper spectrum expressed as $\beta$ value (Huybers and Curry, 2006) for climate and tree-ring variables at locations with tree-ring chronologies from the North American Drought Atlas (Cook et al., 1999, 2010b), the Monsoon Asia Drought Atlas (Cook et al., 2010a), the Old World Drought Atlas (Cook et al., 2015b), and the Mediterranean and North Africa (Touchan et al., 2011, 2014). (a) $\beta$-value frequency distribution for summer (JJA) PDSI from van der Schrier et al. (2011) at tree-ring chronology locations, (b) $\beta$-value frequency distribution for winter (DJF) GPCC precipitation (Schneider et al., 2014) at tree-ring chronology locations, and (c) for the tree-ring chronologies themselves. All data were normalized [0,1] over their common interval and their $\beta$ values were calculated using the multitaper method (Thomson, 1982).

\subsection{Speleothems}

Speleothems (e.g., stalagmites, stalactites) are cave deposits that form when calcium carbonate precipitates from degassing solutions as they seep into limestone caves, leaving behind archives that can provide absolutely dated records of terrestrial hydroclimate over the CE from terrain that contains karst deposits. Dates of the carbonate material are derived from disequilibrium $\mathrm{U} / \mathrm{Th}$ dating that targets intermediate daughters of the ${ }^{238} \mathrm{U}$ decay chain, specifically ${ }^{230} \mathrm{Th}$ 
and ${ }^{234} \mathrm{U}$, to provide absolute chronologies for stalagmitebased paleoclimate records (Edwards et al., 1987; Cheng et al., 2000) with precisions of $<1 \%$ ( 2 sigma; Shen et al., 2012) over the last $\sim 650$ thousand years (e.g., Cheng et al., 2016b). Stalagmite-based paleoclimate records typically resolve millennial- to orbital-scale variations in climate at a given site, owing to their slow and often steady growth averaging $2-20 \mu \mathrm{m} \mathrm{yr}^{-1}$ over many tens of millennia. Currently, numerous absolutely dated, well-replicated stalagmite $\delta^{18} \mathrm{O}$ records with decadal to centennial resolution exist from South America (Cruz et al., 2005; Wang et al., 2007), the western Pacific (Partin et al., 2007; Griffiths et al., 2009, 2010; Meckler et al., 2012; Carolin et al., 2013; Griffiths et al., 2016), China (Wang et al., 2001; Zhang et al., 2008; Cheng et al., 2016a), and the Eastern Mediterranean and Middle East (Bar-Matthews et al., 1997; Bar-Matthews et al., 1999; Fleitmann et al., 2007, 2009; Cheng et al., 2015; Flohr et al., 2017).

The generation of sub-annual to annually resolved stalagmite records holds immense potential to reconstruct hydroclimate conditions in many regions through the CE. In most cases, such high-resolution records rely on $10-500 \mu \mathrm{m}$ sampling of unusually fast-growing stalagmites that form on the order of 100-2000 $\mathrm{m} \mathrm{yr}^{-1}$ (Treble et al., 2003; Partin et al., 2013; Chen et al., 2016). Even for these fast-growing records, however, the period of the CE may only span several centimeters to, in exceptional cases, many tens of centimeters, ultimately limiting the number of $1-2 \mathrm{~mm}$ scale samples that can be drilled for conventional, high-precision U/Th dating. In many cases, stalagmite growth rates also vary significantly over the $\mathrm{CE}$, and/or growth can slow to near-zero values, causing a hiatus that can be poorly resolved by the relatively small number of available U/Th dates. These circumstances represent a significant challenge to the generation of age models for stalagmites spanning the $\mathrm{CE}$ based on radiometric dates. Two programs - BChron (Haslett and Parnell, 2008) and StalAge (Scholz and Hoffmann, 2011) - allow researchers to calculate age models and their uncertainties for stalagmite records given a set of radiometric dating constraints, including the identification of potential hiatuses (see Scholz et al. (2012) for a review of age modeling approaches to speleothem records). In rare cases, annually banded stalagmites afford the generation of layer-counted chronologies that can be tested against radiometric ages (Polyak et al., 2001), although recent work has demonstrated that apparent annual banding in stalagmites may not always be strictly annual (Shen et al., 2013).

The most widely used and best-understood measurement for speleothem-based climate reconstructions is the oxygen isotopic composition, or $\delta^{18} \mathrm{O}$, of calcite (e.g., Fleitmann et al., 2004), which under constant precipitation conditions reflects changes in cave temperature and changes in the $\delta^{18} \mathrm{O}$ of the cave dripwater feeding the stalagmite. Over the CE, air temperature in a given cave likely changed very little $\left(<1^{\circ} \mathrm{C}\right.$ or $\sim 0.2 \%$ in stalagmite $\delta^{18} \mathrm{O}$ units) such that the observed speleothem $\delta^{18} \mathrm{O}$ variations of up to $1 \%$ are governed primarily by groundwater $\delta^{18} \mathrm{O}$ variability. In most scenarios, groundwater $\delta^{18} \mathrm{O}$ composition reflects a weighted mean of rainfall $\delta^{18} \mathrm{O}$ averaged over the preceding months in wet environments (Moerman et al., 2014), while it may reflect years in semiarid and arid environments (Ayalon et al., 1998). Some studies also show that recharge of the aquifer occurs only during months when rainfall passes a given threshold, typically during the wet season in the tropics (e.g., Jones and Banner, 2003; Partin et al., 2012), but possibly associated with the winter storm season in the extratropics. While other indicators, such as band thickness (e.g., Rasbury and Aharon, 2006; Asmerom et al., 2007), trace metal ratios (see Fairchild and Treble, 2009 and references therein), and carbon isotopes (Fairchild et al., 2000; Frappier et al., 2002; Oster et al., 2015) reflect hydroclimate variability at certain sites and continue to be developed, speleothem $\delta^{18} \mathrm{O}$ remains the primary hydroclimate proxy.

Modern studies of rainfall $\delta^{18} \mathrm{O}$, cave dripwater $\delta^{18} \mathrm{O}$, rainfall amount, and speleothem $\delta^{18} \mathrm{O}$ show that, depending on the location, speleothem $\delta^{18} \mathrm{O}$ may be a record of local rainfall amount, regional hydroclimate variability, and/or changes in the source of the moisture that is linked to regional hydroclimate variability (e.g., Flohr et al., 2017 and references therein). In the past, the so-called "amount effect" was invoked to interpret a speleothem $\delta^{18} \mathrm{O}$ record (Dansgaard, 1964), which assumed an inverse, empirical relationship between rainfall amount and rainfall $\delta^{18} \mathrm{O}$ (Rozanski et al., 1993; Gat, 1996). Over the tropical ocean or over small tropical islands, the amount effect dominates the relationship on monthly to interannual timescales (Kurita, 2013), whereby local rainfall $\delta^{18} \mathrm{O}$ reflects the cumulative fractionation of water isotopes over the transit of the vapor parcel through space and time. As such, many calibration efforts demonstrate that speleothem $\delta^{18} \mathrm{O}$ is inversely correlated with the instrumental rainfall at the site on annual to decadal timescales (e.g., Partin et al., 2013). In other locations, rainfall $\delta^{18} \mathrm{O}$ and cave dripwater $\delta^{18} \mathrm{O}$ correlate better with indices of large-scale circulation patterns (e.g., ENSO indices) than with local rainfall amount (Moerman et al., 2013, 2014). Lastly, some studies show that speleothem $\delta^{18} \mathrm{O}$ can reflect changes in the source of precipitation, which alters the $\delta^{18} \mathrm{O}$ of rainfall (Aggarwal et al., 2004; Breitenbach et al., 2010). Unified frameworks and theories are now being tested to determine the underlying mechanisms controlling rainfall $\delta^{18} \mathrm{O}$ in order to more directly compare rainfall output from climate models with speleothem $\delta^{18} \mathrm{O}$ records (e.g., Lewis et al., 2010; Aggarwal et al., 2012; Jones et al., 2016; Tharammal et al., 2017). These efforts are also relevant for other proxy records of precipitation $\delta^{18} \mathrm{O}$ and $\delta \mathrm{D}$, for example sediments (Sect. 2.4) and coral records that are sensitive to the isotopic composition of rainfall (Sect. 2.1).

In addition to whether speleothem $\delta^{18} \mathrm{O}$ records rainfall amount, source, or other large-scale processes, there are other challenges that arise when interpreting them (e.g., 
Cheng et al., 2012; Denniston et al., 2015; Cai et al., 2017). A recent paper by $\mathrm{Hu}$ et al. (2017) pointed out several challenges that especially apply over the CE, including serial autocorrelation, the test multiplicity problem in connection with a climate field, and the presence of age uncertainties. Hu et al. (2017) include information and code on how to address these issues when interpreting a record. Additionally, PSMs (see Sect. 4 for more discussion) are used to simulate depositional processes, which can incorporate karst processes that may redden the karst signal (Dee et al., 2015). Such studies indicate that even in the simplest of karst models, signal reddening and the impacts of high- to low-frequency signal enhancement can be captured and explained (Partin et al., 2013).

Finally, an expanding network of speleothem records is being compiled and characterized by the PAGES2k TransRegional Project, Iso2k (Partin et al., 2015). This effort has identified over 65 published records of speleothem-based hydroclimate estimates over the CE. These records span every major continent outside of Antarctica. Continuing coordinated efforts to generate well-replicated, high-resolution records of speleothem $\delta^{18} \mathrm{O}$ that span all or part of the $\mathrm{CE}$ will yield robust reconstructions of hydroclimate that can be directly compared to the expanding number of simulations spanning the CE, some of which are isotope equipped (and more are expected as part of the CMIP6 archive).

\subsection{Sediments}

Marine and lacustrine sediment cores play an important role in the reconstruction of past hydroclimate variability over the $\mathrm{CE}$, as they often extend further back in time than corals and tree rings. There are typically multiple hydroclimate proxies that can be measured in any given sediment core, theoretically allowing for better isolation of the climatic signal from noise. Such proxies include the following:

Lake level indicators: Inference of past lake levels, particularly from closed-basin lakes, serves as a sensitive indictor of $\mathrm{P}-\mathrm{E}$ and therefore regional moisture balance (cf. Verschuren et al., 2000; Shuman et al., 2009; Xu et al., 2016; Goldsmith et al., 2017).

Pollen and other microfossil transfer functions: Microfossil assemblages such as pollen and diatoms can be directly regressed against modern climatic variables such as $\mathrm{P}-\mathrm{E}$ or mean annual precipitation. A number of statistical approaches may be employed, such as the modern analog technique (e.g., Overpeck et al., 1985), artificial neural networks (e.g., Peyron et al., 1998), variation partitioning and redundancy analysis (e.g., Li et al., 2017), and hierarchical Bayesian models (Haslett et al., 2006).

Runoff indicators: Physical and chemical characteristics of lake and marine sediments, such as the concentration of major elements ( $\mathrm{Ti}, \mathrm{Fe}, \mathrm{Ca}$ ) or grain size, can be used to infer runoff intensity, which is in turn related to the intensity, frequency, or amount of rainfall. Scanning XRF techniques make it possible to analyze such characteristics at very high temporal resolution (e.g., Haug et al., 2001, 2003; Moreno et al., 2008).

Proxies for water isotopes: In marine cores, measurement of the $\delta^{18} \mathrm{O}$ of surface-dwelling foraminifera provides insight into hydroclimatic change over the ocean, just as $\delta^{18} \mathrm{O}$ does in corals (see Sect. 2.1). Simultaneous measurement of the $\mathrm{Mg} / \mathrm{Ca}$ ratio in foraminifera gives an independent constraint on temperature, allowing for the isolation of the signal associated with the $\delta^{18} \mathrm{O}$ of seawater (Elderfield and Ganssen, 2000). In both marine and lacustrine sediments, measurements of the hydrogen isotopic composition of lipids from aquatic algae and terrestrial higher plants can be used to reconstruct sea- or lake-water $\delta \mathrm{D}$ and precipitation $\delta \mathrm{D}$, respectively (e.g., Sachs et al., 2009; Tierney et al., 2010; Richey and Sachs, 2016). Such proxies provide important constraints on processes that influence isotopes of precipitation, such as rainfall amount, source, and seasonality.

The diverse and independent proxy systems available are a clear strength of sedimentary archives. Nevertheless, working with sediment records on recent timescales presents a number of challenges that must be considered when interpreting data and incorporating them into a multi-proxy reconstruction framework. An obstacle inherent to working with sediments is the uncertainty related to chronology - that is, the assignment of depth horizons to points in time. Varved sediments (sediments in which distinct layers are deposited on a demonstrably annual basis) have relatively tightly constrained chronologies, although counting errors will propagate downcore, as is the case with any annually layered archive that is not cross-dated (Comboul et al., 2014). Varves are nevertheless rare in marine environments and in the terrestrial tropics, and in their absence chronological assignment depends on radiometric methods. The two most common systems used in dating recent marine sediments are ${ }^{210} \mathrm{~Pb}$ and ${ }^{14} \mathrm{C}$. With a half-life of 22.2 years, ${ }^{210} \mathrm{~Pb}$ is ideal for dating sediments spanning the last 100-150 years and can provide an accuracy ranging from 1-20 years. Older sediments are dated primarily with ${ }^{14} \mathrm{C}$, which has a halflife of 5730 years. In lakes, ${ }^{14} \mathrm{C}$ may be measured on terrestrial macrofossils or bulk organic carbon, although the latter can be affected by the presence of old carbon (coming from, for example, an isolated hypolimnion or terrestrial $\mathrm{CaCO}_{3}$ input). In marine sediments, ${ }^{14} \mathrm{C}$ is typically measured on species of planktonic foraminifera. In this case, one must account for the ${ }^{14} \mathrm{C}$ age of the ocean water (ca. 2001500 years) or the marine "reservoir effect". Globally, the average ${ }^{14} \mathrm{C}$ age of ocean water is 400 years (Stuiver and Braziunas, 1993). Local deviations from this age are commonly expressed as $\Delta R$, the values of which are determined by measuring the ${ }^{14} \mathrm{C}$ age of contemporary known-age, prenuclear marine specimens such as bivalves and corals.

Uncertainties in ${ }^{14} \mathrm{C}$ dating range from decades (ca. 3040 years) to centuries (ca. 200-300 years) and depend on the accuracy of the measurement, where the date falls on 

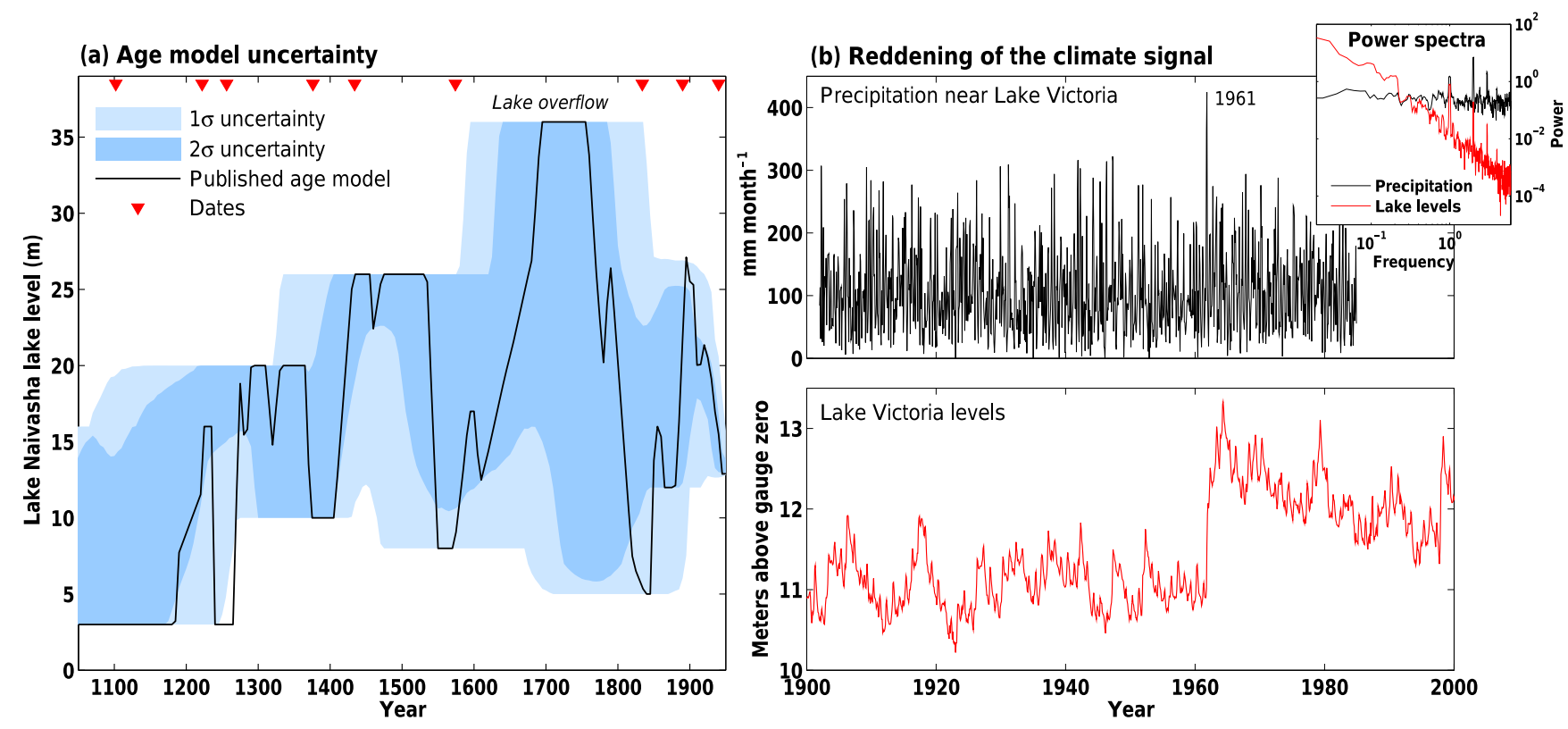

Figure 3. Examples of the effect of age model uncertainty and spectral reddening on paleoclimate signatures in sedimentary archives. (a) Age model uncertainty associated with the Lake Naivasha (East Africa) lake level record (Verschuren et al., 2000) spanning the last millennium. Data on the published age model are plotted in black. Blue regions represent the $1 \sigma$ and $2 \sigma$ uncertainty bounds for the dating of the data, applying a Monte Carlo method for iterating age model uncertainty (Anchukaitis and Tierney, 2013). Red triangles denote the locations of chronological constraints (dates). Note that the timing of lake overflow during the Little Ice Age may have occurred anytime between 1600 and 1800 CE. Figure after Tierney et al. (2013). (b) Comparison of historical monthly precipitation (from the Global Historical Climatology Network; Peterson and Vose, 1997) and lake level data (from Stager et al., 2007) for Lake Victoria, East Africa. Both the precipitation and the lake level data are from Jinja, Uganda. Note the step-change response of lake level to an extreme rainfall event in 1961. Inset shows a comparison of the power spectra; note the loss of high-frequency and increase in low-frequency power in the lake level data compared to precipitation.

the ${ }^{14} \mathrm{C}$ calibration curve (placement on a radiocarbon production "plateau" will increase error), and uncertainties in reservoir corrections (see example in Fig. 3a). Thus, over the timeframe of the $\mathrm{CE}$, chronological uncertainties can be formidable. Increased density of dating and independent constraints on sedimentation rates can improve the precision of the chronology, but multiple age-depth models are always possible. This uncertainty is best dealt with through an ensemble approach, i.e., the use of a Monte Carlo or Bayesian age modeling method to produce a posterior ensemble of age-depth models that can then be used iteratively in a reconstruction framework (Ramsey, 2008; Blaauw and Christen, 2011; Anchukaitis and Tierney, 2013; Tierney et al., 2013; Werner and Tingley, 2015).

Another special consideration for sedimentary archives is the role of bioturbation. In low-oxygen environments, sediments may be deposited essentially "undisturbed" and will appear laminated. In most locations, however, bottom water oxygen is present and the benthos (organisms living on and in the seafloor) will mix the upper layers of the sediment. In the ocean, bioturbation depths average $8 \mathrm{~cm}$ globally but vary from $0-20 \mathrm{~cm}$ depending on productivity, bottom water oxygen, and sedimentation rate (Teal et al., 2008). Bioturbation thus acts as a low-pass filter on sedimentary proxy signatures and will redden the spectra of proxy time series. Diffusionbased forward models for bioturbation exist and can be incorporated into reconstruction frameworks (e.g., Trauth, 2013).

The proxy systems in sediment archives also have the capability to redden the spectra of paleoclimate signatures, and this must be considered both for inter-archive and proxymodel data comparisons. Lake level records, for example, are typically low-pass-filtered representations of regional hydroclimate. Lake water residence time and hydraulic considerations buffer variability in P-E such that lake levels will have more power at low frequencies and less at high frequencies than the local climate variable (see example in Fig. 3b). The amount of reddening depends on individual lake systems and can be forward modeled if lake geometry, inputs, and outputs are known (e.g., Hurst, 1951; Hostetler and Benson, 1994).

Complications arising from chronology and bioturbation mean that most sediment proxy data are best suited for inferring hydroclimate change on multidecadal and longer timescales. Nevertheless, understanding shifts in hydroclimate over these longer intervals during the $\mathrm{CE}$ is important because such changes set the baseline for long-term droughts 
or pluvials and complement higher-resolution perspectives from other hydroclimatic proxies.

\subsection{Documentary evidence}

Documentary evidence includes noninstrumental information on past climate and weather conditions before the advent of continuous meteorological measurements, the principal sources of which are descriptive documentary data (i.e., descriptive observations of weather, reports from chronicles, ship logbooks, travel diaries, etc.) and documentary proxy data. This latter source of information refers to indirect records of events or practices tied to specific weather events or climatic conditions; examples include the beginning of agricultural activities, the freeze and thaw dates of waterways, records of floods, and reports of religious ceremonies in response to impactful meteorological conditions (see Brazdil et al., 2005, for a review).

Descriptive evidence generally has good dating control and high temporal resolution (for specific periods and regions, even daily resolution is possible), but this evidence is also typically discontinuous. Documentary sources also tend to emphasize extreme events because the consequences of their socioeconomic impacts render them more likely to have been recorded (Brazdil et al., 2005). Typical examples include hydrometeorological extremes (flooding, hail, torrential rains) and other natural hazards that impacted the success of harvests or placed livestock in jeopardy (Pfister et al., 1999; Camenisch et al., 2016). China, Japan, and Europe comprise the three main geographic regions where an abundance of historical climatological sources exist. More recently, assessments have been initiated for records from South America that date back to the beginning of Spanish colonization (Neukom et al., 2010). Data from Africa, North America, and Australia are available for much shorter periods into the past in comparison with other regions where more abundant documentary data exist (e.g., Grab and Nash, 2010; Nash and Grab, 2010; Fenby and Gergis, 2013; Gergis and Ashcroft, 2013; Neukom et al., 2014; Nash et al., 2016).

\subsubsection{Europe}

Research on documentary-based past hydroclimate in Europe is temporally and geographically heterogeneous (e.g., Brazdil et al., 2005; Pauling et al., 2006). Potentially useful documentary evidence is available in most of Europe and the Mediterranean regions, although only a few regions include hydroclimatic studies (including droughts, floods, and other extremes), these being in the Czech Republic, Germany, the eastern Mediterranean, Byzantium, Hungary, Italy, Portugal, Spain, Switzerland, and the UK (Brazdil et al., 2005, 2010, 2012, 2013, 2016; Luterbacher et al., 2006; Wetter et al., 2011, 2014; Dobrovolny et al., 2015; Mozny et al., 2016; Xoplaki et al., 2016; Domínguez-Castro et al., 2008, 2014; Barriendos et al., 2003, 2014; Todd et al., 2013; Benito et al., 2015; Himmelsbach et al., 2015). New and promising data from other regions do exist, but they have not yet been fully explored. Some records prior to 1000 CE (e.g., Xoplaki et al., 2016 and references therein) are available during the Byzantine Empire (including the Balkans) and the Carolingian Empire. Subsequent to $1000 \mathrm{CE}$, specific periods can be characterized (Brazdil et al., 2005; Pfister et al., 2008) that include a progression from individual reports of significant socioeconomic anomalies and disasters (weather induced, floods, droughts) from 1000-1200 CE to almost full descriptions for monthly weather (including some daily weather and extremes) from 1500-1800 CE. From around 1650 through $1860 \mathrm{CE}$, early instrumental measurements made by individuals and organized by scientific and economic societies become available. These earlier efforts are followed by shortlived international instrumental networks (up to the end of the 18 th century) and initiatives within 19th century emerging nation states.

Despite the relative abundance of information in Europe, our understanding of hydroclimate variability (including short-duration and extensive drought and flood periods) is still limited because only a small number of well-dated documentary proxy records with high temporal resolution are available and because they are unevenly distributed over the continent (e.g., Brazdil et al., 2005). Some synthesis efforts have nevertheless been pursued. Pauling et al. (2006) and Carro-Calvo et al. (2013) combined early instrumental series, documentary proxy time series, and natural proxies to reconstruct seasonal precipitation fields for European and Mediterranean land areas covering the past half millennium. A similar reconstruction was provided by Casty et al. (2007), who used only documentary and natural proxies tied to precipitation, which allows for comparison to independently reconstructed temperature and pressure fields. Collectively, identifying and characterizing historical extreme events that have severely stressed human or natural systems (e.g., the onset, duration, frequency, and intensity of droughts and floods) is a critical endeavor, and our capacity for studying these events is possible through the continued development and interpretation of documentary records in Europe.

\subsubsection{Asia}

Hydroclimatic reconstructions over China, including those from documentary records, are reviewed in Ge et al. (2016), Fan (2015), and Hao et al. (2016). The region has rich historical resources including classical documents, local gazettes, governmental archives, and personal diaries (Fig. 4). This collection of information has been extensively studied to extract weather and climate information in efforts that extend back to the 1920s (e.g., Chu, 1926, 1973; Yao, 1943; Zhang and Gong, 1980). Abundant hydroclimate reconstructions from these records can be separated into two common classes: (1) qualitative reconstructions such as dryness and wetness (D-W) indices and (2) quantitative precipitation re- 


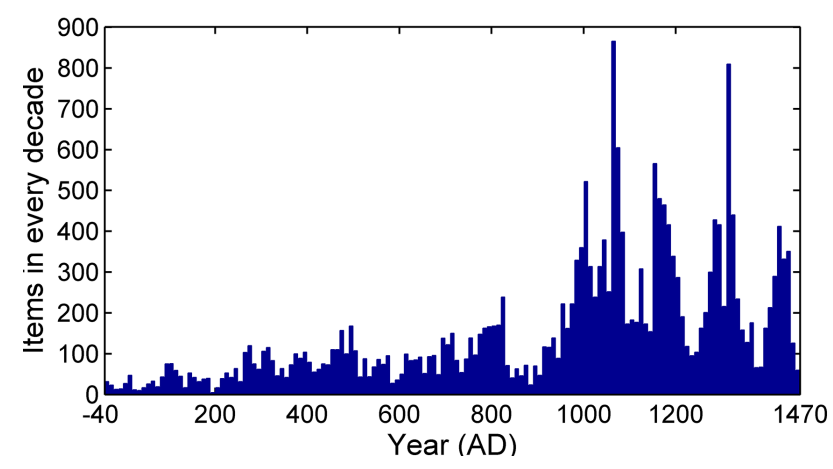

Figure 4. The amount of climatic information extracted from Chinese classical documents (a reproduction of Fig. 7 in Ge et al., 2008b).

constructions. Qualitative reconstructions are generated by counting the number of dry and wet events, which occasionally consider the timing, scale, and severity of these events based on written descriptions in a wide range of historical papers (Gong and Hameed, 1991; Ge et al., 2016). Numerous reconstructions in this class have been published, for instance D-W series for 120 subregions across China from 14702000 CE (CMA, 1981; Zhang et al., 2003), a regional D-W dataset from 960-1992 CE (Zhang et al., 1997), a 1000-year D-W dataset for the Guanzhong Plain (Hao et al., 2017), the history of moisture conditions for the last 2000 years (Gong and Hameed, 1991), D-W series for 63 sites since 137 BCE (Zhang, 1996), and a relatively new D-W dataset for the period 501-2000 CE that has been subsequently extended to cover the last 2000 years (Zheng et al., 2006, 2014). The characteristics of droughts and floods based on these records have been extensively studied, such as the frequency, severity, spatial patterns, and decadal to centennial variability of hydroclimate, as well as the relationship between D-W indices and temperature (e.g., Wang and Zhao, 1979; Zhang and Crowley, 1989; Yan et al., 1992; Qian et al., 2003; Shen et al., 2009; PAGES 2k Consortium, 2013).

For quantitative reconstructions, around 300 years of annual and/or seasonal precipitation time series are available in northern China and the mid-lower Yangtze River valley (Zhang and Liu, 2002; Zhang et al., 2005; Zheng et al., 2005) using accurate weather and climate descriptions from "Qing Yu Lu" (clear and rain records), "Yu Xue Fen Cun" (rainfall infiltration and snowfall depth, Ge et al., 2005), and others. Qualitative precipitation reconstructions have been used to study meiyu (plum rain) activity (Zhang and Wang, 1991; Ge et al., 2008a; Ding et al., 2014a), an exceptional flooding event in 1755 CE (Zhang et al., 2013), and East Asian summer monsoon variations at multidecadal and centennial scales (Hao et al., 2015). Because quantitative precipitation reconstructions over China are relatively short and spatially limited, researchers have tried to provide quantitative precipitation information by combining $\mathrm{D}-\mathrm{W}$ indices and other high-resolution proxies. For example, by incorporating D-W indices and tree-ring proxies, Yi et al. (2012) reconstructed annual summer precipitation in north-central China back to $1470 \mathrm{CE}$, and Feng et al. (2013) generated a gridded reconstruction of warm season precipitation over Asia spanning the last 500 years. Some of these Chinese efforts are complemented by efforts in Japan - many documents dating from the Edo era (1603-1868 CE) contain records of daily weather conditions. The majority of the known daily weather records have been digitized and added to the Historical Weather Database of Japan (Mikami, 1988, 2008). Other long documentary records come from phenological information from Kyoto (Aono and Kazui, 2008) and from direct human observations of freezing dates for Lake Suwa, Japan (Sharma et al., 2016, and references therein).

\section{Coupled model simulations of the Common Era}

In concert with hydroclimate proxy development over the last several decades, efforts to model the CE have also progressed considerably. In the last decade, two complementary approaches have enhanced the relevance of paleoclimate simulations for our understanding of past climate evolution. The first is the use of single-model ensembles (Jungclaus et al., 2010; Hofer et al., 2011; Otto-Bliesner et al., 2016) comprising multiple simulations with the same model configuration and experimental design (i.e., Schmidt et al., 2011; OttoBliesner et al., 2016). These ensemble frameworks allow for the systematic characterization of simulated internal climate variability and forced responses, as well as an assessment of uncertainties in boundary forcing estimates. Single-model ensembles are nevertheless subject to the peculiarities and deficiencies of the individual model used.

The second development has been coordinated multimodel ensembles, such as the PMIP last-millennium simulations (Braconnot et al., 2012; Schmidt et al., 2014; Jungclaus et al., 2017), that allow for the combination of model information either probabilistically or via measures of multimodel consensus. The incorporation of the core PMIP simulations into the framework of CMIP has allowed for crosstime-period analyses of past, present, and future climate states and variability. Moreover, the fidelity of CMIP models is thoroughly evaluated over the historical instrumental period (e.g., Flato et al., 2013). Because the same models are used for simulations of the past, their strengths and limitations can be taken into account when comparing them with paleoclimatic information. Collectively, the analyses of single-model ensembles, multi-model ensembles, and individual models can provide insight into how models simulate climate dynamics on paleoclimatic timescales, thus informing our understanding of the real climate system and improving our assessments of climate risks in the future. See Table 1 for a list of available simulations of the last millennium, including the associated forcings. 
Table 1. PMIP3/CMIP5 and post-PMIP3/CMIP5 simulations of the CE and their associated forcings.

\begin{tabular}{|c|c|c|c|}
\hline \multicolumn{4}{|c|}{ PMIP3/CMIP5 experiments } \\
\hline BCC-csm1-1* & $(1 \times) 850-2005$ & $\mathrm{SW}^{15} \cdot \mathrm{V}^{24} \cdot \mathrm{G}^{30,33,34} \cdot \mathrm{A}^{45} \cdot \mathrm{O}^{60}$ & \\
\hline $\mathrm{CCSM}^{*}$ & $(1 \times) 850-2005$ & $\mathrm{SW}^{18} \cdot \mathrm{V}^{24} \cdot \mathrm{G}^{30,33,34} \cdot \mathrm{A}^{45} \cdot \mathrm{L}^{51} \cdot \mathrm{O}^{60}$ & Landrum et al. (2013) \\
\hline CSIRO-MK3L-1-2 & $(1 \times) 851-2000$ & $\mathrm{SW}^{14} \cdot \mathrm{V}^{25 *} \cdot \mathrm{G}^{30,33,34} \cdot \mathrm{O}^{60}$ & \\
\hline FGOALS-s $2 *$ & $(1 \times) 850-2005$ & $\mathrm{SW}^{18} \cdot \mathrm{V}^{24} \cdot \mathrm{G}^{30,33,34} \cdot \mathrm{A}^{45} \mathrm{O}^{60}$ & \\
\hline GISS-E2-R & $(8 \times) 850-2005$ & $\begin{array}{l}{ }^{*} \mathrm{SW}^{17} \cdot \mathrm{V}^{25} \cdot \mathrm{G}^{30,33,34} \cdot \mathrm{A}^{45} \cdot \mathrm{L}^{51} \cdot \mathrm{O}^{60} \\
\mathrm{SW}^{17} \cdot \mathrm{V}^{24} \cdot \mathrm{G}^{30,33,34} \cdot \mathrm{A}^{45} \cdot \mathrm{L}^{51} \cdot \mathrm{O}^{60} \\
\mathrm{SW}^{17} \cdot \mathrm{G}^{30,33,34} \cdot \mathrm{A}^{4} \cdot \mathrm{L}^{51} \cdot \mathrm{O}^{60} \\
\mathrm{SW}^{18} \cdot \mathrm{V}^{25} \cdot \mathrm{G}^{30,33,34} \cdot \mathrm{A}^{45} \cdot \mathrm{L}^{51} \cdot \mathrm{O}^{60} \\
\mathrm{SW}^{18} \cdot \mathrm{V}^{24} \cdot \mathrm{G}^{30,33,34} \cdot \mathrm{A}^{45} \cdot \mathrm{L}^{52} \cdot \mathrm{O}^{60} \\
\mathrm{SW}^{18} \cdot \mathrm{G}^{30,33,34} \cdot \mathrm{A}^{4} \cdot \mathrm{L}^{51} \cdot \mathrm{O}^{60} \\
\mathrm{SW}^{18} \cdot \mathrm{V}^{25} \cdot \mathrm{G}^{30,33,34} \cdot \mathrm{A}^{45} \cdot \mathrm{L}^{52} \cdot \mathrm{O}^{60} \\
\mathrm{SW}^{18} \cdot \mathrm{V}^{24} \cdot \mathrm{G}^{30,33,34} \cdot \mathrm{A}^{45} \cdot \mathrm{L}^{51} \cdot \mathrm{O}^{60}\end{array}$ & (4) \\
\hline HadCM3* & $(1 \times) 800-2000$ & $\mathrm{SW}^{14} \cdot \mathrm{V}^{25} \cdot \mathrm{G}^{30,32,34} \cdot \mathrm{A}^{43} \cdot \mathrm{L}^{51} \cdot \mathrm{O}^{60}$ & Schurer et al. (2013) \\
\hline IPSL-CM5A-LR* & $(1 \times) 850-2005$ & $\mathrm{SW}^{15} \cdot \mathrm{V}^{24} \cdot \mathrm{G}^{30,33,34} \cdot \mathrm{O}^{60}$ & \\
\hline MIROC-ESM & $(1 \times) 850-2005$ & $\mathrm{SW}^{16} \cdot \mathrm{V}^{25} \cdot \mathrm{G}^{30,34,39} \cdot \mathrm{O}^{60}$ & (5) \\
\hline MPI-ESM-P* & $(1 \times) 850-2005$ & $\mathrm{SW}^{15} \cdot \mathrm{V}^{25} \cdot \mathrm{G}^{30,33,34} \cdot \mathrm{A}^{45} \cdot \mathrm{L}^{51} \cdot \mathrm{O}^{60}$ & \\
\hline \multicolumn{4}{|c|}{ Post-PMIP3/CMIP5 experiments } \\
\hline CESM1(CAM5) & $\begin{array}{l}(13 \times) 850-2005^{*} \\
(4 \times) 850-2005 \\
(5 \times) 850-2005 \\
(3 \times) 850-2005 \\
(3 \times) 850-2005 \\
(3 \times) 850-2005 \\
(5 \times) 1850-2005\end{array}$ & $\begin{array}{l}\mathrm{SW}^{18} \cdot \mathrm{V}^{24} \cdot \mathrm{G}^{30,33,34} \cdot \mathrm{A}^{45} \cdot \mathrm{L}^{51} \cdot \mathrm{O}^{60} \\
\mathrm{SW}^{18} \\
\mathrm{~V}^{24} \\
\mathrm{G}^{30,33,34} \\
\mathrm{~L}^{51} \\
\mathrm{O}^{60} \\
\mathrm{~A}^{45}\end{array}$ & Otto-Bliesner et al. (2016) \\
\hline
\end{tabular}

(1) Key for superscript indices in forcing acronyms:

[1] Solar:

[14] Steinhilber et al. (2009) spliced to Wang et al. (2005).

[15] Vieira and Solanki (2010) spliced to Wang et al. (2005)

[16] Delaygue and Bard (2011) spliced to (Wang et al., 2005).

[17] Steinhilber et al. (2009) spliced to Lean et al. (2005).

[18] Vieira et al. (2011) spliced to Lean et al. (2005).

[2] Volcanic:

[24] Gao et al. (2008). In the GISS-E2-R simulations this forcing was implemented twice as large as in Gao et al. (2008).

[25] Crowley and Unterman (2013). In the CSIRO simulation this forcing was implemented as a global mean reduction in total solar irradiance.

[3] GHGs:

[30] Fluckiger et al. (1999); Fluckiger et al. (2002); Machida et al. (1995)

[32] Johns et al. (2003).

[33] Hansen and Sato (2004)

[34] MacFarling Meure et al. (2006)

[39] $\mathrm{CO}_{2}$ diagnosed by the model.

[4] Aerosols:

[43] Johns et al. (2003).

[45] Lamarque et al. (2010).

[5] Land use, land cover:

[51] Pongratz et al. (2009) spliced to Hurtt et al. (2006)

[52] Kaplan (2011).

[6] Orbital:

[60] Berger (1978).

\subsection{Simulating hydroclimate over the Common Era}

In general, climate models do not simulate hydroclimatic variables, such as precipitation, as realistically as surface temperatures (Flato et al., 2013; e.g., Fig. 5a). This is due to the fact that hydroclimate is described by processes such as convection and cloud physics (Stephens et al., 2010) that operate at a fine spatial scale and must therefore be described by parameterizations within the current generation of global climate models. There are also limitations in the represen- 
(a) Taylor Plot : PMIP3 : AM- vs GPCP : 1980-99

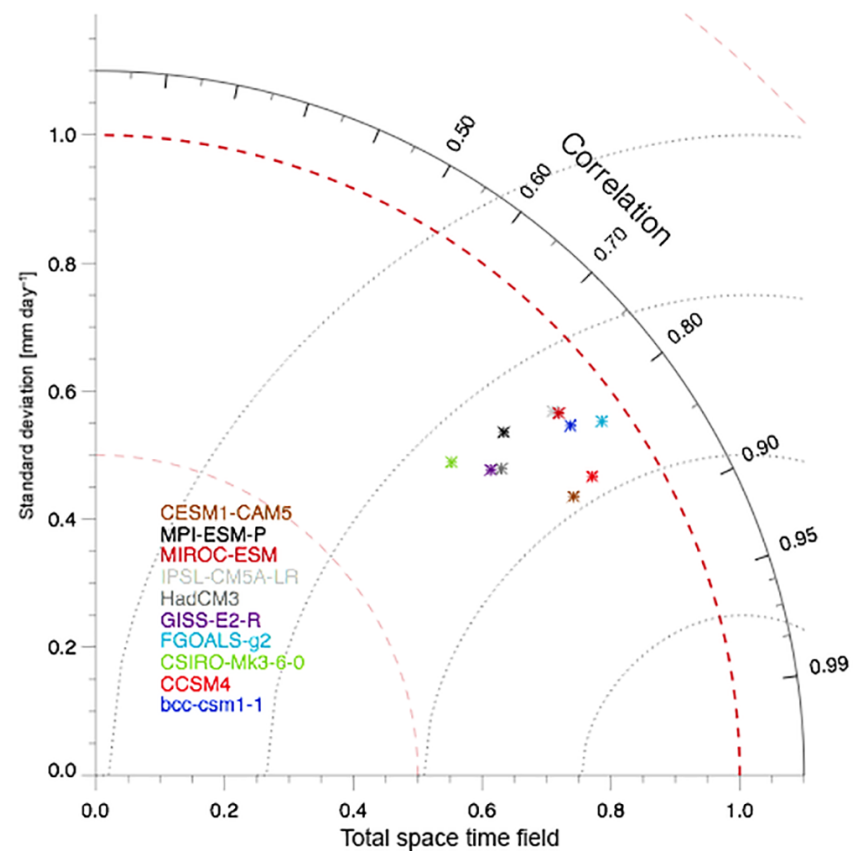

(b) Taylor Plot : PMIP3 : ENSO - vs GPCP

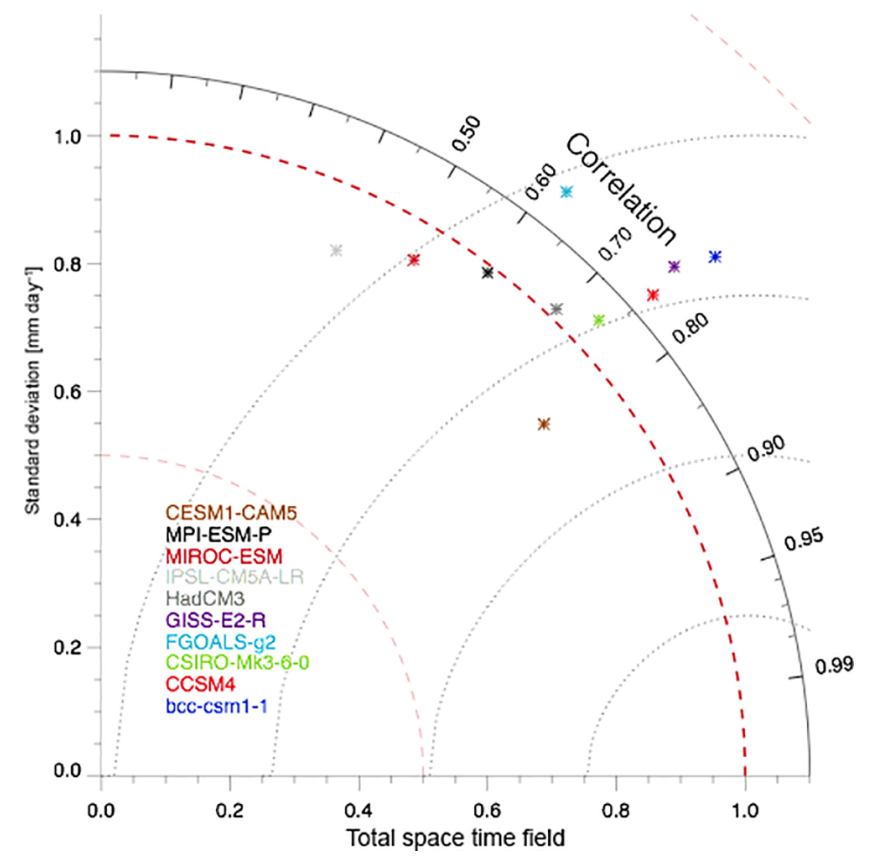

Figure 5. Taylor diagrams of global precipitation over land (a) and ENSO (as defined by the Nino3.4 index) correlations to precipitation over land (b). Each panel shows models that completed PMIP3 simulations of the last millennium compared to precipitation observations from GPCP for the overlapping periods of 1980-1999 (a) 1980-2014 for (b) (not all models simulated the full period, but all are at least 1980-2004).

tation of hydroclimatic impacts associated with modes of variability (Davini and Cagnazzo, 2014; see Fig. 5b). Nevertheless, models are generally successful at simulating the large-scale atmospheric circulations that drive areas of subsidence and uplift, and thus generally represent the zonal mean hydroclimate well, particularly in the multi-model ensemble mean (Flato et al., 2013). This is less true of regional hydroclimate dynamics, as many models struggle to reproduce the full characteristics of observed phenomena such as the global monsoon systems (e.g., Geil et al., 2013; Langford et al., 2014, for the North American monsoon; Sperber et al., 2013, for the Asian monsoon), some midlatitude storm tracks and the frequency of associated cyclonic systems (e.g., in the western and northern Atlantic; Colle et al., 2013; DunnSigouin and Son, 2013; Sheffield et al., 2013; Zappa et al., 2013), and atmospheric blocking (Masato et al., 2013). A full consideration of hydroclimate also includes the representation of land surface processes. While hydrology, vegetation, and soil moisture modeling has become increasingly complex, these components of models have not been as widely validated, and paleoclimate simulations often do not include important processes such as dynamic vegetation (Braconnot et al., 2007, 2012). To overcome some of these challenges, regional climate model simulations are used where processes important for simulating hydroclimate are better resolved. Due to the high computational demand, however, few re- gional modeling studies have been applied in the context of proxy-model comparisons over the CE. Gómez-Navarro et al. (2015) is one of the few examples of a regional simulation study for Europe that has been used to assess drought indices (Raible et al., 2017), covariability of seasonal temperature and precipitation (Fernandez-Montes et al., 2017), and the interpretation of lake sediments (Hernandez-Almeida et al., 2017).

Because of the multiple model challenges listed above, paleoclimate information plays a critical role in evaluating model fidelity, as it provides the only source of "out-ofsample" validation information (see Sect. 4). Model assessment is performed by directly comparing reconstructed and simulated time series or fields by studying statistics of variability and extreme events and by analyzing important processes, such as the simulated responses to changes in external forcing. The limited spatial and temporal resolution of the paleoclimate record (i.e., relative to the observational record) nevertheless leads to important challenges associated with explicitly characterizing model deficiencies in simulating climate dynamics on paleoclimate timescales. Despite these challenges, existing studies have demonstrated important uncertainties associated with hydroclimate comparisons between paleoclimate information and model simulations that illustrate the importance of future work on the subject. 
At the continental scale, Ljungqvist et al. (2016) presented a spatial reconstruction of $\mathrm{NH}$ hydroclimate variability for the last 1200 years and compared the data with PMIP3 lastmillennium simulations. They discussed the relationship between long-term temperature evolution and hydroclimate and diagnosed a statistically significant covariability for particular regions, but also widespread deviations from this relationship. In particular, the authors found that reconstructions and simulations agree reasonably well over the preindustrial interval and indicate that the 13th century had the most extensive dry conditions. Attribution to external forcing could, however, not be obtained from the assessment.

Models are also capable of reproducing multidecadal drought periods in some arid regions, a prominent and socioeconomically relevant feature of past hydroclimate variations. For instance, Coats et al. (2015b) analyzed megadroughts in the American Southwest in proxy reconstructions and in PMIP3 simulations, finding that models can reproduce events that are similar in extent and severity to tree-ring-derived reconstructions. The authors nevertheless also described pronounced differences between paleoclimatic reconstructions and models. For example, not all of the PMIP3 models associate megadroughts with teleconnections originating in the tropical Pacific Ocean, which is the assumed origin in the real climate system, and therefore may not accurately represent the dynamics underlying real-world megadroughts (Coats et al., 2016a, b). Conversely, internal atmospheric variability and land surface coupling may have instead been the dominant mechanism behind the occurrence of many megadroughts (Stevenson et al., 2015b). Whereas Coats et al. (2015b) diagnosed the general ability of climate models to reproduce low-frequency hydroclimate variability from a dynamical perspective, other studies based on statistical rescaling (Ault et al., 2012) find that model simulations underestimate low-frequency (in the 50 to 200 year range) precipitation variability. Spectra of reconstructed hydroclimatic variables from western North America show a considerably "redder" characteristic than those from models (Ault et al., 2013a). These findings are also tied to interpretations of proxy spectral fidelity, as discussed in Sect. 2.

\subsection{Natural forcing of hydroclimate}

Natural exogenous forcing factors have led to hydroclimate variability during the $\mathrm{CE}$; the strongest influences are volcanic eruptions and changes in solar activity. The former, namely stratospheric aerosols from strong volcanic eruptions, is the most important of these two forcings at the global scale during the preindustrial interval of the CE. Although the impacts persist for only a few years, volcanic forcing from multiple events constitutes the most important contributor to the global centennial-scale cooling observed from 850-1800 CE based on comparisons of single-forcing experiments (Otto-Bliesner et al., 2016) or through the use of all-forcing simulations in which the contributions from in- dividual forcings are isolated offline (Atwood et al., 2016). For this reason, volcanic eruptions are particularly important for gauging the forced hydroclimatic response in lastmillennium simulations.

Both observational and modeling studies consistently find a decrease in global precipitation following large explosive eruptions; the main regions experiencing decreased precipitation tend to be the tropics (Robock and Liu, 1994; Yoshimori et al., 2005; Trenberth and Dai, 2007; Schneider et al., 2009) and monsoon regions (Schneider et al., 2009; Joseph and Zeng, 2011; Wegmann et al., 2014; Stevenson et al., 2016). Iles and Hegerl (2014) further examined the precipitation response to volcanic eruptions in the CMIP5 historical simulations compared to three observational datasets. Global precipitation significantly decreases following eruptions in CMIP5 models, with the largest decrease in wet tropical regions. Iles et al. (2013) examined the global precipitation response to large low-latitude volcanic eruptions using an ensemble of last-millennium simulations from HadCM3 that indicated a significant reduction in global mean precipitation following these events. In the tropics, areas experiencing post-eruption drying coincide with climatologically wet regions, while dry regions get wetter on average, but the changes are spatially heterogeneous; a similar pattern has also been noted over Europe (Rao et al., 2017). These responses are physically consistent with future global warming projections, but of opposite sign because volcanoes and greenhouse gases have contrasting influences on radiative forcing. It must also be noted that the general pattern of wet regions getting wetter and dry regions getting drier in response to warming forced by increasing greenhouse gases is not universally applicable and can break down, particularly over land and in the tropics (Chou et al., 2009; Scheff and Frierson, 2012; Chadwick et al., 2013; Huang et al., 2013; Byrne and O'Gorman, 2015).

Despite earlier studies, substantial uncertainties still affect our understanding of hydroclimate responses to volcanic forcing in certain tropical regions. For instance, the CMIP5/PMIP3 last-millennium ensemble does not robustly feature the persistent drying over Mesoamerica that was detected in a recent speleothem record and ascribed to volcanically induced changes in dominant modes of variability in the tropical Pacific and Atlantic, including ENSO (Winter et al., 2015). There are still apparent discrepancies in proxyderived hydroclimate responses to volcanic eruptions in Asia and those simulated by several models (e.g., Anchukaitis et al., 2010) although it is not clear whether this is due to poorly simulated dynamics (and, if so, what dynamics are not adequately treated), uncertainties in forcing estimates, large contributions from internal variability, or deficiencies in the interpretation of the proxy network (Stevenson et al., 2016, 2017).

Among the known uncertainties, the hemispheric structure of stratospheric aerosol forcing plays a critical role in the hydroclimate response to volcanic events. Colose et al. (2016b) 

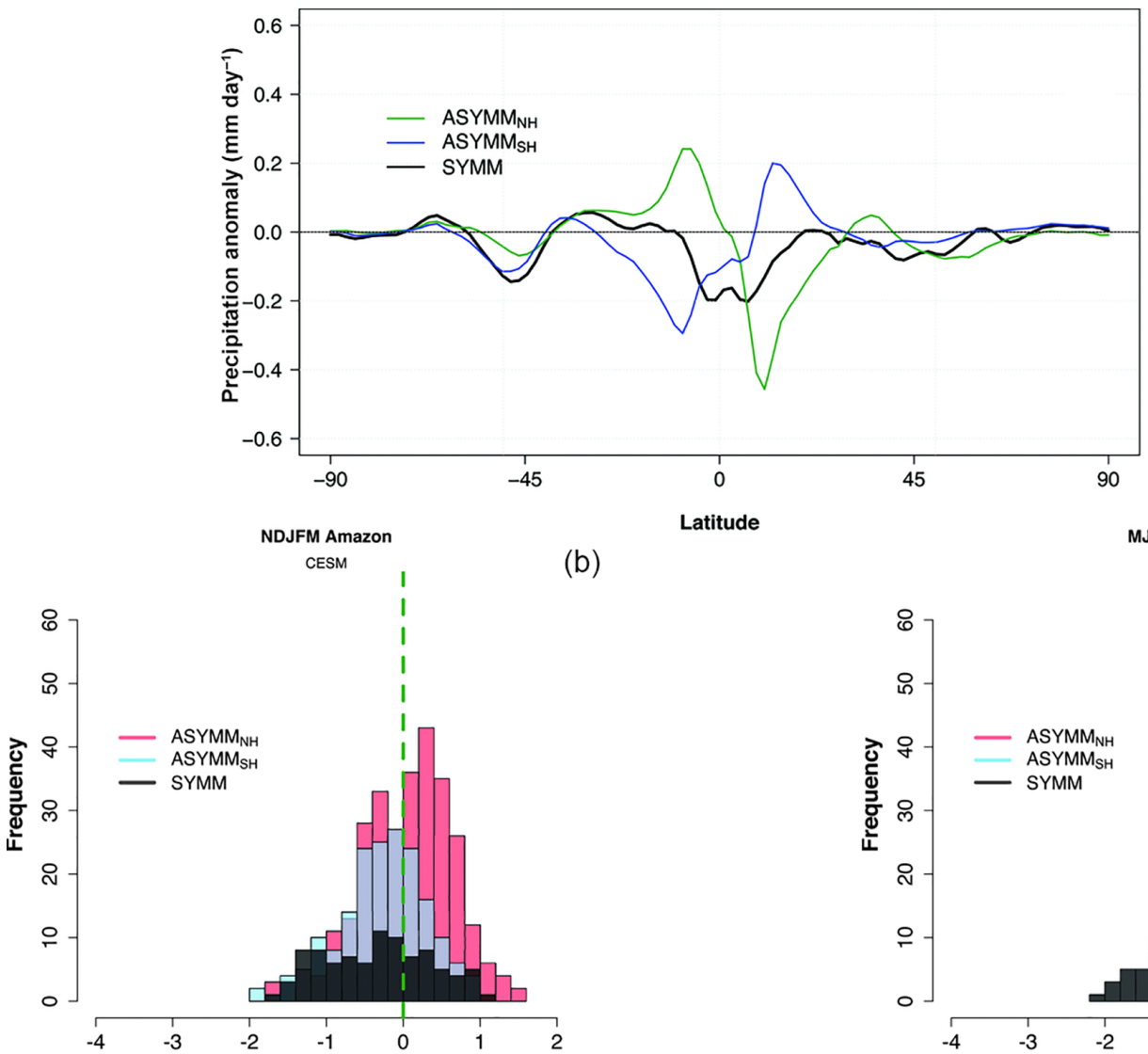

(b)
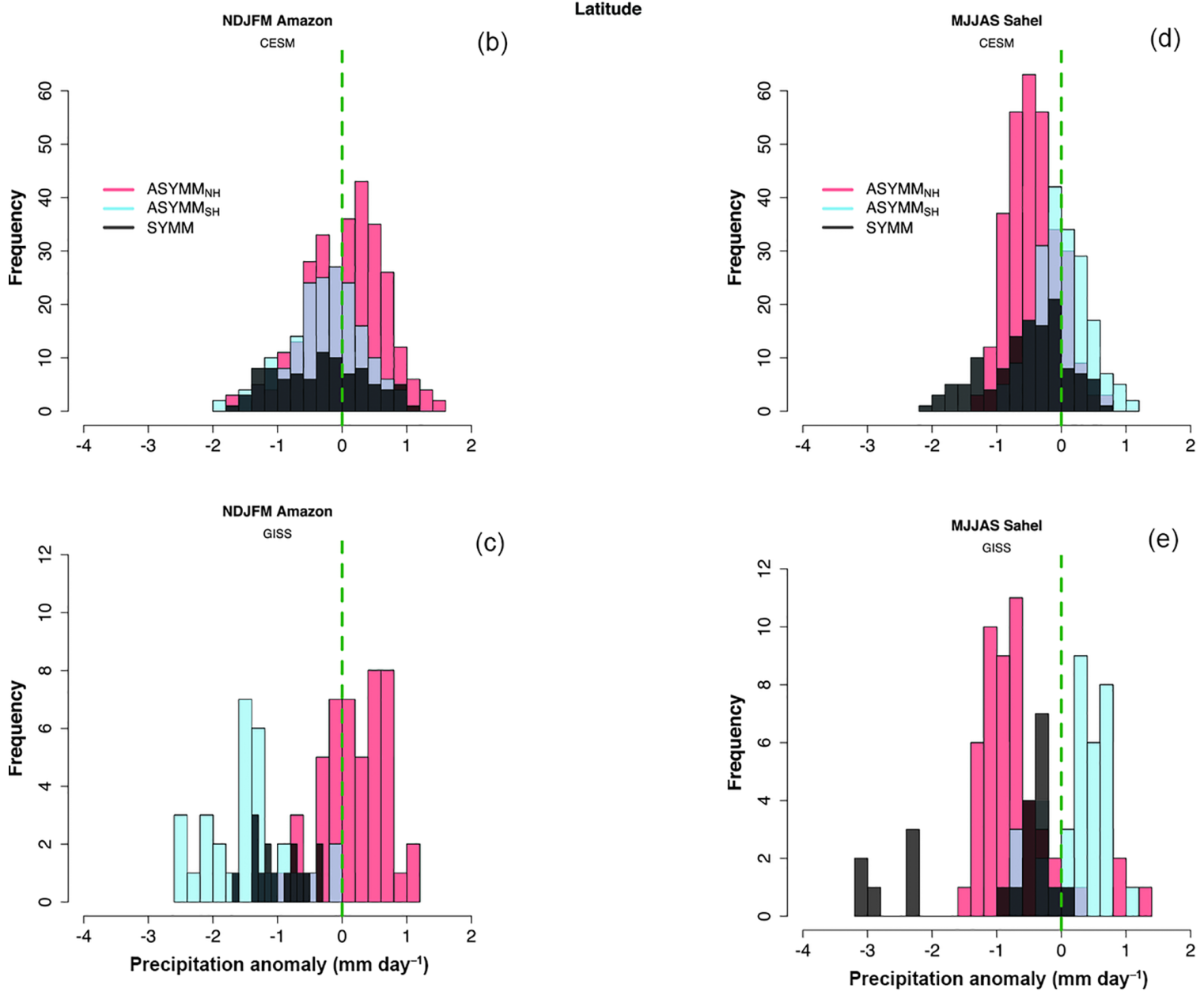

Figure 6. (a) Composite zonal mean precipitation anomalies $\left(\mathrm{mmday}^{-1}\right)$ following volcanic eruptions with hemispherically symmetric loading (black) and for preferential aerosol loading in the NH (green) and SH (blue). The grouping of eruption categories follows the methodology in Colose et al. (2016b) and results are shown for all-inclusive eruptions within 18 ensemble members in CESM LME. (b) Histogram showing frequency of precipitation response in CESM LME during the NDJFM season over the Amazon and (d) MJJAS in the Sahel. Results are for all NH eruptions (red), SH eruptions (aqua-blue), and symmetric events (black). Panels (c) and (e) are as in (b) and (d) except using NASA GISS ModelE2-R with three ensemble members and larger forcing. Note that the forcing implementation in this version used the spatial structure in Gao et al. (2008) but with approximately 2 times the appropriate radiative forcing, as described in the text. 
demonstrated that the response of the Intertropical Convergence Zone (ITCZ) differs dramatically for aerosol loading centered in the Northern vs. the Southern Hemisphere in the Community Earth System Model (CESM) Last Millennium Ensemble (LME) and NASA ModelE2-R last-millennium simulations (Table 1), with the ITCZ shifting away from the hemisphere with the greater concentration of aerosols (Haywood et al., 2013). Liu et al. (2016) also classified volcanic eruptions based on their meridional aerosol distributions and noted that $\mathrm{NH}$ volcanic eruptions are more efficient in reducing NH monsoon precipitation than SH eruptions. Figure 6a characterizes precipitation anomalies after volcanic eruptions, while Fig. $6 \mathrm{~b}$ and d separate the precipitation response to the volcanic forcing of differing meridional structures in CESM LME (18 ensemble members; see Colose et al. (2016a) for details on eruption classifications) during boreal winter in the Amazon and boreal summer in the Sahel, respectively. Although there is considerable spread within a given classification related to different eruption magnitudes and internal variability, there is a strong tendency for an increase in local precipitation if the aerosol loading is preferentially located in the opposite hemisphere. Unique local responses to different volcanic eruptions, even for a particular configuration of the atmospheric state, should therefore not be expected. Figure $6 \mathrm{c}$ and e show the same result using all eruptions within three ensemble members in NASA GISS ModelE2-R. Volcanic eruptions were incorrectly implemented in these three simulations (those using Gao et al., 2008) such that the aerosol optical depth for all events is approximately 2 times too large (Masson-Delmotte et al., 2013), but the implementation fortuitously allowed for an analysis of events with a very large signal.

In addition to the spatial distribution of volcanic aerosols, descriptions of volcanic aerosol cloud properties are also critical for simulations of the hydroclimate response to past eruptions. Substantial differences exist between reference volcanic forcing datasets in terms of overall aerosol loading and their latitudinal structure (Gao et al., 2008; Crowley and Unterman, 2013; Sigl et al., 2015). The differences include the timing, magnitude, and spatial structure of the forcing, as well as the reported variable (e.g., AOD or aerosol mass). Furthermore, implementation of a given forcing dataset may differ among modeling groups, for instance by varying the aerosol effective radius (Crowley and Unterman, 2013; Zanchettin et al., 2016). Other understudied aspects of uncertainties in eruption characteristics may also play a substantial role in hydroclimate impacts, such as plume composition, vertical profiles (LeGrande et al., 2016), and the initial month of eruptions; the latter is often assumed constant, but variability in the timing of eruptions has a significant controlling influence on the structure of forced hydroclimate anomalies (Stevenson et al., 2017). A consideration of the forcing implementation is therefore critical for meaningful proxy-model comparisons and adds a dimension of uncertainty that is independent of model skill or the climatic interpretation of the proxies of interest.

The robustness of the ENSO response following volcanic eruptions has been a longstanding subject of inquiry and represents another important dynamic response that needs to be better understood in the context of hydroclimatic responses to volcanic events. Many studies have yielded equivocal results, with some arguing that eruptions bias the tropical hydroclimate state toward El Niño conditions (e.g., Mann et al., 2005; Emile-Geay et al., 2008; Li et al., 2013; Wahl et al., 2014; Maher et al., 2015) or toward La Niña conditions (D’Arrigo et al., 2008, 2009; McGregor and Timmermann, 2011; Zanchettin et al., 2012); others argue that there is no evidence of an ENSO response to volcanic forcing (Robock and Mao, 1995; Self et al., 1997; Ding et al., 2014b; Tierney et al., 2015a). More recently, Pausata et al. (2016) have argued that eruptions with preferential aerosol loading in the NH will generate El Niño conditions by virtue of a southward ITCZ shift, which slackens the trade winds over the Pacific Ocean. The tendency for NH eruptions to favor initiation of El Niño was also found by Stevenson et al. (2016) in the CESM LME; in contrast, eruptions with stronger aerosol loading in the SH tend to suppress El Niño conditions during the following winter. Predybaylo et al. (2017) investigated the ENSO response to a Pinatubo-sized eruption using the GFDL-CM2.1 coupled climate model under different initial ENSO conditions and eruption seasons and identified a statistically significant El Niño response in the year after eruption for all initial ENSO conditions except La Niña. Stevenson et al. (2016) also used the CESM LME to investigate the separate influences of volcanic eruptions and ENSO on hydroclimate variability. Hydroclimate anomalies in monsoon Asia and the Western United States resemble the El Niño teleconnection pattern following volcanic forcing that is either symmetric about the Equator or preferentially located in the NH. El Niño events following an eruption can then intensify the ENSO-neutral hydroclimate signature. This implies that uncertainties in either the ENSO response to eruptions or the hemispheric loading of aerosols can contribute to proxy-model disagreement in hydroclimatic responses subsequent to eruptions. Multiple mechanisms, however, may be responsible for initiating this response (McGregor and Timmermann, 2011; Pausata et al., 2016; Stevenson et al., 2017). Internal variability in the form of a coincidental superposition of El Niño events with volcanic eruptions can also be responsible for proxy-model discrepancies (Lehner et al., 2016).

Decadal to multi-centennial (or grand) variations in solar radiative forcing are another known factor that influences hydroclimate variability during the CE (e.g., Gray et al., 2010). Quantification of total solar irradiance variations during the CE involves substantial uncertainties, but current estimates for solar grand minima are typically below about $1.4 \mathrm{~W} \mathrm{~m}^{-2}$ (Jungclaus et al., 2017). Current climate models have difficulties in simulating the temporal and spatial signature of 
solar irradiance changes on surface climate (Mitchell et al., 2015; Misios et al., 2016). A possible reason is poor representation of stratospheric dynamics linked to solar-induced changes in the photolytic production rate of stratospheric ozone (Mitchell et al., 2015) corresponding to the so-called "top down" or "dynamical" mechanism of solar forcing. Significant but modest regional solar forcing signals have been detected in last-millennium simulations performed with different models and forcing configurations, but these signals are largely limited to surface temperature (e.g., Phipps et al., 2013; Schurer et al., 2013; Otto-Bliesner et al., 2016). Sensitivity experiments with different forcing configurations further demonstrate that the co-occurrence of grand solar minima with clusters of strong volcanic eruptions can significantly amplify exogenously forced climate variability over decades or longer. This was shown, for instance, for temperature and precipitation changes in the early 19th century that likely resulted from the combined effect of the Dalton Minimum of solar activity and volcanic forcing from the 1809 and 1815 tropical eruptions (Zanchettin et al., 2013a; Anet et al., 2014). The response to solar forcing is sensitive to upper atmosphere processes that are not included in most simulations of the $\mathrm{CE}$, i.e., stratospheric dynamics and ultravioletradiation-related ozone effects in the stratosphere. This highlights the need for future work with so-called "high-top" models allowing changes in stratospheric circulation to manifest in surface hydroclimate on last-millennium timescales.

\subsection{Diagnosing mechanisms of hydroclimate variability}

Although much progress has been made towards understanding the mechanisms of hydroclimate variability on annual and longer timescales, substantial uncertainties remain, particularly on multidecadal to centennial timescales. The linkages between modes of coupled atmosphere-ocean variability and hydroclimate have been extensively explored on annual to decadal timescales and have also been regularly exploited during the creation of proxy reconstructions of modes of atmosphere-ocean variability (Mann et al., 2009; EmileGeay et al., 2013a; Li et al., 2013). Impacts from modes such as ENSO, the Atlantic Multidecadal Oscillation (AMO), the Pacific Decadal Oscillation (PDO), and the North Atlantic Oscillation (NAO) take several forms. Hydroclimate anomalies can result from Rossby-wave-driven teleconnections, as in the ENSO influence on the Pacific North American and Pacific South American patterns (Ropelewski and Halpert, 1986; Renwick and Wallace, 1996; Garreaud and Battisti, 1999). They can arise from changes to monsoonal flows, such as the AMO impact on North America (Oglesby et al., 2012), alterations in the zonal mean circulation in response to changes in ocean conditions during strong ENSO events (Seager, 2007), in response to systematic shifts in the NAO following strong volcanic eruptions (Shindell et al., 2004; Wegmann et al., 2014; Ortega et al., 2015), or from decadal modulation of the NAO by solar activity (e.g., Zanchettin,
2017). This implies that the representation of coupled climate variability is critical for simulating hydroclimate variations in climate models.

The precise contribution of different modes of variability to hydroclimatic changes is still an ongoing area of research. For the American Southwest, substantial work has indicated that interactions between modes such as ENSO, the AMO, and the PDO can affect the patterns and occurrence of megadroughts and pan-continental droughts over the CE (Cook et al., 2014b; Coats et al., 2015a, 2016b). The degree to which externally forced changes in coupled modes of variability modulate hydroclimate variations is another key target for the community. For instance, ensemble simulations indicate that the overall forced changes to ENSO are minimal over the CE but that volcanic activity substantially enhances the power in the AMO (Otto-Bliesner et al., 2016).

The availability of large model ensembles has demonstrated the key importance of internally coupled variability relative to the forced response in hydroclimate. Even for relatively strong external forcings, such as the 1815 eruption of Mt. Tambora, internal variability appears to be significant: the CESM LME shows an El Niño event (and associated hydroclimate impacts) following this eruption in only half of the ensemble members (Otto-Bliesner et al., 2016). Analyses of the CMIP5 simulations show similar scatter across ensemble members and across different models for 20th century eruptions (Maher et al., 2015).

The coupled nature of the hydroclimate problem provides a unique opportunity to perform attribution studies using climate model simulations and to quantify the sensitivity of hydroclimate to particular dynamical mechanisms in a manner that is impossible using paleoclimate reconstructions or observations alone. For example, Cook et al. (2013a) used experiments with and without prognostic dust aerosol physics to demonstrate the importance of dust mobilization to the persistence of megadroughts over the Midwestern United States. More recently, Stevenson et al. (2015b) performed simulations in both a coupled configuration and an atmosphere-only setup using a repeating 12-month SST climatology to show that internal atmospheric variability can generate megadrought-like behavior in the absence of coupled climate variations. Future targeted simulations will likely provide additional insights into the relevant dynamics associated with hydroclimate variability over the CE.

\subsection{Opportunities for modeling progress}

Climate simulations are affected by large systematic biases, including discrepancies between observed and simulated characteristics of the mean state, seasonal cycles, and variability (e.g., Flato et al., 2013; Wang et al., 2014a). The possible impacts of model biases in last-millennium simulations have been explicitly discussed for only a few specific regional aspects of climate dynamics and variability (e.g., Anchukaitis et al., 2010; Coats et al., 2013a, 2016a; Zanchet- 
tin et al., 2015; Stevenson et al., 2016). A broader assessment of model biases in simulated patterns, variability, and teleconnections would therefore increase our confidence in both climate dynamics and the variability inferred from climate simulations of the last millennium.

In some cases, bias is almost completely determined by lack of spatial model resolution and poorly resolved topography or bathymetry (e.g., Milinski et al., 2016). Increases in horizontal and vertical model resolution have the potential to not only improve the spatial detail of simulations, but also strongly alleviate or even remove some of the biases affecting the current generation of models. Another aspect of model improvement is increasing complexity, i.e., including an explicit or implicit treatment of additional processes such as cloud microphysics, cold pools, and mesoscale organization of tropical convection. Regional modeling represents one attempt in which both the resolution and complexity of processes relevant for the hydrological cycle are increased (e.g., Gómez-Navarro et al., 2015), but the use of convectionresolving regional models (e.g., Messmer et al., 2017) is currently only possible for short time windows due to the computational demand and thus only applicable for very specific paleoclimate questions. Regional modeling is also sensitive to the applied boundary conditions, and therefore ensemble simulations using boundary conditions derived from multiple GCMs are likely required to fully characterize the range of possible hydroclimatic conditions. The inclusion of water isotope tracers in model simulations is another means by which progress toward understanding hydroclimate variability is expected. These efforts allow isotopic fields to be simulated directly and compared with isotope-based proxy records rather than making a priori assumptions about the amount effect or other factors controlling precipitation $\delta^{18} \mathrm{O}$ and $\delta \mathrm{D}$ (see Sect. 2). Additional progress is expected from an improved treatment of the indirect effects of aerosols.

In addition to model refinement, progress is expected through improved characterization and implementation of the external forcings used in last-millennium simulations. Forcing characteristics must be reconstructed based on indirect evidence, implying large uncertainties in the climatically relevant parameters of the forcing. For volcanic eruptions, for instance, this concerns the uncertainties discussed in Sect. 3.2. A recently published reconstruction of volcanic forcing (Sigl et al., 2015) has demonstrated advances in terms of more accurate dating of the events, which has been corroborated by independent estimates of large volcanic events derived from hemispheric temperature reconstructions using tree rings (Anchukaitis et al., 2017; Schneider et al., 2017), and a better estimate of the amplitude of sulfur emissions. Together with an improved module for translating volcanic emissions into aerosol optical properties (Toohey et al., 2016), the better-constrained volcanic forcing reconstructions will lead to improved direct radiative and indirect dynamical responses in PMIP4 (Jungclaus et al., 2017). Further progress is expected from increased complexity of the forcing-related processes explicitly treated in the models. For instance, the inclusion of modules for chemistry and aerosol microphysics improves the representation of volcanic plume development and hence the climatic impacts of volcanic eruptions (LeGrande et al., 2016). Nevertheless, a multi-model assessment of the volcanic forcing generated by different aerosol climate models for a Tambora-like equatorial eruption produces a substantial ensemble spread, raising questions as to the level of model complexity that is necessary to estimate the range of inherent climate uncertainty (Zanchettin et al., 2016). New reconstructions of solar irradiance have also been developed and progress is expected from a more consistent representation of spectral solar irradiance in the PMIP4 solar forcing datasets (Jungclaus et al., 2017). Improvements in atmospheric chemistry (particularly stratospheric and tropospheric ozone responses) also increase the magnitude of response to solar changes (Shindell et al., 2006). The use of climate model configurations with realistic stratospheric dynamics can also improve the simulation of "top down" mechanisms of solar forcing and the quantification of solar impacts on hydroclimate variability during the $\mathrm{CE}$. In addition to determining changes in the radiative energy input, solar variability can affect the Earth system by altering the chemical composition of the highlatitude middle atmosphere through energetic particle forcing (Seppälä and Clilverd, 2014). This forcing and its transfer mechanisms toward the Earth's surface remain largely unexplored (Zanchettin, 2017), but are receiving increasing attention from the climate modeling community (Anet et al., 2014; Matthes et al., 2017). Future simulations of the CE that include stratospheric processes are anticipated over the next few years, which will provide important new insights into solar influences on hydroclimate.

Finally, the complexity of current climate models implies numerous potential sources of uncertainty, the individual impact of which can be hard to distinguish in transient climate simulations. This establishes the need for coordinated modeling efforts to tackle specific aspects of uncertainty. For instance, the Model Intercomparison Project on the climatic response to Volcanic forcing (VolMIP; Zanchettin et al., 2016) has defined a set of idealized volcanic perturbation experiments with well-constrained applied radiative forcing. The effort will identify primary limitations in the abilities of models to simulate climate responses to volcanic forcing, especially concerning differences in the treatment of relevant physical processes.

\section{Comparing proxy data and climate model simulations during the Common Era}

Hydroclimatic changes during the $\mathrm{CE}$ provide a salient proving ground to investigate responses to major climatic forcings (e.g., solar, volcanic, greenhouse gases, land use or land cover changes) and also to better quantify the internal 
variability of the climate system. Such investigations are arguably best carried out by leveraging the abilities of both climate model simulations and proxy data. Nevertheless, conducting meaningful, quantitative comparisons between proxies and models or interpreting model and proxy information in tandem is not straightforward. We therefore offer a set of "best practices" for integrating proxies and model simulations in the following subsections, all of which are aimed at improving comparisons of hydroclimate reconstructions with model simulations and therefore enhancing our ability to both simulate climates of the past and future and improve our interpretations of the signals recorded by proxies (e.g., Yoshimori et al., 2006).

\subsection{Best practices for proxy-model comparisons of hydroclimate}

Proxy-model comparisons are most effective when they leverage the complementary strengths of both information sources. It is tempting to view proxy-based data and reconstructions as the "ground truth" against which model simulations should be judged. Paleoclimate data, however, are incomplete climate system indicators and this imposes various constraints and uncertainties that differ across proxies, many of which are summarized in Sect. 2. In the context of a climate reconstruction, these constraints can affect (among other things) the seasonality of the reconstructed climate signal, the spatial and temporal coverage and resolution of the reconstruction, and the fidelity with which different timescales of variability (e.g., annual, decadal, centennial) are recovered. As described earlier with regard to sediments, for instance, low frequencies in reconstructions of closed lake basins can arise simply through the integration of high-frequency climatic signals (Huybers et al., 2016), while tree rings, because of their limited length, may not accurately represent long-term (multicentennial) variability.

Climate models, in turn, can provide nearly complete information on any climate system variable or process of interest (e.g., temperature, precipitation, circulation) for any time interval in a manner internally consistent with model physics. They may, however, diverge from the "true" state of the climate system because of specific physical processes that are either not represented or contain representational errors, misdiagnoses of climate forcings, or mismatches in the timing or spatial pattern of internally generated variability, as discussed in Sect. 3. Proxy-model comparisons are therefore best cast in a framework in which simulations and proxy observations compensate for the deficiencies that they each contain. Given these general considerations, we articulate below several recommendations for hydroclimatic proxymodel comparisons.

\section{Expectations of temporal or spatial consistency between proxies and models should be critically evaluated; e.g.,}

temporal consistency should only be expected for variability associated with exogenous forcings.

Given natural variability in the climate system, it is unrealistic to expect congruent time histories of hydroclimate derived from proxy data and model simulations. Direct time comparisons can be misleading, especially if events in the paleoclimate record are associated with internal variability rather than exogenous forcing. Internal (unforced) variations will evolve differently from one model simulation to the next if initial conditions are not identical, and amplitudes of decadal and longer timescale modes of climate variability (e.g., the AMO, PDO) differ between model frameworks (Deser et al., 2012; Zanchettin et al., 2013b; Kay et al., 2015; Fleming and Anchukaitis, 2016; Otto-Bliesner et al., 2016). As an example, Fig. 7 plots the PDO index (Phillips et al., 2014) from four full-forcing ensemble members of the LME (Otto-Bliesner et al., 2016). Each simulation is forced identically but started from slightly different atmospheric initial conditions, resulting in unforced patterns of variability (e.g., the PDO) that are uncorrelated with one another over the majority of the simulation interval (Kay et al., 2015; Fleming and Anchukaitis, 2016).

Despite the uncorrelated temporal behavior, however, the power spectra of these time series (Fig. 7) are quite similar to each other in their underlying distributions. This highlights the fact that although temporal correlation is not expected, proxy-model comparisons are still meaningful as long as they focus on the underlying basic processes and full spectrum of variability. Such comparisons may include statistics of extremes (e.g., droughts), analogs (e.g., similar events in models and reconstructions that share certain characteristics but do not necessarily align in time), and physical mechanisms (e.g., the teleconnection between ENSO and drought in a given region). For example, Coats et al. (2015b) used a suite of PMIP3/CMIP5 simulations to investigate ocean forcing of North American megadroughts during the Medieval era. In this case, the models did not match the timing of the megadroughts seen in the proxy reconstruction, but were able to produce all other megadrought aspects (e.g., frequency, duration, etc.) through variability and teleconnections that were in some cases consistent with observations. Similar conclusions are evident in Fig. 8, which compares the occurrence of megadroughts as estimated by the North American Drought Atlas (NADA; Cook et al., 2004), the PMIP3 ensemble of PDSI, and PDSI calculated from the LME.

Models may also misrepresent the exact spatial signature of climate phenomena, such as the spatial extent of monsoon regions, or coupled modes of hydroclimate variability, such as the ENSO or the Indian Ocean 

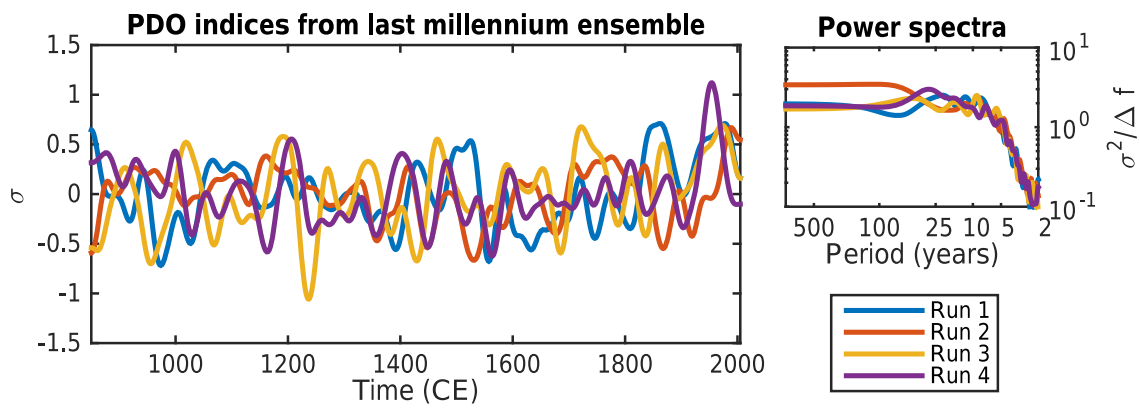

Figure 7. Time series (low-pass filtered to emphasize decadal variations) of the PDO from the four runs of the CESM Large Ensemble (LENS; Kay et al., 2015) experiment (left) and the power spectra of each run (right).

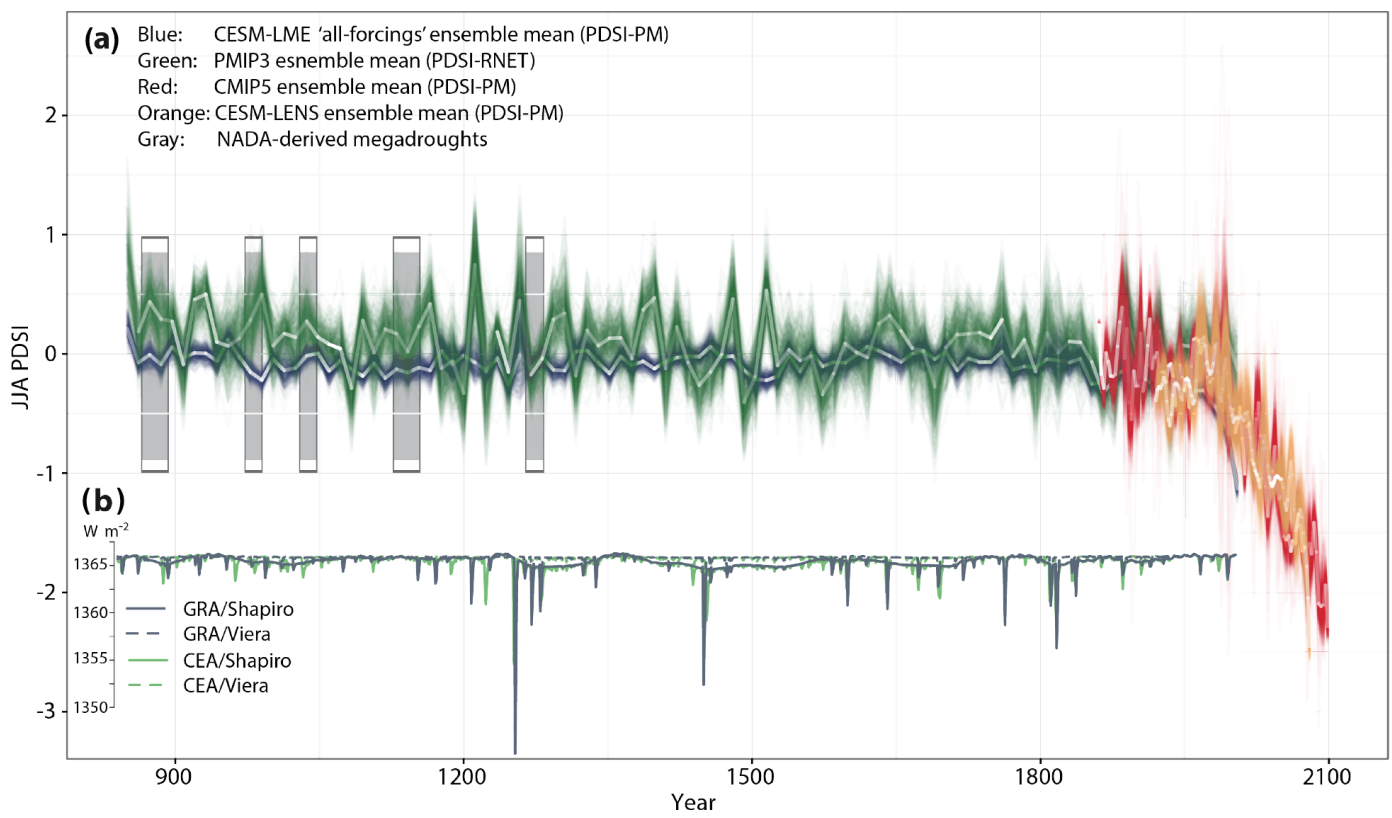

Figure 8. (a) JJA PDSI over the American Southwest for the CESM LME (blues), the CMIP5 historical and projection interval (red), the CESM LENS for the historical and projection interval (orange), and the PMIP3 net radiation PDSI for the last-millennium and projection interval (green). For the CESM LME, the ensemble mean is shown for the all-forcings experiment. For the PMIP3, CMIP5, and LENS, the ensemble mean is shown. For each of the ensemble means, a locally weighted regression is bootstrapped 500 times to highlight the uncertainty in filtering. The median bootstrap value is indicated as a white line in each series, with the color opacity indicating the confidence of the true median value of the regression at that point. Gray bars indicate the five largest megadroughts estimated by the NADA, all of which occurred during the Medieval Climate Anomaly. (b) The combinations of two volcanic (GRA, Gao et al., 2008; CEA, Crowley and Unterman, 2013) and two solar (Viera, Vieira and Solanki, 2010; Shapiro, Shapiro et al., 2011) forcing datasets for the period 1000-2000 CE (from Coats et al., 2016a).

Dipole. Proxy-model comparisons can proceed, however, as long as the spatial representation in the model is taken into consideration when compared with proxy data (e.g., Konecky et al., 2014), similar to assessments with instrumental data (Marvel and Bonfils, 2013).

2. Proxy-model comparisons should be viewed as a "twoway conversation".

Proxy-model comparisons are most effective when viewed as a two-way conversation between two independent sources of information that can be used to pro- pose and test process-based hypotheses. For example, model simulations can be a priori designed to better understand outstanding features in the CE paleoclimate record, such as megadroughts and volcanic-related coolings (e.g., Seager et al., 2005; Stevenson et al., 2015b). These may include, for example, single-forcing simulations that can isolate mechanisms that may explain an observed climatic response (e.g., Schurer et al., 2013; Otto-Bliesner et al., 2016). On the other hand, features that emerge in climate model simulations can serve 
as targets for paleoclimatic investigation. For example, Tierney et al. (2015b) observed that 21 st century climate projections overwhelmingly show that East Africa will get wetter in the 21 st century under rising greenhouse gases as a result of a simulated "El Niño-like" mean state in the tropical Indo-Pacific. This motivated the construction of a hydroclimate record from East Africa to test the relationship between regional precipitation, recent warm climate intervals, and the mean state of the Indo-Pacific system. The paleoclimate record showed that the strong 20th century drying trend was unprecedented over the last millennium, indicating that greenhouse gases may in fact be driving the East African region toward a drier state; model predictions of wetter conditions in the 21 st century due to greenhouse gas forcing therefore stand in contrast to this finding and require further vetting.

3. Uncertainties and limitations of models and proxies must be rigorously assessed to achieve robust conclusions from proxy-model comparisons.

The comparison of paleoclimate reconstructions and models will always be challenged by the presence of uncertainties inherent in each data source. The magnitude of this uncertainty differs depending on the application, and such uncertainties are largely unavoidable. Nevertheless, there are ways to limit the effect that this uncertainty has on subsequent hydroclimatic comparisons and interpretations.

Summarizing from Sect. 3, some of the major sources of uncertainty for climate models are (1) limits to spatial resolution causing errors in the simulation of topographical effects and finer-scale processes, (2) parameterization of physical processes (e.g., small thunderstorms cannot be directly modeled), (3) biasing toward modern-day climate (i.e., adjusting model parameters to best represent aspects of historical observations), and (4) selection of forcing data. External users should always ensure that the model data selected are suitable for their purpose and should be aware of the limitations associated with Factors 1-4. Important means of quantifying the sensitivity of proxy-model comparisons to these sources of uncertainty include assessment of structural modeling error (Dee et al., 2016) and the use of multi-model ensembles (Coats et al., 2015a-c; Lewis and LeGrande, 2015; McGregor et al., 2015) to characterize structural uncertainty, evaluating model simulations of the relevant processes, and using an ensemble of simulations (Otto-Bliesner et al., 2016) to address internal variability.

For hydroclimate comparisons, some of the sources of uncertainty can be minimized. Precipitation amount is a complex target for proxy-model comparisons due to highly localized influences such as topography, which can skew the precipitation regime at any individual location. Moreover, the coarse nature of model grids means that a single grid point may represent an area on the order of $100 \mathrm{~km}^{2}$ or larger. Comparing station observations and model grid boxes is therefore problematic due to contrasting geographic resolutions (e.g., Osborn and Hulme, 1997), and the same is true for proxy data that represent only a small area or a single point in space. This precludes making direct comparisons between a reconstruction from a single location, for example from an individual cave or lake, and the nearest grid cell in a model. Directly comparing gridded model output to data at a specific point should therefore be avoided, and while such a comparison is tempting, it can be falsely analogous; for instance, some models are not expected to reproduce highly regional hydroclimate dynamics (e.g., orographic rainfall or mountainous microclimates). Such comparisons also can be unrealistic; for instance, CMIP5-class models underrepresent or omit small landmasses (Karnauskas et al., 2016), such as the grid boxes nearest the Perida Cave, Puerto Rico reconstruction (Winter et al., 2011) that are represented as ocean in the PMIP3 simulations (not shown).

To avoid the potentially large uncertainties associated with the coarse spatial resolution of climate models, proxy-model comparisons should focus on atmosphere-ocean dynamics or hydroclimate features with large spatial scales that span multiple grid boxes. This is usually on the order of thousands of kilometers or larger. For analogous comparisons in which multiple proxy records are available, a synthesis of these records provides better estimates of the region's hydroclimate variability than a single record and is more suitable for comparisons with the spatial patterns simulated by models (e.g., Tierney et al., 2013; Otto-Bliesner et al., 2014; Cook et al., 2016). If comparing a hydroclimate reconstruction from a single location with a model simulation is absolutely necessary, the model variable of interest should be considered over a regional scale to account for the possibility that the simulated hydroclimate dynamics do not exactly covary with the location of the reconstruction (that is to say, the nearest model grid point may not be the most relevant given the model physics). Alternatively, regional climate simulations produced from dynamically or statistically downscaled products should also be considered for comparison, although such downscaling introduces additional structural uncertainties (e.g., Gómez-Navarro et al., 2015).

Summarizing from Sect. 2, some of the major uncertainties for proxy archives include (1) variables measured in the proxy archive that may not match a variable available from the model, (2) inherent non-climatic effects decreasing the signal-to-noise ratio, (3) spectral redden- 
ing, and (4) chronological error. As discussed above, the latter may be mitigated as long as the focus of the proxy-model comparison is process based and not tied to the identification of specific events at specific times. Steps to mitigate Factor 1 are discussed in the subsequent subsection. Factor 2 can be partially addressed by designing optimal proxy networks that target climatically sensitive regions (Evans et al., 1998, 2002; Comboul et al., 2015; Lewis and LeGrande, 2015; Dee et al., 2016) and statistical pretreatment; see, for example, the discussion regarding isolation of the climatic signal in tree rings in Sect. 2.2.

The issue of spectral reddening (Factor 3) deserves special mention given that several previous studies have compared low-frequency variability in proxy records and model simulations (Ault et al., 2013a, b; Bunde et al., 2013; Franke et al., 2013; Markonis and Koutsoyiannis, 2016). It should first be noted that these efforts are dependent on the proxy archives that are employed and may involve incompatible comparisons between model output and the environmental variable that proxies actually record (cf. the discussion of Franke et al. (2013) in Sect. 2.2 and Fig. 2). Most proxy archives also contain at least some non-climate sources of autocorrelation that result in reddening of the primary climatic signal. As discussed in Sect. 2, trees store carbohydrates in their needles, leaves, and cambium (Fritts, 1976) and suffer injuries due to short-term climatic events (e.g., droughts) that may affect growth rates for years after the event (Anderegg et al., 2015); soil moisture persists from one season to the next (Delworth and Manabe, 1993), and water in lakes and caves can take years or decades to cycle through such archives (Hurst, 1951; Benson et al., 2003; Evans et al., 2006; Truebe et al., 2010). Accordingly, spectral reddening will distort the importance of low-frequency variations by making them seem more substantial in the proxy than they are in the underlying climate system (see Fig. 3).

Misleading conclusions regarding the spectral power of the climate system can be avoided by (1) choosing an appropriate quantity from model simulations to compare to proxy-based reconstructions that accounts for autocorrelation and (2) applying a forward model of proxy behavior (see the following recommendation) to model output to explicitly simulate spectral reddening. When these steps are taken, spectral comparisons between models and proxies can be undertaken with confidence; model PDSI (or soil moisture) and tree-ringreconstructed PDSI offer an example of a successfully analogous comparison (Fig. 2). Comparing proxies and models on "equal ground" indeed provides a tractable way to deal with proxy- and model-related uncertainties that has the potential to significantly advance proxy- model comparisons, as highlighted in the next recommendation.

4. Proxy-model comparisons should take place on equal ground.

As highlighted in Sect. 2, data that can be measured in proxy archives are in many cases indirect indicators of hydroclimate rather than concrete variables, such as precipitation or evaporation, that are the standard output for a climate model. To reconcile these different types of information and facilitate meaningful comparisons, attempts should be made to either transform the proxy into a climatic variable or transform climate model output into a proxy variable. Conversion of the proxy into a climatic variable can be achieved through regression or traditional inverse methods as is done with the widely used regional drought atlases (Cook et al., 2004, 2010a, 2015b; Palmer et al., 2015). Nevertheless, in many cases the multivariate nature of proxy data, the presence of large uncertainties and limited spatiotemporal coverage in a calibration proxy network or nonstationary behavior between the proxy predictor and the climate predictand render regression and inversion challenging (e.g., Wilson et al., 2010; Lehner et al., 2012; Smerdon, 2012; Tingley et al., 2012; Coats et al., 2013a; Gallant et al., 2013; Evans et al., 2014; Konecky et al., 2014; Raible et al., 2014; Wang et al., 2014b, 2015; Konecky et al., 2016).

In many situations, conversion of model data into a proxy variable is more tractable and is increasingly being pursued. PSMs (Evans et al., 2013) that mathematically describe the way in which climate is encoded into a proxy archive can provide an ideal method of translation. PSMs are simplified representations of a biological, physical, or chemical sensor response to environmental processes, which are subsequently imprinted onto a physical archive and observed via physical or geochemical measurements (Evans et al., 2013; Dee et al., 2015). PSMs are forward models and therefore do not require assumptions of local or regional stationarity and linearity that are typically applied in inverse approaches, and they can characterize multivariate influences (Evans et al., 2013; Phipps et al., 2013). Paleoclimate observations in their "native" units may be directly compared to models by using the output variables of simulations or other climate models that have been processed through a PSM to generate simulated paleoclimate observations - sometimes called "pseudoproxies" in the literature (Thompson et al., 2011; Tolwinski-Ward et al., 2011; Smerdon, 2012; Phipps et al., 2013; Evans et al., 2014). PSMs may therefore provide more appropriately analogous comparisons for models and proxies; they also allow for the propagation of uncertainties because PSM-derived estimates of parameter errors and observational random error do not 
need to be inverted. It is important to note, however, that PSMs are simplified representations of the proxy system and do not perfectly capture all the vagaries of actual proxy data. In many cases, limitations in our mechanistic understanding of the proxy sensor or archive, or the existence of processes that are mathematically complex, preclude the development of a truly process-based model. For example, Thompson et al. (2011) developed a PSM for coral $\delta^{18} \mathrm{O}$ based on geochemical expectations rather than explicitly modeling fractionation during the calcification process, the details of which are understudied. Further refining PSMs is therefore an important area of research, as is testing PSM results with observational data.

If there is one particular quantity for which establishing equal-ground comparisons is paramount for our understanding of hydroclimate, it is the isotopes of water (oxygen and hydrogen). Water isotopes are measured in every major paleoclimatic archive (trees, speleothems, corals, sediments, ice cores) and are complex but powerful indicators of the hydrological cycle. Isotopic records reflect large-scale atmospheric processes, such as changes in precipitation source region, vapor transport, local amount effects, and the seasonality of precipitation, and often capture large-scale climate modes, such as ENSO, the Indian Ocean Dipole, and monsoon characteristics, more strongly than precipitation amount at a given location (Vuille et al., 2005a, b; Vuille and Werner, 2005; Konecky et al., 2014; Moerman et al., $2013,2014)$. Water isotopes are therefore in many ways ideal indicators for comparison with coarse-resolution model output (Jouzel et al., 1994; Hoffmann et al., 1998; Schmidt et al., 2007; Risi et al., 2010; Pausata et al., 2011; Dee et al., 2015). The best way to analyze isotope proxy information is to compare the proxy data to simulations from climate models that incorporate isotope tracers. Recent simulations that do include isotope tracers have greatly simplified the task of undertaking proxy-model comparisons for a large component of the proxy data that are available during the $\mathrm{CE}$ (Colose et al., 2016a). Intercomparison projects such as the SWING2 project are also compiling the results from isotope-equipped atmospheric climate models (Sturm et al., 2010; Conroy et al., 2013) to provide the community with a diverse set of simulations to probe the drivers of spatiotemporal water isotope variability. Further efforts to even more widely include isotope tracers in coupled climate models are nevertheless necessary and would significantly advance our ability to compare proxy and model simulations.

\subsection{Model-data comparisons with data assimilation}

Data assimilation (DA) is an emerging, promising, and specific means of proxy-model comparison, which, among mul- tiple benefits, can incorporate the use of water isotope modeling and PSMs. While paleoclimate DA is based on the same methodological framework as other DA applications, its motivations are typically different. DA for paleoclimate provides a coherent statistical framework for optimally fusing proxy information with the dynamical constraints of climate models, providing many climate variables in the reconstruction, coherently modeling proxy systems, and explicitly accounting for some of the sources of uncertainty inherent in reconstructions (Goosse et al., 2010; Luterbacher et al., 2010; Widmann et al., 2010; Goosse et al., 2012b; Steiger et al., 2014; Hakim et al., 2016; Matsikaris et al., 2016). Unlike traditional statistical approaches that have been used more widely for climate reconstruction to date, DA-based reconstructions simultaneously produce hydroclimate and dynamically related climate variables that can be used to infer the physical causes of past climate changes. Another key advantage of the approach is that it incorporates additional information into a fundamentally information-limited problem: DA-based reconstructions have been able to achieve high reconstruction skill (Hakim et al., 2016) by merging model covariance information with noisy proxy data. Such reconstructions specifically targeting hydroclimatic fields are currently being developed (Steiger and Smerdon, 2017), and the approach is expected to provide a more complete picture of hydroclimate over the past millennium while allowing for tests of many existing hypotheses about hydroclimatic change in the past. DA-based hydroclimate reconstructions may therefore be able to more clearly elucidate the dynamics associated with droughts, pluvials, their temporal phasing across multiple regions, and their multidecadal to centennial variability over the past millennium on a truly global scale because the method simultaneously provides additional dynamically relevant fields in addition to reconstructions of specific hydroclimate variables (as opposed to more traditional approaches that may target dynamical fields or indices independently).

While DA methods provide many opportunities, we note two major challenges. The foremost challenge is the high computational cost: for an ensemble DA scheme, cycling tens or hundreds of CMIP5-class coupled climate models for 1000 years or more is simply impossible given the limits of current technologies. Two main approaches have emerged in response to this issue: either using computationally efficient "intermediate complexity" models with small ensemble sizes (e.g., Goosse et al., 2010, 2012b) or using an "offline" DA approach in which large ensembles of climatologically plausible states are drawn from preexisting climate simulations (e.g., Steiger et al., 2014; Hakim et al., 2016). Another major challenge is the integration of proxy data, PSMs, and climate models, each of which must work in concert while being subject to their own uncertainties and assumptions (Dee et al., 2016). It is therefore critical that such DA-based reconstructions be well validated and account for uncertainties in all of the employed information sources. 


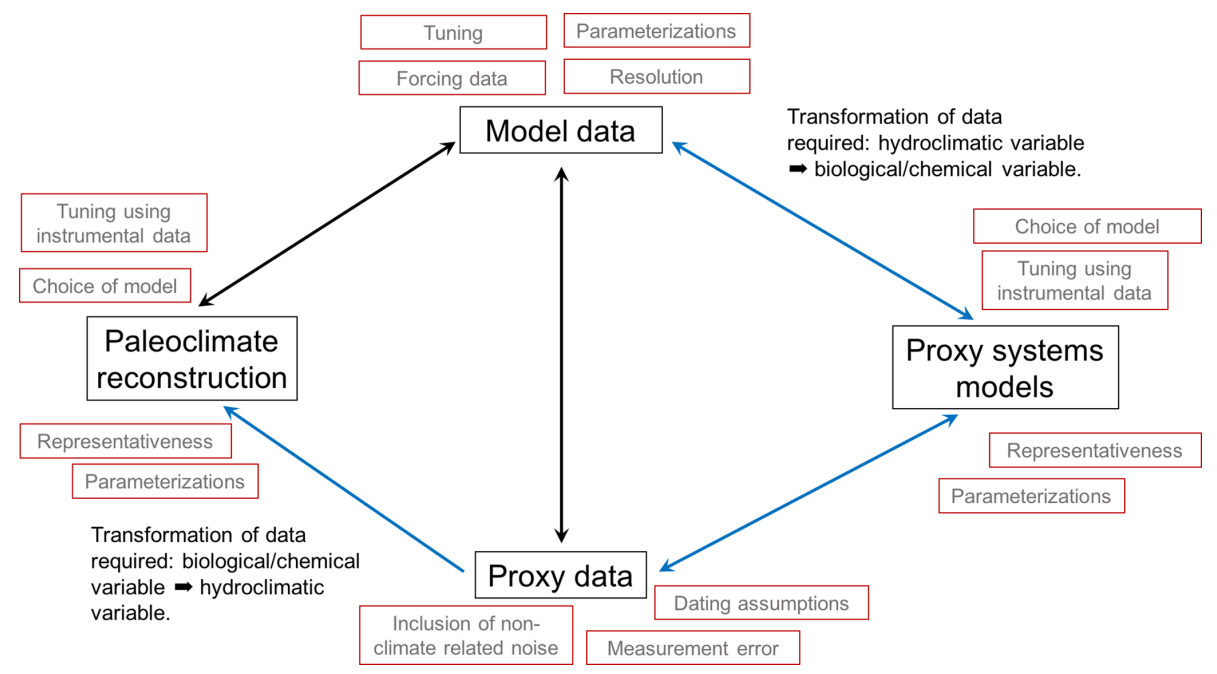

Figure 9. The black boxes show the data sources and the transformations between data sources that are required for paleoclimate proxymodel comparisons. The red boxes show the sources of uncertainty for each data source or data transformation step. The arrows show the directions in which any comparisons or data transformations take place. Following the data transformation or comparison, those sections with red arrows result in variables that are not explicitly associated with hydroclimate, and further interpretation is required. Blue arrows show where data have been transformed into a variable that is directly relevant to hydroclimate.

\subsection{Schematic summary of proxy-model comparisons}

The schematic presented in Fig. 9 summarizes the challenges and recommendations regarding proxy-model comparisons discussed in this section. These include practices for interpreting the data directly from climate models, measured proxy data, and data from PSMs and paleoclimate reconstructions. Note that the data produced by the PSMs and reconstructions have been transformed (e.g., via a statistical model) so that the values from the model and/or proxy data are directly comparable. The red boxes in Fig. 9 show the major sources of uncertainty that are implicit in each of the data sources. The arrows in Fig. 9 show the usual paths of proxy-model comparisons and those steps requiring a transformation are shown in blue (e.g., from proxy data to paleoclimate data or from model data to proxy data via a PSM).

\section{Quantitative estimates of future hydroclimatic risks}

A critical goal of proxy-model comparisons over the CE is to help assess the future risks of hydroclimatic anomalies under global warming. In particular, extreme events and decadalscale predictability are attractive targets for climate prediction because knowledge of these features is useful for water resource managers, stakeholders, and regional planners. On these timescales climate is likely to evolve as a consequence of both forced changes from human activity and internal climate fluctuations. Risks of extreme and/or persistent hydroclimatic phenomena (both pluvials and megadroughts) will therefore be sensitive to both of these contributions. For example, if unforced decadal to multidecadal variations are strong (high amplitude), then they could mask long-term forced changes; estimating prolonged drought risk in such a setting would require models (either statistical or dynamical) of hydroclimatic variability to include comparably highamplitude variability at these timescales to simulate possible near-term climate trajectories. If, on the other hand, decadal to multidecadal variability is weak, then regional hydroclimate will likely evolve primarily as a function of forced changes superimposed onto year-to-year variability. For example, consider an area projected to become wetter as a consequence of anthropogenic climate change. If the actual decadal variability is more important to hydroclimate in this region than represented in climate models, prolonged drought risk would be underestimated by model simulations. In contrast, if the amplitudes of model- and proxy-based estimates of decadal to multidecadal variability are similar, confidence in near-term model projections will be enhanced. It is also desirable to quantify the long-term mean state of the system because limited instrumental observations could overlap in part with decadal-scale anomalies not representative of the multi-centennial average.

The motivations and considerations above are critical and can be addressed by proxy-model comparisons over the $\mathrm{CE}$ because the magnitude of internal variability and the longterm mean state of hydroclimate can be more accurately estimated over this time period. The promise of improving these estimates is that the range of possible conditions in the future, and therefore the risk that we associate with a given hydroclimatic anomaly, will be better constrained. Below we review two approaches that have used the paleoclimate record and model simulations to quantify future hydroclimate risks. 
The examples are relevant to water resources in the Western United States, in particular semiarid regions with significant populations exposed to hydroclimate risks, but such applications are broadly applicable in regions where sufficient paleoclimate data are available.

\subsection{Probabilistic estimates of megadrought risk}

Estimating the risk of decadal-scale phenomena such as megadroughts during the first half of this century can be cast in terms of the probability of a given indicator (e.g., a drought index, soil moisture, or precipitation anomalies) falling below some reference threshold for an unusual amount of time. This probability can be written as $\operatorname{Pr}\left\{X<q \mid \Delta \mu \sigma^{\prime}\right\}$, where $X$ is the time series of interest - for instance, PDSI - averaged over a sufficiently long period of time, $q$ is a threshold for megadrought, and $\Delta \mu$ and $\sigma^{\prime}$ are changes in the mean and SD of $X$ relative to some historical baseline (Ault et al., 2014, 2016; Cook et al., 2014a; see also Fig. 8). One means of estimating $\operatorname{Pr}\left\{X<q \mid \Delta \mu, \sigma^{\prime}\right\}$ is accomplished by deriving the parameters describing $\Delta \mu$ and $\sigma^{\prime}$ directly from ensembles of climate model simulations (Ault et al., 2014; Cook et al., 2015a). These parameters are then used to generate many realizations of Monte Carlo time series that emulate the shifted mean and modified SD of $X$. The occurrence rate of megadroughts in such realizations is calculated from each constituent model simulation or ensemble member. Risk is therefore expressed as the fraction of all realizations that include at least one megadrought for a given change in mean and variability, and all estimates from all realizations can be averaged to generate a "master" multi-model probability density function (PDF). Alternatively, megadrought probabilities can be assessed by computing risks over a plausible range of values for the mean and SD to generate a two-dimensional PDF. Megadrought risks estimated from specific models can then be assessed by identifying where in the two-dimensional PDF they simulate future hydroclimate. This approach can also be used to identify the individual contributions of temperature and precipitation to megadrought probabilities (Ault et al., 2016).

While the above approaches can be pursued exclusively with climate model simulations, paleoclimate information can be incorporated and used to enhance the characterization of future changes in hydroclimate. Specifically, the spectral characteristics of hydroclimate in a given region (e.g., $X$ from above) can be quantified and then used to constrain the frequency characteristics of the Monte Carlo time series used to emulate $X$. For example, Ault et al. (2014) used paleoclimate estimates of the continuum of hydroclimate variability in the Southwestern United States to inform the stochastic noise generators used in the Monte Carlo procedure. This approach is based on the argument that last-millennium hydroclimate variability is generally higher in proxies than in models, but it remains unclear if this difference reflects true deficiencies in models, their forcings, non-climate processes responsible for modifying proxy spectra (Sect. 2), or some combination of these factors. Moreover, this approach has not been widely or systematically applied to other parts of the world, let alone to near-term time horizons. PSMs (Sect. 4) offer an especially useful opportunity for reconciling model and proxy spectra that could also be used in these contexts, but they have not yet been applied to help constrain decadal to multidecadal hydroclimate amplitudes.

The quantitative megadrought risk estimates discussed above are best suited to the second half of the 21 st century, when forced changes dominate the mean state and may also affect hydroclimatic variability. Estimating megadrought hazards during the coming decades requires that initial conditions be factored into any credible assessment. One strategy to do so would be to use decadal prediction (Meehl et al., 2009) to estimate near-term values of $\Delta \mu$ and $\sigma^{\prime}$, then apply the direct method described above to complete a PDF of megadrought risk. Paleoclimate constraints on the amplitude of decadal to multidecadal variations in the Monte Carlo time series could likewise be applied, yielding raw and "paleoclimate-informed" estimates of risk.

In all of the above applications, several guiding principles can be articulated for future work that involves proxy-model comparisons for the purpose of constraining probabilistic estimates of megadrought risks. First, prolonged hydroclimate events should be identified as anomalies in long-term (either decadal or multidecadal) averages with respect to a historical baseline that can be constrained by paleoclimatic estimates. Second, prolonged hydroclimate events are infrequent events, making Monte Carlo (or other statistical) methods useful for generating robust estimates of their probability of occurrence. At some future date, ensemble sizes may include hundreds of members, not just dozens (e.g., Kay et al., 2015), yielding yet another method for estimating the PDF of hydroclimate risks (Coats and Mankin, 2016). In either of these approaches, the statistical characteristics of decadal to centennial variability in proxies will continue to provide important constraints on these timescales and the ability of models to realistically reproduce them.

\subsection{River flow reconstructions applied to water resources management}

Studies of river flow represent another area in which proxymodel comparisons have been important for informing future risk projections. Long proxy reconstructions of river flow constrain the historical mean state and range of variability in the amount of water flowing through major river systems, which are a critical resource, particularly in arid and semiarid environments. In the Western United States, for instance, the water supply for states including California and Arizona depend on an allocation of the annual flow of the Colorado River (Pulwarty et al., 2005). Rising temperatures, changes in precipitation, and alterations to snowfall amount and snowmelt timing threaten to reduce the flow in the Col- 
orado and other western North American rivers (Christensen et al., 2004). In addition to concerns about ongoing and future climate change modification of river flow, tree-ring reconstructions covering parts of the $\mathrm{CE}$ also suggest that past megadroughts were substantially more severe and prolonged than observed during the last century (Woodhouse et al., 2006; Meko et al., 2007; Gray et al., 2011) and that observations from the early 20th century used to allocate water from the Colorado River reflected an exceptionally wet period relative to the rest of the CE (Stockton and Jacoby, 1976). Paleoclimate estimates therefore provide more complete information for water managers and policymakers on the possible range of variability in interannual, decadal, and multidecadal flows of the Colorado River (Woodhouse and Lukas, 2006; Woodhouse and Lukas, 2006; Rice et al., 2009; Meko and Woodhouse, 2011). Moreover, reconstructions from multiple river systems reveal the frequency of multi-basin droughts that could affect the large-scale water supply infrastructure across the Western United States (Meko and Woodhouse, 2005; MacDonald et al., 2008). River flow reconstructions from tree rings are not limited to the Western United States and can be developed in other basins where tree-ring proxies reflect large-scale, seasonally integrated moisture balance (e.g., Lara et al., 2008; Wils et al., 2010; Urrutia et al., 2011; Cook et al., 2013b; Allen et al., 2015).

The widespread development of river flow reconstructions offers the ability to constrain model projections of the future using these paleoclimatic estimates. Barnett and Pierce (2009) evaluated a range of future water delivery scenarios for the Colorado River using tree-ring estimates of its mean river flow in combination with imposed flow reductions intended to mimic possible future climatic changes. They found that using the long-term CE reconstructed mean flow resulted in an increasing likelihood of future shortfalls and unsustainable water deliveries in the 21 st century, relative to using 20th century observations of river flow alone, and that climate change further exacerbated these shortfalls. Meko et al. (2012) used a river management model to show that a reoccurrence of 12th century Medieval megadroughts in the Colorado River basin would reduce Lake Mead to "deadpool", the point at which water falls below the outlet at Hoover Dam, within a few decades. By combining modern flow observations with tree-ring reconstructions, they also estimated that a megadrought as severe as the 12th century would be expected to occur every 4 to 6 centuries, even in the absence of climate change (Meko et al., 2012). Miller et al. (2013) combined observations and tree-ring reconstructions of Gunnison River (Colorado) flow to predict the probability of future wet and dry regime shifts. Thus, paleoclimate reconstructions of river flow not only more fully characterize the range of variability across timescales and reveal longterm changes in the mean state, but can also be integrated with water management tools and used in probabilistic analyses to provide quantitative information about future water availability in these systems.
The examples provided in this subsection and in Sect. 5.1 illustrate how proxies and models have been used to collectively constrain future hydroclimatic risks. The approaches have applicability in other parts of the world beyond western North America and to other types of prolonged hydroclimate extremes beyond droughts. The utility of these efforts are therefore widespread and significant and can ultimately provide stakeholders and water resource managers with new tools to prepare for a realistic range of near- and long-term climate change outcomes.

\section{Conclusions}

The focus of this contribution has been on hydroclimatic proxy-model comparisons over the $\mathrm{CE}$. The challenge of such comparisons over this time interval is not only to develop a set of practices to combine the individual strengths of proxies and models to synergistically reveal fundamental insights about the climate system that each would be unable to achieve alone, but also to do so with appropriate deference to their numerous individual and combined limitations. Hydroclimate presents a unique challenge in this regard because precipitation is more variable in time and space than temperature, rendering the characterization of its past and future behavior a challenge in both proxies and models. Moreover, many hydroclimatically relevant variables, such as soil moisture, runoff, transpiration, and water isotopes, are subject to multivariate influences that can be convoluted in both proxy and model analyses. Despite these challenges, this review highlights the substantive advances in hydroclimate reconstructions and model simulations and their associated comparisons, as well as best practices for such efforts in the future. It complements previous workshop assessments that have focused on how proxy-model comparisons over multiple paleoclimatic intervals can be used to constrain future projections (Schmidt et al., 2014) and more recent work that investigates CE proxy-model comparisons specifically for temperature (PAGES 2k-PMIP3 Group, 2015). We have reviewed the most relevant hydroclimatic proxies available for study over the CE (Sect. 2) and the state of the science regarding last-millennium simulations from fully coupled climate models (Sect. 3). In each case, we have articulated contemporary interpretations of these data sources, the current understanding of their uncertainties, and how each subfield is moving forward to address them. Given the context of our assessment of available proxy and model information, we have emphasized a set of considerations and best practices for proxy-model comparisons of hydroclimate over the $\mathrm{CE}$ (Sect. 4). The recommendations are as follows:

\section{Expectations of temporal or spatial consistency between proxies and models should be critically evaluated; e.g., temporal consistency should only be expected for vari- ability associated with exogenous forcings.}


2. Proxy-model comparisons should be viewed as a twoway conversation.

3. Uncertainties and limitations of models and proxies must be rigorously assessed to achieve robust conclusions from proxy-model comparisons.

\section{Proxy-model comparisons should take place on equal ground.}

These recommendations can be generalized beyond the specific focus of this review, but also provide important and specific context for hydroclimate proxy-model comparisons over the $\mathrm{CE}$ at a time when such investigations are only just becoming possible. Finally, a particularly important potential application of paleoclimatic proxy-model comparisons is their use in quantitatively constraining risk projections of future climate change. We have reviewed initial efforts to achieve these constraints specifically in the context of megadrought risks and river flow estimates (Sect. 5). These examples represent starting points for applications that seek to explicitly use paleoclimatic information to evaluate models and the risk assessments associated with the future emissions pathways that they provide. Such risk assessments are fundamentally based on the ability of climate models to simulate the full range of internal hydroclimate variability in addition to their forced responses, and the CE is a vital paleoclimatic target for assessing the ability of models to do so. The framework for such constraints is indeed an area of active research. In particular, the presence of incomplete information in the error and bias structures of climate models and the proxy records against which we compare them make it difficult to move beyond a traditional equal-weighting scheme in the representation of model ensembles (Knutti et al., 2009; Weigel et al., 2010). Historical observations are nevertheless beginning to be used in this context (Knutti et al., 2017) and therefore suggest that the use of paleoclimate records to constrain future projections may indeed be within reach.

Data availability. The coral-based reconstructions of seawater $\delta^{18} \mathrm{O} \quad\left(\delta^{18} \mathrm{O}_{\mathrm{sw}}\right)$ shown in Fig. 1 were downloaded from PANGAEA and NOAA Paleoclimatology (Felis et al., 2009a; https://doi.org/10.1594/PANGAEA.743956; Hendy et al., 2017; https://www.ncdc.noaa.gov/paleo/study/1869; Hetzinger et al., 2017; https://doi.org/10.1594/PANGAEA.873994), and annual averages with respect to the calendar year were calculated where necessary (Nurhati et al., 2016; https://www.ncdc.noaa.gov/paleo/study/10373; Zinke et al., 2016; https://www.ncdc.noaa.gov/paleo/study/8606; Linsley, 2017b; https://doi.org/10.1594/PANGAEA.874078; Linsley, 2017a; https://doi.org/10.1594/PANGAEA.874070). Drought atlas and tree-ring data used in Figs. 2 and 8 are publicly available through the National Centers for Environmental Information (https: //www.ncdc.noaa.gov/data-access/paleoclimatology-data/datasets/ tree-ring/north-american-drought-variability) and the International Tree-Ring Data Bank (https://www.ncdc.noaa.gov/data-access/ paleoclimatology-data/datasets/tree-ring). Instrumental-based self-calibrating PDSI data used in Fig. 2 are available through the Climatic Research Unit of the University of East Anglia: https://crudata.uea.ac.uk/cru/data/drought/\#global. GPCC data used in Fig. 2 are available through the Earth System Research Laboratory (https://www.esrl.noaa.gov/psd/data/gridded/data.gpcc.html, NOAA, 2017), as are the GPCP data used in Fig. 5 (https://www.esrl.noaa.gov/psd/data/gridded/data.gpcp.html,

NOAA, 2017). Proxy data in Fig. 3 are available through the National Centers for Environmental Information (https://www.ncdc.noaa.gov/paleo-search/study/13686, Tierney et al., 2017) and the GHCN station data (https: //www.ncdc.noaa.gov/data-access/land-based-station-data/

land-based-datasets/global-historical-climatology-network-ghen). As noted in its caption, Fig. 4 is a reproduction of Fig. 7 in Ge et al. (2008b). PMIP3 and CMIP5 data used in Figs. 5 and 8 are available through the Earth System Grid Federation: https://esgf.llnl.gov/. All CESM LME and LENS data used in Figs. 6, 7, and 8 are available through the Earth System Grid at the National Center for Atmospheric Research: https://www.earthsystemgrid.org/home.html. Forcing data plotted in Fig. 8 are available through the National Centers for Environmental Information: https://www.ncdc.noaa.gov/data-access/ paleoclimatology-data/datasets/climate-forcing. The processed data used to construct Figs. 2, 5, 6, and 8 are publicly available through the research-sharing site Zenodo. The links to these data and their associated DOIs are available at the following website: http://pages2kpmip3.github.io/.

Team list. Jason E. Smerdon (Lamont-Doherty Earth Observatory of Columbia University, Palisades, NY, USA), Jürg Luterbacher (Department of Geography, Climatology, Climate Dynamics and Climate Change, Justus Liebig University of Giessen, Giessen, Germany; Centre for International Development and Environmental Research, Justus Liebig University Giessen, Giessen, Germany), Steven J. Phipps (Institute for Marine and Antarctic Studies, University of Tasmania, Hobart, Tasmania, Australia), Kevin J. Anchukaitis (School of Geography and Development and Laboratory of Tree Ring Research, University of Arizona, Tucson, AZ, USA), Toby Ault (Department of Earth and Atmospheric Sciences, Cornell University, Ithaca, NY, USA), Sloan Coats (National Center for Atmospheric Research, Boulder, CO, USA; Cooperative Institute for Research in Environmental Sciences, University of Colorado, Boulder, CO, USA), Kim M. Cobb (Department of Earth and Atmospheric Sciences, Georgia Institute of Technology, Atlanta, GA, USA), Benjamin I. Cook (Lamont-Doherty Earth Observatory of Columbia University, Palisades, NY, USA; NASA Goddard Institute for Space Studies, New York, NY, USA), Chris Colose (NASA Goddard Institute for Space Studies, New York, NY, USA), Thomas Felis (MARUM - Center for Marine Environmental Sciences, University of Bremen, Bremen, Germany), Ailie Gallant (School of Earth, Atmosphere and Environment, Monash University, Melbourne, Australia), Johann H. Jungclaus (Max-Planck-Institute for Meteorology, Hamburg, Germany), Bronwen Konecky (Cooperative Institute for Research in Environmental Sciences, University of Colorado, Boulder, CO, USA), Allegra LeGrande (NASA Goddard Institute for Space Studies, New York, NY, USA), Sophie Lewis (Fenner School of Environment and Society, The Australian Na- 
tional University, Canberra, ACT, Australia), Alex S. Lopatka (Department of Geology, University of Maryland, College Park, MA, USA), Wenmin Man (LASG, Institute of Atmospheric Physics, Chinese Academy of Sciences, Beijing, China), Justin S. Mankin (Lamont-Doherty Earth Observatory of Columbia University, Palisades, NY, USA; NASA Goddard Institute for Space Studies, New York, NY, USA), Justin T. Maxwell (Department of Geography, Indiana University, Bloomington, IN, USA), Bette L. Otto-Bliesner (National Center for Atmospheric Research, Boulder, CO, USA), Judson W. Partin (Institute for Geophysics, Jackson School of Geosciences, University of Texas at Austin, Austin, TX, USA), Deepti Singh (Lamont-Doherty Earth Observatory of Columbia University, Palisades, NY, USA), Nathan J. Steiger (Lamont-Doherty Earth Observatory of Columbia University, Palisades, NY, USA), Samantha Stevenson (National Center for Atmospheric Research, Boulder, CO, USA), Jessica E. Tierney (Department of Geosciences, University of Arizona, Tucson, AZ, USA), Davide Zanchettin (Department of Environmental Sciences, Informatics and Statistics, $\mathrm{Ca}$ ' Foscari University of Venice, Venice, Italy), Huan Zhang (Department of Geography, Climatology, Climate Dynamics and Climate Change, Justus Liebig University of Giessen, Giessen, Germany), Alyssa R. Atwood (Department of Earth and Atmospheric Sciences, Georgia Institute of Technology, Atlanta, GA, USA; Department of Geography, University of California, Berkeley, Berkeley, CA, USA), Laia Andreu-Hayles (Lamont-Doherty Earth Observatory of Columbia University, Palisades, NY, USA), Seung H. Baek (Lamont-Doherty Earth Observatory of Columbia University, Palisades, NY, USA), Brendan Buckley (Lamont-Doherty Earth Observatory of Columbia University, Palisades, NY, USA), Edward R. Cook (Lamont-Doherty Earth Observatory of Columbia University, Palisades, NY, USA), Rosanne D'Arrigo (Lamont-Doherty Earth Observatory of Columbia University, Palisades, NY, USA), Sylvia G. Dee (Department of Earth, Environmental, and Planetary Sciences, Brown University, Providence, RI, USA), Michael L. Griffiths (Department of Environmental Science, William Paterson University, Wayne, NJ, USA), Charuta Kulkarni (Department of Earth and Environmental Sciences, The Graduate Center, City University of New York, New York, NY, USA), Yochanan Kushnir (LamontDoherty Earth Observatory of Columbia University, Palisades, NY, USA), Flavio Lehner (National Center for Atmospheric Research, Boulder, CO, USA), Caroline Leland (Lamont-Doherty Earth Observatory of Columbia University, Palisades, NY, USA), Hans W. Linderholm (Regional Climate Group, Department of Earth Sciences, University of Gothenburg, Gothenburg, Sweden), Atsushi Okazaki (Atmosphere and Ocean Research Institute, University of Tokyo, Tokyo, Japan), Jonathan Palmer (Palaeontology, Geobiology and Earth Archives Research Centre, School of Biological, Earth and Environmental Sciences, University of New South Wales, Australia), Eduardo Piovano (Centro de Investigaciones en Ciencias de la Tierra (CICTERRA/CONICET - Universidad Nacional de Córdoba), Córdoba, Argentina), Christoph C. Raible (Climate and Environmental Physics, Physics Institute and Oeschger Centre for Climate Change Research, University of Bern, Bern, Switzerland), Mukund P. Rao (Lamont-Doherty Earth Observatory of Columbia University, Palisades, NY, USA), Jacob Scheff (Lamont-Doherty Earth Observatory of Columbia University, Palisades, NY, USA), Gavin A. Schmidt (NASA Goddard Institute for Space Studies, New York, NY, USA), Richard Seager (Lamont-Doherty Earth Observatory of Columbia University, Palisades, NY, USA), Martin Wid- mann (School of Geography, Earth and Environmental Sciences, University of Birmingham, Birmingham, UK), A. Park Williams (Lamont-Doherty Earth Observatory of Columbia University, Palisades, NY, USA), Elena Xoplaki (Department of Geography, Climatology, Climate Dynamics and Climate Change, Justus Liebig University of Giessen, Giessen, Germany).

Author contributions. All authors belong to the PAGES Hydro2k Consortium. All authors contributed to the conception and scope of the paper during the course of the aforementioned workshop and in subsequent exchanges. JS, JL, and SP coordinated and led the construction of the paper. Sections 1 and 6 were jointly written by all authors. The principal contributions for each technical section were composed by the writing team as follows (in alphabetical order): Sect. 2.1: KC and TF; Sect. 2.2: KA and JM; Sect. 2.3: KC and JP; Sect. 2.4: JT; Sect. 2.5 JL and HZ; Sect. 3: SC, CC, JJ, WM, BO-B, SS, and DZ; Sect. 4: BC, AG, BK, AL, DS, NS, and JT; Sect. 5: KA, TA, JM, and SL. Lamont contribution \#8154.

Competing interests. The authors declare that they have no conflict of interest.

Special issue statement. This article is part of the special issue "Climate of the past 2000 years: regional and trans-regional syntheses". It is not associated with a conference.

Acknowledgements. This paper reflects findings and discussions from a workshop held at the Lamont-Doherty Earth Observatory of Columbia University on 1-3 June 2016 titled Comparing data and model estimates of hydroclimate variability and change over the Common Era (see http://pages2kpmip3.github.io/ and Smerdon et al., 2016). The PAGES2k and PMIP communities were instrumental in the motivation and conceptualization of the workshop and we gratefully acknowledge funding from PAGES and the Lamont Climate Center. We also acknowledge the workshop for inspiring the establishment of the CoralHydro2k project as part of the PAGES 2k Network (http://www.pastglobalchanges.org/ini/wg/ 2k-network/projects/coral-hydro). We thank the World Climate Research Program's Working Group on Coupled Modeling, which oversees CMIP, and the individual model groups (listed in Table 1) for making their data available.

Individual researchers on this study were supported in part by the US National Science Foundation through the National Center for Atmospheric Research and the following: grants AGS-1502150, AGS-1303976, AGS-1433551, AGS-1602564, AGS-1501856, AGS-1243125, AGS-1243107, AGS-1404003, AGS-1243204, AGS-1401400, AGS-1602581, AGS-1502830, AGS-1203785, AGS-1602920, and OCE-1502832; Australian Research Council grants SR140300001, FL100100195, and DECRA DE16010092; National Natural Science Foundation of China grant numbers 41305069 and 41675082 and the Jiangsu Collaborative Innovation Center for Climate Change; the German Federal Ministry of Education and Research (BMBF) and JPI-Climate/Belmont Forum projects PACMEDY (FKZ: 01LP1607B) and Collaborative Research Action "INTEGRATE, An integrated data-model study of 
interactions between tropical monsoons and extratropical climate variability and extremes"; the DFG-Research Center/Cluster of Excellence "The Ocean in the Earth System" at the University of Bremen; the Swedish Science Council (VR) (2012-5246); the Swiss National Science Foundation; the Brown Institute for Environment and Society; the Lamont-Doherty Postdoctoral Fellowship and Earth Institute Postdoctoral Fellowship programs of Columbia University; and the NOAA Climate and Global Change Postdoctoral Fellowship Program administered by the University Corporation for Atmospheric Research Visiting Scientist Program.

Edited by: Helen McGregor

Reviewed by: Hai $\mathrm{Xu}$ and one anonymous referee

\section{References}

Aggarwal, P. K., Frohlich, K., Kulkarni, K. M., and Gourcy, L. L.: Stable isotope evidence for moisture sources in the Asian summer monsoon under present and past climate regimes, Geophys. Res. Lett., 31, L08203, https://doi.org/10.1029/2004g1019911, 2004.

Aggarwal, P. K., Alduchov, O. A., Froehlich, K. O., AraguasAraguas, L. J., Sturchio, N. C., and Kurita, N.: Stable isotopes in global precipitation: A unified interpretation based on atmospheric moisture residence time, Geophys. Res. Lett., 39, L11705, https://doi.org/10.1029/2012g1051937, 2012.

Allen, K. J., Nichols, S. C., Evans, R., Cook, E. R., Allie, S., Carson, G., Ling, F., and Baker, P. J.: Preliminary December-January inflow and streamflow reconstructions from tree rings for western Tasmania, southeastern Australia, Water Resour. Res., 51, 54875503, https://doi.org/10.1002/2015wr017062, 2015.

Alpert, A. E., Cohen, A. L., Oppo, D. W., DeCarlo, T. M., Gove, J. M., and Young, C. W.: Comparison of equatorial Pacific sea surface temperature variability and trends with $\mathrm{Sr} / \mathrm{Ca}$ records from multiple corals, Paleoceanography, 31, 252-265, https://doi.org/10.1002/2015pa002897, 2016.

Ammann, C. M., Joos, F., Schimel, D. S., Otto-Bliesner, B. L., and Tomas, R. A.: Solar influence on climate during the past millennium: results from transient simulations with the NCAR Climate System Model, P. Natl. Acad. Sci. USA, 104, 3713-3718, https://doi.org/10.1073/pnas.0605064103, 2007.

Anchukaitis, K. J. and Evans, M. N.: Tropical cloud forest climate variability and the demise of the Monteverde golden toad, P. Natl. Acad. Sci. USA, 107, 5036-5040, https://doi.org/10.1073/pnas.0908572107, 2010.

Anchukaitis, K. J. and Tierney, J. E.: Identifying coherent spatiotemporal modes in time-uncertain proxy paleoclimate records, Clim. Dynam., 41, 1291-1306, https://doi.org/10.1007/s00382012-1483-0, 2013.

Anchukaitis, K. J., Buckley, B. M., Cook, E. R., Cook, B. I., D'Arrigo, R. D., and Ammann, C. M.: Influence of volcanic eruptions on the climate of the Asian monsoon region, Geophys. Res. Lett., 37, L22703, https://doi.org/10.1029/2010g1044843, 2010.

Anchukaitis, K. J., D’Arrigo, R. D., Andreu-Hayles, L., Frank, D., Verstege, A., Curtis, A., Buckley, B. M., Jacoby, G. C., and Cook, E. R.: Tree-ring-reconstructed summer temperatures from northwestern North America during the last nine centuries, J. Cli- mate, 26, 3001-3012, https://doi.org/10.1175/jcli-d-11-00139.1, 2013.

Anchukaitis, K. J., Wilson, R., Briffa, K. R., Büntgen, U., Cook, E. R., D’Arrigo, R., Davi, N., Esper, J., Frank, D., Gunnarson, B. E., Hegerl, G., Helama, S., Klesse, S., Krusic, P. J., Linderholm, H. W., Myglan, V., Osborn, T. J., Zhang, P., Rydval, M., Schneider, L., Schurer, A., Wiles, G., and Zorita, E.: Last millennium Northern Hemisphere summer temperatures from tree rings: Part II, spatially resolved reconstructions, Quaternary Sci. Rev., 163, 1-22, https://doi.org/10.1016/j.quascirev.2017.02.020, 2017.

Anderegg, W. R. L., Schwalm, C., Biondi, F., Camarero, J. J., Koch, G., Litvak, M., Ogle, K., Shaw, J. D., Shevliakova, E., Williams, A. P., Wolf, A., Ziaco, E., and Pacala, S.: Pervasive drought legacies in forest ecosystems and their implications for carbon cycle models, Science, 349, 528-532, https://doi.org/10.1126/science.aab1833, 2015.

Andreu-Hayles, L., Ummenhofer, C. C., Barriendos, M., Schleser, G. H., Helle, G., Leuenberger, M., Gutiérrez, E., and Cook, E. R.: 400 Years of summer hydroclimate from stable isotopes in Iberian trees, Clim. Dynam., 49, 1-19, https://doi.org/10.1007/s00382-016-3332-z, 2016.

Anet, J. G., Muthers, S., Rozanov, E. V., Raible, C. C., Stenke, A., Shapiro, A. I., Brönnimann, S., Arfeuille, F., Brugnara, Y., Beer, J., Steinhilber, F., Schmutz, W., and Peter, T.: Impact of solar versus volcanic activity variations on tropospheric temperatures and precipitation during the Dalton Minimum, Clim. Past, 10, 921-938, https://doi.org/10.5194/cp-10-921-2014, 2014.

Aono, Y. and Kazui, K.: Phenological data series of cherry tree flowering in Kyoto, Japan, and its application to reconstruction of springtime temperatures since the 9th century, Int. J. Climatol., 28, 905-914, https://doi.org/10.1002/joc.1594, 2008.

Asmerom, Y., Polyak, V., Burns, S., and Rassmussen, J.: Solar forcing of Holocene climate: new insights from a speleothem record, southwestern United States, Geology, 35, 1-4, https://doi.org/10.1130/g22865a.1, 2007.

Atwood, A. R., Wu, E., Frierson, D. M. W., Battisti, D. S., and Sachs, J. P.: Quantifying climate forcings and feedbacks over the last millennium in the CMIP5-PMIP3 models, J. Climate, 29, 1161-1178, https://doi.org/10.1175/jcli-d-15-0063.1, 2016.

Ault, T. R., Cole, J. E., and George, S. S.: The amplitude of decadal to multidecadal variability in precipitation simulated by state-of-the-art climate models, Geophys. Res. Lett., 39, L21705, https://doi.org/10.1029/2012gl053424, 2012.

Ault, T. R., Cole, J. E., Overpeck, J. T., Pederson, G. T., St George, S., Otto-Bliesner, B., Woodhouse, C. A., and Deser, C.: The continuum of hydroclimate variability in western North America during the last millennium, J. Climate, 26, 5863-5878, https://doi.org/10.1175/jcli-d-11-00732.1, 2013a.

Ault, T. R., Deser, C., Newman, M., and Emile-Geay, J.: Characterizing decadal to centennial variability in the equatorial Pacific during the last millennium, Geophys. Res. Lett., 40, 3450-3456, https://doi.org/10.1002/grl.50647, 2013b.

Ault, T. R., Cole, J. E., Overpeck, J. T., Pederson, G. T., and Meko, D. M.: Assessing the risk of persistent drought using climate model simulations and paleoclimate data, J. Climate, 27, 7529-7549, https://doi.org/10.1175/jcli-d-12-00282.1, 2014.

Ault, T. R., Mankin, J. S., Cook, B. I., and Smerdon, J. E.: Relative impacts of mitigation, temperature, and precipitation on 21 st- 
century megadrought risk in the American Southwest, Science Advances, 2, e1600873, https://doi.org/10.1126/sciadv.1600873, 2016.

Ayalon, A., Bar-Matthews, M., and Sass, E.: Rainfall-recharge relationships within a karstic terrain in the Eastern Mediterranean semi-arid region, Israel: $\delta^{18} \mathrm{O}$ and $\delta \mathrm{D}$ characteristics, J. Hydrol., 207, 18-31, https://doi.org/10.1016/S00221694(98)00119-X, 1998.

Babst, F., Poulter, B., Trouet, V., Tan, K., Neuwirth, B., Wilson, R., Carrer, M., Grabner, M., Tegel, W., Levanic, T., Panayotov, M., Urbinati, C., Bouriaud, O., Ciais, P., and Frank, D.: Site- and species-specific responses of forest growth to climate across the European continent, Global Ecol. Biogeogr., 22, 706-717, https://doi.org/10.1111/geb.12023, 2013.

Baek, S. H., Smerdon, J. E., Coats, S., Williams, A. P., Cook, B. I., Cook, E. R., and Seager, R.: Precipitation, temperature, and teleconnection signals across the combined North American, Monsoon Asia, and Old World Drought Atlases, J. Climate, 30, 71417155, https://doi.org/10.1175/JCLI-D-16-0766.1, 2017.

Bar-Matthews, M., Ayalon, A., and Kaufman, A.: Late quaternary paleoclimate in the eastern Mediterranean Region from stable isotope analysis of speleothems at Soreq Cave, Israel, Quaternary Res., 47, 155-168, https://doi.org/10.1006/qres.1997.1883, 1997.

Bar-Matthews, M., Ayalon, A., Kaufman, A., and Wasserburg, G. J.: The Eastern Mediterranean paleoclimate as a reflection of regional events: Soreq Cave, Israel, Earth Planet. Sc. Lett., 166, 85-95, https://doi.org/10.1016/S0012-821X(98)00275-1, 1999.

Barriendos, M., Coeur, D., Lang, M., Llasat, M. C., Naulet, R., Lemaitre, F., and Barrera, A.: Stationarity analysis of historical flood series in France and Spain (14th-20th centuries), Natural Hazards and Earth System Sciences, 3, 583-592, https://doi.org/10.5194/nhess-3-583-2003, 2003.

Barriendos, M., Ruiz-Bellet, J. L., Tuset, J., Mazón, J., Balasch, J. C., Pino, D., and Ayala, J. L.: The "Prediflood" database of historical floods in Catalonia (NE Iberian Peninsula) AD 10352013, and its potential applications in flood analysis, Hydrol. Earth Syst. Sci., 18, 4807-4823, https://doi.org/10.5194/hess-184807-2014, 2014.

Barnett, T. P. and Pierce, D. W.: Sustainable water deliveries from the Colorado River in a changing climate, P. Natl. Acad. Sci. USA of the United States of America, 106, 7334-7338, https://doi.org/10.1073/pnas.0812762106, 2009.

Bauer, E., Claussen, M., Brovkin, V., and Huenerbein, A.: Assessing climate forcings of the Earth system for the past millennium, Geophys. Res. Lett., 30, 1276, https://doi.org/10.1029/2002GL016639, 2003.

Benson, L., Linsley, B., Smoot, J., Mensing, S., Lund, S., Stine, S., and Sarna-Wojcicki, A.: Influence of the Pacific Decadal Oscillation on the climate of the Sierra Nevada, California and Nevada, Quaternary Res., 59, 151-159, https://doi.org/10.1016/s00335894(03)00007-3, 2003.

Benway, H. M. and Mix, A. C.: Oxygen isotopes, upperocean salinity, and precipitation sources in the eastern tropical Pacific, Earth Planet. Sc. Lett., 224, 493-507, https://doi.org/10.1016/j.epsl.2004.05.014, 2004.

Berger, A. L.: Long-term variations of daily insolation and quaternary climatic changes, J. Atmos.
Sci., 35, 2362-2367, https://doi.org/10.1175/1520 0469(1978)035<2362:Itvodi>2.0.co;2, 1978.

Bertrand, C., Loutre, M.-F., Crucifix, M., and Berger, A.: Climate of the last millennium: a sensitivity study, Tellus A, 54, 221-244, https://doi.org/10.1034/j.1600-0870.2002.00287.x, 2002.

Bhend, J., Franke, J., Folini, D., Wild, M., and Brönnimann, S.: An ensemble-based approach to climate reconstructions, Clim. Past, 8, 963-976, https://doi.org/10.5194/cp-8-963-2012, 2012.

Blaauw, M. and Christen, J. A.: Flexible paleoclimate age-depth models using an autoregressive gamma process, Bayesian Anal., 6, 457-474, https://doi.org/10.1214/ba/1339616472, 2011.

Benito, G., Brázdil, R., Herget, J., and Machado, M. J.: Quantitative historical hydrology in Europe, Hydrol. Earth Syst. Sci., 19, 3517-3539, https://doi.org/10.5194/hess-19-3517-2015, 2015.

Braconnot, P., Otto-Bliesner, B., Harrison, S., Joussaume, S., Peterchmitt, J.-Y., Abe-Ouchi, A., Crucifix, M., Driesschaert, E., Fichefet, Th., Hewitt, C. D., Kageyama, M., Kitoh, A., Laîné, A., Loutre, M.-F., Marti, O., Merkel, U., Ramstein, G., Valdes, P., Weber, S. L., Yu, Y., and Zhao, Y.: Results of PMIP2 coupled simulations of the Mid-Holocene and Last Glacial Maximum Part 1: Experiments and large-scale features, Clim. Past, 3, 261277, https://doi.org/10.5194/cp-3-261-2007, 2007.

Braconnot, P., Harrison, S. P., Kageyama, M., Bartlein, P. J., Masson-Delmotte, V., Abe-Ouchi, A., Otto-Bliesner, B., and Zhao, Y.: Evaluation of climate models using palaeoclimatic data, Nat. Clim. Change, 2, 417-424, https://doi.org/10.1038/nclimate1456, 2012.

Brazdil, R., Pfister, C., Wanner, H., Von Storch, H., and Luterbacher, J.: Historical climatology in Europe - the state of the art, Climatic Change, 70, 363-430, https://doi.org/10.1007/s10584005-5924-1, 2005.

Brazdil, R., Demaree, G. R., Deutsch, M., Garnier, E., Kiss, A., Luterbacher, J., Macdonald, N., Rohr, C., Dobrovolny, P., Kolar, P., and Chroma, K.: European floods during the winter 1783/1784: scenarios of an extreme event during the "Little Ice Age", Theor. Appl. Climatol., 100, 163-189, https://doi.org/10.1007/s00704-009-0170-5, 2010.

Brázdil, R., Chromá, K., Valášek, H., and Dolák, L.: Hydrometeorological extremes derived from taxation records for south-eastern Moravia, Czech Republic, 1751-1900 AD, Clim. Past, 8, 467481, https://doi.org/10.5194/cp-8-467-2012, 2012.

Brázdil, R., Dobrovolný, P., Trnka, M., Kotyza, O., Řezníčková, L., Valášek, H., Zahradníček, P., and Štěpánek, P.: Droughts in the Czech Lands, 1090-2012 AD, Clim. Past, 9, 1985-2002, https://doi.org/10.5194/cp-9-1985-2013, 2013.

Brazdil, R., Dobrovolny, P., Trnka, M., Büntgen, U., Reznickova, L., Kotyza, O., Valasek, H., and Stepanek, P.: Documentary and instrumental-based drought indices for the Czech Lands back to AD 1501, Clim. Res., 70, 103-117, https://doi.org/10.3354/cr01380, 2016.

Breitenbach, S. F. M., Adkins, J. F., Meyer, H., Marwan, N., Kumar, K. K., and Haug, G. H.: Strong influence of water vapor source dynamics on stable isotopes in precipitation observed in Southern Meghalaya, NE India, Earth Planet. Sc. Lett., 292, 212 220, https://doi.org/10.1016/j.eps1.2010.01.038, 2010.

Breitenmoser, P., Brönnimann, S., and Frank, D.: Forward modelling of tree-ring width and comparison with a global network of tree-ring chronologies, Clim. Past, 10, 437-449, https://doi.org/10.5194/cp-10-437-2014, 2014. 
Brewer, S., Alleaume, S., Guiot, J., and Nicault, A.: Historical droughts in Mediterranean regions during the last 500 years: a data/model approach, Clim. Past, 3, 355-366, https://doi.org/10.5194/cp-3-355-2007, 2007.

Briffa, K. R., Jones, P. D., Bartholin, T. S., Eckstein, D., Schweingruber, F. H., Karlen, W., Zetterberg, P., and Eronen, M.: Fennoscandian summers from AD-500 - temperature-changes on short and long timescales, Clim. Dynam., 7, 111-119, 1992a.

Briffa, K. R., Jones, P. D., and Schweingruber, F. H.: Tree-ring density reconstructions of summer temperature patterns across western North-America since 1600, J. Climate, 5, 735-754, https://doi.org/10.1175/15200442(1992)005<0735:trdros>2.0.co;2, 1992b.

Briffa, K. R., Osborn, T. J., Schweingruber, F. H., Jones, P. D., Shiyatov, S. G., and Vaganov, E. A.: Tree-ring width and density data around the Northern Hemisphere: Part 1, local and regional climate signals, Holocene, 12, 737-757, https://doi.org/10.1191/0959683602hl587rp, 2002a.

Briffa, K. R., Osborn, T. J., Schweingruber, F. H., Jones, P. D., Shiyatov, S. G., and Vaganov, E. A.: Tree-ring width and density data around the Northern Hemisphere: Part 2, spatio-temporal variability and associated climate patterns, Holocene, 12, 759-789, https://doi.org/10.1191/0959683602hl588rp, 2002b.

Briffa, K. R. and Melvin, T. M.: A Closer Look at Regional Curve Standardization of Tree-Ring Records: Justification of the Need, a Warning of Some Pitfalls, and Suggested Improvements in Its Application A Closer Look at Regional Curve Standardization, in: Dendroclimatology: Progress and Prospects, edited by: Hughes, M. K., Swetnam, T. W., and Diaz, H. F., Developments in Paleoenvironmental Research, Springer, Dordrecht, Netherlands, 113-145, 2011.

Buentgen, U., Frank, D., Trouet, V., and Esper, J.: Diverse climate sensitivity of Mediterranean tree-ring width and density, TreesStruct. Funct., 24, 261-273, https://doi.org/10.1007/s00468-0090396-y, 2010.

Buentgen, U., Tegel, W., Nicolussi, K., McCormick, M., Frank, D., Trouet, V., Kaplan, J. O., Herzig, F., Heussner, K.-U., Wanner, H., Luterbacher, J., and Esper, J.: 2500 years of European climate variability and human susceptibility, Science, 331, 578582, https://doi.org/10.1126/science.1197175, 2011.

Bunde, A., Buentgen, U., Ludescher, J., Luterbacher, J., and von Storch, H.: Is there memory in precipitation?, Nat. Clim. Change, 3, 174-175, 2013.

Byrne, M. P. and O'Gorman, P. A.: The response of precipitation minus evapotranspiration to climate warming: why the "Wet-Get-Wetter, Dry-Get-Drier" scaling does not hold over land, J. Climate, 28, 8078-8092, https://doi.org/10.1175/jcli-d15-0369.1, 2015.

Cahyarini, S. Y., Pfeiffer, M., Timm, O., Dullo, W. C., and Schonberg, D. G.: Reconstructing seawater $\delta^{18} \mathrm{O}$ from paired coral $\delta^{18} \mathrm{O}$ and $\mathrm{Sr} / \mathrm{Ca}$ ratios: Methods, error analysis and problems, with examples from Tahiti (French Polynesia) and Timor (Indonesia), Geochim. Cosmochim. Ac., 72, 2841-2853, https://doi.org/10.1016/j.gca.2008.04.005, 2008.

Cai, Y., Chiang, J. C. H., Breitenbach, S. F. M., Tan, L., Cheng, H., Edwards, R. L., and An, Z.: Holocene moisture changes in western China, Central Asia, inferred from stalagmites, Quaternary Sci. Rev., 158, 15-28, https://doi.org/10.1016/j.quascirev.2016.12.014, 2017.
Camenisch, C., Keller, K. M., Salvisberg, M., Amann, B., Bauch, M., Blumer, S., Brázdil, R., Brönnimann, S., Büntgen, U., Campbell, B. M. S., Fernández-Donado, L., Fleitmann, D., Glaser, R., González-Rouco, F., Grosjean, M., Hoffmann, R. C., Huhtamaa, H., Joos, F., Kiss, A., Kotyza, O., Lehner, F., Luterbacher, J., Maughan, N., Neukom, R., Novy, T., Pribyl, K., Raible, C. C., Riemann, D., Schuh, M., Slavin, P., Werner, J. P., and Wetter, O.: The 1430s: a cold period of extraordinary internal climate variability during the early Spörer Minimum with social and economic impacts in north-western and central Europe, Clim. Past, 12, 2107-2126, https://doi.org/10.5194/cp-12-2107-2016, 2016.

Campbell, R., McCarroll, D., Loader, N. J., Grudd, H., Robertson, I., and Jalkanen, R.: Blue intensity in Pinus sylvestris treerings: developing a new palaeoclimate proxy, Holocene, 17, 821828, https://doi.org/10.1177/0959683607080523, 2007.

Carolin, S. A., Cobb, K. M., Adkins, J. F., Clark, B., Conroy, J. L., Lejau, S., Malang, J., and Tuen, A. A.: Varied response of Western Pacific hydrology to climate forcings over the last glacial period, Science, 340, 1564-1566, https://doi.org/10.1126/science.1233797, 2013.

Carro-Calvo, L., Salcedo-Sanz, S., and Luterbacher, J.: Neural Computation in Paleoclimatology: General methodology and a case study, Neurocomputing, 113, 262-268, https://doi.org/10.1016/j.neucom.2012.12.045, 2013.

Casty, C., Raible, C. C., Stocker, T. F., Wanner, H., and Luterbacher, J.: A European pattern climatology 1766-2000, Clim. Dynam., 29, 791-805, https://doi.org/10.1007/s00382007-0257-6, 2007.

Chadwick, R., Boutle, I., and Martin, G.: Spatial patterns of precipitation change in CMIP5: why the rich do not get richer in the tropics, J. Climate, 26, 3803-3822, https://doi.org/10.1175/jclid-12-00543.1, 2013.

Chen, J. H., Chen, F. H., Feng, S., Huang, W., Liu, J. B., and Zhou, A. F.: Hydroclimatic changes in China and surroundings during the Medieval Climate Anomaly and Little Ice Age: spatial patterns and possible mechanisms, Quaternary Sci. Rev., 107, 98-111, https://doi.org/10.1016/j.quascirev.2014.10.012, 2015.

Chen, S., Hoffmann, S. S., Lund, D. C., Cobb, K. M., EmileGeay, J., and Adkins, J. F.: A high-resolution speleothem record of western equatorial Pacific rainfall: implications for Holocene ENSO evolution, Earth Planet. Sc. Lett., 442, 61-71, https://doi.org/10.1016/j.epsl.2016.02.050, 2016.

Cheng, H., Edwards, R. L., Hoff, J., Gallup, C. D., Richards, D. A., and Asmerom, Y.: The half-lives of uranium-234 and thorium230, Chem. Geol., 169, 17-33, https://doi.org/10.1016/s00092541(99)00157-6, 2000.

Cheng, H., Zhang, P. Z., Spotl, C., Edwards, R. L., Cai, Y. J., Zhang, D. Z., Sang, W. C., Tan, M., and An, Z. S.: The climatic cyclicity in semiarid-arid central Asia over the past 500,000 years, Geophys. Res. Lett., 39, 5, https://doi.org/10.1029/2011gl050202, 2012.

Cheng, H., Sinha, A., Verheyden, S., Nader, F. H., Li, X. L., Zhang, P. Z., Yin, J. J., Yi, L., Peng, Y. B., Rao, Z. G., Ning, Y. F., and Edwards, R. L.: The climate variability in northern Levant over the past 20000 years, Geophys. Res. Lett., 42, 8641-8650, https://doi.org/10.1002/2015GL065397, 2015.

Cheng, H., Edwards, R. L., Sinha, A., Spötl, C., Yi, L., Chen, S., Kelly, M., Kathayat, G., Wang, X., Li, X., Kong, X., Wang, Y., Ning, Y., and Zhang, H.: The Asian monsoon over the past 
640,000 years and ice age terminations, Nature, 534, 640-646, https://doi.org/10.1038/nature18591, 2016a.

Cheng, H., Edwards, R. L., Sinha, A., Spotl, C., Yi, L., Chen, S. T., Kelly, M., Kathayat, G., Wang, X. F., Li, X. L., Kong, X. G., Wang, Y. J., Ning, Y. F., and Zhang, H. W.: The Asian monsoon over the past 640000 years and ice age terminations, Nature, 534, 640, https://doi.org/10.1038/nature18591, 2016 b.

Chou, C., Neelin, J. D., Chen, C.-A., and Tu, J.-Y.: Evaluating the "Rich-Get-Richer" mechanism in tropical precipitation change under global warming, J. Climate, 22, 1982-2005, https://doi.org/10.1175/2008jcli2471.1, 2009.

Christensen, N. S., Wood, A. W., Voisin, N., Lettenmaier, D. P., and Palmer, R. N.: The effects of climate change on the hydrology and water resources of the Colorado River basin, Climatic Change, 62, 337-363, https://doi.org/10.1023/B:CLIM.0000013684.13621.1f, 2004.

Christiansen, B. and Ljungqvist, F. C.: Challenges and perspectives for large-scale temperature reconstructions of the past two millennia, Rev. Geophys., 55, 40-96, https://doi.org/10.1002/2016RG000521, 2017.

Chu, K. C.: Climatic pulsations during historic time in China, Geogr. Rev., 16, 274-282, https://doi.org/10.2307/208683, 1926.

Chu, K. C.: A preliminary study on the climatic fluctuations during the last 5000 years in China, Acad. Sin., 16, 226-256, 1973.

CMA: Yearly charts of dryness wetness in China for the last 500year period, Di Tu Chu Ban She, Cartological Press, Beijing, China, 1981.

Coats, S. and Mankin, J. S.: The challenge of accurately quantifying future megadrought risk in the American Southwest, Geophys. Res. Lett., 43, 9225-9233, https://doi.org/10.1002/2016gl070445, 2016.

Coats, S., Smerdon, J. E., Cook, B. I., and Seager, R.: Stationarity of the tropical pacific teleconnection to North America in CMIP5/PMIP3 model simulations, Geophys. Res. Lett., 40, 4927-4932, https://doi.org/10.1002/grl.50938, 2013a.

Coats, S., Smerdon, J. E., Seager, R., Cook, B. I., and GonzálezRouco, J. F.: Megadroughts in southwestern North America in ECHO-G millennial simulations and their comparison to proxy drought reconstructions, J. Climate, 26, 7635-7649, https://doi.org/10.1175/jcli-d-12-00603.1, 2013b.

Coats, S., Cook, B. I., Smerdon, J. E., and Seager, R.: North American pancontinental droughts in model simulations of the last millennium, J. Climate, 28, 2025-2043, https://doi.org/10.1175/jclid-14-00634.1, 2015a.

Coats, S., Smerdon, J. E., Cook, B. I., and Seager, R.: Are simulated megadroughts in the North American southwest forced?, J. Climate, 28, 124-142, https://doi.org/10.1175/jcli-d-14-00071.1, 2015b.

Coats, S., Smerdon, J. E., Seager, R., Griffin, D., and Cook, B. I.: Winter-to-summer precipitation phasing in southwestern North America: a multicentury perspective from paleoclimatic modeldata comparisons, J. Geophys. Res.-Atmos., 120, 8052-8064, https://doi.org/10.1002/2015jd023085, 2015c.

Coats, S., Smerdon, J. E., Cook, B. I., Seager, R., Cook, E. R., and Anchukaitis, K. J.: Internal ocean-atmosphere variability drives megadroughts in Western North America, Geophys. Res. Lett., 43, 9886-9894, https://doi.org/10.1002/2016GL070105, 2016a.

Coats, S., Smerdon, J. E., Karnauskas, K. B., and Seager, R.: The improbable but unexceptional occurrence of megadrought clustering in the American West during the Medieval Climate Anomaly, Environ. Res. Lett., 11, 74025, https://doi.org/10.1088/1748-9326/11/7/074025, 2016 b.

Cobb, K. M., Charles, C. D., and Hunter, D. E.: A central tropical Pacific coral demonstrates Pacific, Indian, and Atlantic decadal climate connections, Geophys. Res. Lett., 28, 22092212, https://doi.org/10.1029/2001GL012919, 2001.

Cobb, K. M., Charles, C. D., Cheng, H., and Edwards, R. L.: El Nino/Southern Oscillation and tropical Pacific climate during the last millennium, Nature, 424, 271-276, https://doi.org/10.1038/nature01779, 2003.

Colle, B. A., Zhang, Z. H., Lombardo, K. A., Chang, E., Liu, P., and Zhang, M. H.: Historical evaluation and future prediction of eastern North American and Western Atlantic extratropical cyclones in the CMIP5 models during the cool season, J. Climate, 26, 6882-6903, https://doi.org/10.1175/jcli-d-12-00498.1, 2013.

Colose, C. M., LeGrande, A. N., and Vuille, M.: The influence of volcanic eruptions on the climate of tropical South America during the last millennium in an isotope-enabled general circulation model, Clim. Past, 12, 961-979, https://doi.org/10.5194/cp-12961-2016, 2016a.

Colose, C. M., LeGrande, A. N., and Vuille, M.: Hemispherically asymmetric volcanic forcing of tropical hydroclimate during the last millennium, Earth Syst. Dynam., 7, 681-696, https://doi.org/10.5194/esd-7-681-2016, 2016b.

Comboul, M., Emile-Geay, J., Evans, M. N., Mirnateghi, N., Cobb, K. M., and Thompson, D. M.: A probabilistic model of chronological errors in layer-counted climate proxies: applications to annually banded coral archives, Clim. Past, 10, 825-841, https://doi.org/10.5194/cp-10-825-2014, 2014.

Comboul, M., Emile-Geay, J., Hakim, G. J., and Evans, M. N.: Paleoclimate sampling as a sensor placement problem, J. Climate, 28, 7717-7740, https://doi.org/10.1175/jcli-d-14-00802.1, 2015.

Conroy, J. L., Cobb, K. M., and Noone, D.: Comparison of precipitation isotope variability across the tropical Pacific in observations and SWING2 model simulations, J. Geophys. Res.-Atmos., 118, 5867-5892, https://doi.org/10.1002/jgrd.50412, 2013.

Conroy, J. L., Cobb, K. M., Lynch-Stieglitz, J., and Polissar, P. J.: Constraints on the salinity-oxygen isotope relationship in the central tropical Pacific Ocean, Mar. Chem., 161, 26-33, https://doi.org/10.1016/j.marchem.2014.02.001, 2014.

Cook, E. R.: The decomposition of tree-ring series for environmental studies, Tree-Ring Bull., 47, 37-60, 1987.

Cook, E. R. and Jacoby, G. C.: Tree-ring drought relationships in Hudson Valley, New-York, Science, 198, 399-401, https://doi.org/10.1126/science.198.4315.399, 1977.

Cook, E. R. and Kairiukstis, L. A.: Methods of dendrochronology applications in the environmental sciences, XII + 394P pp., Kluwer Academic Publishers, Dordrecht, Netherlands, 1990.

Cook, E. R., Briffa, K. R., Meko, D. M., Graybill, D. A., and Funkhouser, G.: THE segment length curse in long tree-ring chronology development for paleoclimatic studies, Holocene, 5, 229-237, https://doi.org/10.1177/095968369500500211, 1995.

Cook, E. R., Meko, D. M., Stahle, D. W., and Cleaveland, M. K.: Drought reconstructions for the continental United States, J. Climate, 12, 1145-1162, https://doi.org/10.1175/15200442(1999)012<1145:drftcu >2.0.co;2, 1999.

Cook, E. R., Woodhouse, C. A., Eakin, C. M., Meko, D. M., and Stahle, D. W.: Long-term aridity changes in 
the western United States, Science, 306, 1015-1018, https://doi.org/10.1126/science.1102586, 2004.

Cook, E. R., Anchukaitis, K. J., Buckley, B. M., D’Arrigo, R. D., Jacoby, G. C., and Wright, W. E.: Asian monsoon failure and megadrought during the last millennium, Science, 328, 486-489, https://doi.org/10.1126/science.1185188, 2010a.

Cook, E. R., Seager, R., Heim, R. R., Jr., Vose, R. S., Herweijer, C., and Woodhouse, C.: Megadroughts in North America: placing IPCC projections of hydroclimatic change in a longterm palaeoclimate context, J. Quaternary Sci., 25, 48-61, https://doi.org/10.1002/jqs.1303, 2010b.

Cook, B. I., Seager, R., Miller, R. L., and Mason, J. A.: Intensification of North American megadroughts through surface and dust aerosol forcing, J. Climate, 26, 4414-4430, https://doi.org/10.1175/jcli-d-12-00022.1, 2013a.

Cook, E. R., Palmer, J. G., Ahmed, M., Woodhouse, C. A., Fenwick, P., Zafar, M. U., Wahab, M., and Khan, N.: Five centuries of Upper Indus River flow from tree rings, J. Hydrol., 486, 365375, https://doi.org/10.1016/j.jhydrol.2013.02.004, $2013 \mathrm{~b}$.

Cook, B. I., Smerdon, J. E., Seager, R., and Coats, S.: Global warming and 21st century drying, Clim. Dynam., 43, 2607-2627, https://doi.org/10.1007/s00382-014-2075-y, 2014a.

Cook, B. I., Smerdon, J. E., Seager, R., and Cook, E. R.: Pancontinental droughts in North America over the last millennium, J. Climate, 27, 383-397, https://doi.org/10.1175/jcli-d-1300100.1, 2014b.

Cook, B. I., Ault, T. R., and Smerdon, J. E.: Unprecedented 21st century drought risk in the American Southwest and Central Plains, Sci. Adv., 1, e1400082, https://doi.org/10.1126/sciadv.1400082, 2015a.

Cook, E. R., Seager, R., Kushnir, Y., Briffa, K. R., Büntgen, U., Frank, D., Krusic, P. J., Tegel, W., van der Schrier, G., AndreuHayles, L., Baillie, M., Baittinger, C., Bleicher, N., Bonde, N., Brown, D., Carrer, M., Cooper, R., Čufar, K., Dittmar, C., Esper, J., Griggs, C., Gunnarson, B., Günther, B., Gutierrez, E., Haneca, K., Helama, S., Herzig, F., Heussner, K.-U., Hofmann, J., Janda, P., Kontic, R., Köse, N., Kyncl, T., Levanič, T., Linderholm, H., Manning, S., Melvin, T. M., Miles, D., Neuwirth, B., Nicolussi, K., Nola, P., Panayotov, M., Popa, I., Rothe, A., Seftigen, K., Seim, A., Svarva, H., Svoboda, M., Thun, T., Timonen, M., Touchan, R., Trotsiuk, V., Trouet, V., Walder, F., Ważny, T., Wilson, R., and Zang, C.: Old World megadroughts and pluvials during the Common Era, Sci. Adv., 1, e1500561, https://doi.org/10.1126/sciadv.1500561, 2015b.

Cook, B. I., Cook, E. R., Smerdon, J. E., Seager, R., Williams, A. P., Coats, S., Stahle, D. W., and Villanueva Diaz, J.: North American megadroughts in the Common Era: reconstructions and simulations, WIREs Clim. Change, 7, 411-432, https://doi.org/10.1002/wcc.394, 2016.

Coulthard, B. and Smith, D. J.: A 477-year dendrohydrological assessment of drought severity for Tsable River, Vancouver Island, British Columbia, Canada, Hydrol. Process., 30, 16761690, https://doi.org/10.1002/hyp.10726, 2016.

Crowley, T. J. and Unterman, M. B.: Technical details concerning development of a $1200 \mathrm{yr}$ proxy index for global volcanism, Earth Syst. Sci. Data, 5, 187-197, https://doi.org/10.5194/essd5-187-2013, 2013.

Crowley, T. J., Baum, S. K., Kim, K.-Y., Hegerl, G. C., and Hyde, W. T.: Modeling ocean heat content changes during the last millennium, Geophys. Res. Lett., 30, 1932, https://doi.org/10.1029/2003GL017801, https://doi.org/10.1029/2003GL017801, 2003.

Cruz, F. W., Burns, S. J., Karmann, I., Sharp, W. D., Vuille, M., Cardoso, A. O., Ferrari, J. A., Silva Dias, P. L., and Viana, O.: Insolation-driven changes in atmospheric circulation over the past 116000 years in subtropical Brazil, Nature, 434, 63-66, 2005.

D’Arrigo, R., Allan, R., Wilson, R., Palmer, J., Sakulich, J., Smerdon, J. E., Bijaksana, S., and Ngkoimani, L. O.: Pacific and Indian Ocean climate signals in a tree-ring record of Java monsoon drought, Int. J. Climatol., 28, 1889-1901, https://doi.org/10.1002/joc.1679, 2008.

D’Arrigo, R., Wilson, R., and Tudhope, A.: The impact of volcanic forcing on tropical temperatures during the past four centuries, Nat. Geosci., 2, 51-56, https://doi.org/10.1038/ngeo393, 2009.

Dannenberg, M. P. and Wise, E. K.: Performance of climate field reconstruction methods over multiple seasons and climate variables, J. Geophys. Res.-Atmos., 118, 9595-9610, https://doi.org/10.1002/jgrd.50765, 2013.

Dansgaard, W.: Stable isotopes in precipitation, Tellus, 16, 436468, https://doi.org/10.1111/j.2153-3490.1964.tb00181.x, 1964.

Davini, P. and Cagnazzo, C.: On the misinterpretation of the North Atlantic Oscillation in CMIP5 models, Clim. Dynam., 43, 14971511, https://doi.org/10.1007/s00382-013-1970-y, 2014.

DeCarlo, T. M., Gaetani, G. A., Cohen, A. L., Foster, G. L., Alpert, A. E., and Stewart, J. A.: Coral Sr-U thermometry, Paleoceanography, 31, 626-638, https://doi.org/10.1002/2015PA002908, 2016.

Dee, S., Emile-Geay, J., Evans, M. N., Allam, A., Steig, E. J., and Thompson, D. M.: PRYSM: an open-source framework for PRoxY System Modeling, with applications to oxygenisotope systems, J. Adv. Model. Earth Sy., 7, 1220-1247, https://doi.org/10.1002/2015MS000447, 2015.

Dee, S. G., Steiger, N. J., Emile-Geay, J., and Hakim, G. J.: On the utility of proxy system models for estimating climate states over the common era, J. Adv. Model. Earth Sy., 8, 1164-1179, https://doi.org/10.1002/2016MS000677, 2016.

Delaygue, G. and Bard, E.: An Antarctic view of Beryllium-10 and solar activity for the past millennium, Clim. Dynam., 36, 22012218, https://doi.org/10.1007/s00382-010-0795-1, 2011.

DeLong, K. L., Quinn, T. M., Taylor, F. W., Lin, K., and Shen, C.C.: Sea surface temperature variability in the southwest tropical Pacific since AD 1649, Nat. Clim. Change, 2, 799-804, https://doi.org/10.1038/nclimate1583, 2012.

DeLong, K. L., Quinn, T. M., Taylor, F. W., Shen, C.C., and Lin, K.: Improving coral-base paleoclimate reconstructions by replicating 350 years of coral $\mathrm{Sr} / \mathrm{Ca}$ variations, Palaeogeogr. Palaeocl., 373, 6-24, https://doi.org/10.1016/j.palaeo.2012.08.019, 2013.

Delworth, T. and Manabe, S.: Climate variability and land-surface processes, Adv. Water Resour., 16, 3-20, https://doi.org/10.1016/0309-1708(93)90026-c, 1993.

Denniston, R. F., Villarini, G., Gonzales, A. N., Wyrwoll, K.H., Polyak, V. J., Ummenhofer, C. C., Lachniet, M. S., Wanamaker, A. D., Jr., Humphreys, W. F., Woods, D., and Cugley, J.: Extreme rainfall activity in the Australian tropics reflects changes in the $\mathrm{El} \mathrm{NiNo/Southern} \mathrm{Oscillation} \mathrm{over} \mathrm{the}$ 
last two millennia, P. Natl. Acad. Sci. USA, 112, 4576-4581, https://doi.org/10.1073/pnas.1422270112, 2015.

Deser, C., Phillips, A., Bourdette, V., and Teng, H. Y.: Uncertainty in climate change projections: the role of internal variability, Clim. Dynam., 38, 527-546, https://doi.org/10.1007/s00382010-0977-x, 2012.

Diaz, H. F., Trigo, R., Hughes, M. K., Mann, M. E., Xoplaki, E., and Barriopedro, D.: Spatial and temporal characteristics of climate in medieval times revisited, B. Am. Meteorol. Soc., 92, 1487, https://doi.org/10.1175/bams-d-10-05003.1, 2011.

Ding, L., Ge, Q., Zheng, J., and Hao, Z.: Variations in the starting date of the pre-summer rainy season in South China, 1736-2010, J. Geogr. Sci., 24, 845-857, https://doi.org/10.1007/s11442-0141124-0, 2014a.

Ding, Y. N., Carton, J. A., Chepurin, G. A., Stenchikov, G., Robock, A., Sentman, L. T., and Krasting, J. P.: Ocean response to volcanic eruptions in Coupled Model Intercomparison Project 5 simulations, J. Geophys. Res.-Oceans, 119, 5622-5637, https://doi.org/10.1002/2013jc009780, 2014b.

Dobrovolny, P., Brazdil, R., Trnka, M., Kotyza, O., and Valasek, H.: Precipitation reconstruction for the Czech Lands, AD 1501-2010, Int. J. Climatol., 35, 1-14, https://doi.org/10.1002/joc.3957, 2015.

Domínguez-Castro, F., Santisteban, J. I.,Barriendos, M., and Mediavilla, R: Reconstruction of drought episodes for central Spain from rogation ceremonies recorded at the Toledo Cathedral from 1506 to 1900: A methodological approach, Global Planet. Change, 63, 230-242, https://doi.org/10.1016/j.gloplacha.2008.06.002, 2008.

Domínguez-Castro, F., de Miguel, J. C., Vaquero, J. M., Gallego, M. C., and García-Herrera, R: Climatic potential of Islamic chronicles in Iberia: Extreme droughts (AD 711-1010), The Holocene, 24, 370-374, https://doi.org/10.1177/0959683613518591, 2014.

Douglass, A. E.: Crossdating in dendrochronology, J. Forest., 39, 825-831, 1941.

Dunn-Sigouin, E. and Son, S. W.: Northern Hemisphere blocking frequency and duration in the CMIP5 models, J. Geophys. Res.Atmos., 118, 1179-1188, https://doi.org/10.1002/jgrd.50143, 2013.

Edwards, R. L., Chen, J. H., and Wasserburg, G. J.: U-238 U234-TH-230-TH-232 systematics and the precise measurement of time over the past 500000 years, Earth Planet. Sc. Lett., 81, 175-192, 1987.

Edwards, T. W. D. and Fritz, P.: Assessing meteoric water composition and relative humidity from ${ }^{18} \mathrm{O}$ and ${ }^{2} \mathrm{H}$ in wood cellulose: paleoclimatic implications for southern Ontario, Canada, Appl. Geochem., 1, 715-723, https://doi.org/10.1016/08832927(86)90093-4, 1986.

Elderfield, H. and Ganssen, G.: Past temperature and $\delta^{18} \mathrm{O}$ of surface ocean waters inferred from foraminiferal $\mathrm{Mg} / \mathrm{Ca}$ ratios, Nature, 405, 442-445, 2000.

Emile-Geay, J., Seager, R., Cane, M. A., Cook, E. R., and Haug, G. H.: Volcanoes and ENSO over the past millennium, J. Climate, 21, 3134-3148, https://doi.org/10.1175/2007jcli1884.1, 2008.

Emile-Geay, J., Cobb, K. M., Mann, M. E., and Wittenberg, A. T.: Estimating Central Equatorial Pacific SST variability over the past millennium. Part II: Reconstructions and implications,
J. Climate, 26, 2329-2352, https://doi.org/10.1175/jcli-d-1100511.1, 2013a.

Emile-Geay, J., Cobb, K. M., Mann, M. E., and Wittenberg, A. T.: Estimating Central Equatorial Pacific SST variability over the past millennium. Part I: Methodology and validation, J. Climate, 26, 2302-2328, https://doi.org/10.1175/jcli-d-11-00510.1, $2013 b$.

Esper, J., Cook, E. R., and Schweingruber, F. H.: Lowfrequency signals in long tree-ring chronologies for reconstructing past temperature variability, Science, 295, 2250-2253, https://doi.org/10.1126/science.1066208, 2002.

Esper, J., Frank, D., Büntgen, U., Verstege, A., Luterbacher, J., and Xoplaki, E.: Long-term drought severity variations in Morocco, Geophys. Res. Lett., 34, L17702, https://doi.org/10.1029/2007GL030844, 2007.

Evans, M. N., Kaplan, A., and Cane, M. A.: Optimal sites for coralbased reconstruction of global sea surface temperature, Paleoceanography, 13, 502-516, https://doi.org/10.1029/98pa02132, 1998.

Evans, M. N., Kaplan, A., and Cane, M. A.: Pacific sea surface temperature field reconstruction from coral delta O-18 data using reduced space objective analysis, Paleoceanography, 17, 1007, https://doi.org/10.1029/2000pa000590, 2002.

Evans, M. N. and Schrag, D. P.: A stable isotope-based approach to tropical dendroclimatology, Geochim. Cosmochim. Ac., 68, 3295-3305, https://doi.org/10.1016/j.gca.2004.01.006, 2004.

Evans, M. N., Reichert, B. K., Kaplan, A., Anchukaitis, K. J., Vaganov, E. A., Hughes, M. K., and Cane, M. A.: A forward modeling approach to paleoclimatic interpretation of tree-ring data, J. Geophys. Res.-Biogeo., 111, G03008, https://doi.org/10.1029/2006jg000166, 2006.

Evans, M. N., Tolwinski-Ward, S. E., Thompson, D. M., and Anchukaitis, K. J.: Applications of proxy system modeling in high resolution paleoclimatology, Quaternary Sci. Rev., 76, 16-28, https://doi.org/10.1016/j.quascirev.2013.05.024, 2013.

Evans, M. N., Smerdon, J. E., Kaplan, A., Tolwinski-Ward, S. E., and González-Rouco, J. F.: Climate field reconstruction uncertainty arising from multivariate and nonlinear properties of predictors, Geophys. Res. Lett., 41, 9127-9134, https://doi.org/10.1002/2014g1062063, 2014.

Fairbanks, R. G., Evans, M. N., Rubenstone, J. L., Mortlock, R. A., Broad, K., Moore, M. D., and Charles, C. D.: Evaluating climate indices and their geochemical proxies measured in corals, Coral Reefs, 16, S93-S100, https://doi.org/10.1007/s003380050245, 1997.

Fairchild, I. J., Borsato, A., Tooth, A. F., Frisia, S., Hawkesworth, C. J., Huang, Y., McDermott, F., and Spiro, B.: Controls on trace element $(\mathrm{Sr}-\mathrm{Mg})$ compositions of carbonate cave waters: implications for speleothem climatic records, Chem. Geol., 166, 255-269, https://doi.org/10.1016/S00092541(99)00216-8, 2000.

Fairchild, I. J. and Treble, P. C.: Trace elements in speleothems as recorders of environmental change, Quaternary Sci. Rev., 28, 449-468, https://doi.org/10.1016/j.quascirev.2008.11.007, 2009.

Fan, K.-W.: Climate change and Chinese history: a review of trends, topics, and methods, WIREs Clim. Change, 6, 225-238, https://doi.org/10.1002/wcc.331, 2015.

Felis, T., Suzuki, A., Kuhnert, H., Dima, M., Lohmann, G., and Kawahata, H.: Ogasawara annual $\mathrm{Sr} / \mathrm{Ca}, \mathrm{U} / \mathrm{Ca}$, stable isotope 
and $\delta^{18} \mathrm{O}$ seawater data of coral core OGA-02-1, PANGAEA, available at: https://doi.org/10.1594/PANGAEA.743956 (last access: May 2016), 2009a.

Felis, T., Suzuki, A., Kuhnert, H., Dima, M., Lohmann, G., and Kawahata, H.: Subtropical coral reveals abrupt early-twentiethcentury freshening in the western North Pacific Ocean, Geology, 37, 527-530, https://doi.org/10.1130/g25581a.1, 2009 b.

Fenby, C. and Gergis, J.: Rainfall variations in south-eastern Australia part 1: consolidating evidence from pre-instrumental documentary sources, 1788-1860, Int. J. Climatol., 33, 2956-2972, https://doi.org/10.1002/joc.3640, 2013.

Feng, S., Hu, Q., Wu, Q., and Mann, M. E.: A gridded reconstruction of warm season precipitation for Asia spanning the past half millennium, J. Climate, 26, 2192-2204, https://doi.org/10.1175/jcli-d-12-00099.1, 2013.

Fernández-Donado, L., González-Rouco, J. F., Raible, C. C., Ammann, C. M., Barriopedro, D., García-Bustamante, E., Jungclaus, J. H., Lorenz, S. J., Luterbacher, J., Phipps, S. J., Servonnat, J., Swingedouw, D., Tett, S. F. B., Wagner, S., Yiou, P., and Zorita, E.: Large-scale temperature response to external forcing in simulations and reconstructions of the last millennium, Clim. Past, 9, 393-421, https://doi.org/10.5194/cp-9-393-2013, 2013.

Fernandez-Montes, S., Gomez-Navarro, J. J., Rodrigo, F. S., Garcia-Valero, J. A., and Montavez, J. P.: Covariability of seasonal temperature and precipitation over the Iberian Peninsula in high-resolution regional climate simulations (1001-2099), Global Planet. Change, 151, 122-133, https://doi.org/10.1016/j.gloplacha.2016.09.007, 2017.

Flato, G., Marotzke, J., Abiodun, B., Braconnot, P., Chou, S. C., Collins, W., Cox, P., Driouech, F., Emori, S., Eyring, V., Forest, C., Gleckler, P., Guilyardi, E., Jakob, C., Kattsov, V., Reason, C., and Rummukainen, M.: Evaluation of climate models, in: Climate Change 2013 - The Physical Science Basis: Working Group I Contribution to the Fifth Assessment Report of the Intergovernmental Panel on Climate Change, edited by: Stocker, T. F., Qin, D., Plattner, G.-K., Tignor, M. B., Allen, S. K., Boschung, J., Nauels, A., Xia, Y., Bex, V., Midgley, P. M., Cambridge University Press, Cambridge, 741-866, 2013.

Fleitmann, D., Burns, S. J., Neff, U., Mudelsee, M., Mangini, A., and Matter, A.: Palaeoclimatic interpretation of high-resolution oxygen isotope profiles derived from annually laminated speleothems from Southern Oman, Quaternary Sci. Rev., 23, 935-945, https://doi.org/10.1016/j.quascirev.2003.06.019, 2004.

Fleitmann, D., Burns, S. J., Mangini, A., Mudelsee, M., Kramers, J., Villa, I., Neff, U., Al-Subbary, A. A., Buettner, A., Hippler, D., and Matter, A.: Holocene ITCZ and Indian monsoon dynamics recorded in stalagmites from Oman and Yemen (Socotra), Quaternary Sci. Rev., 26, 170-188, https://doi.org/10.1016/j.quascirev.2006.04.012, 2007.

Fleitmann, D., Cheng, H., Badertscher, S., Edwards, R. L., Mudelsee, M., Gokturk, O. M., Fankhauser, A., Pickering, R., Raible, C. C., Matter, A., Kramers, J., and Tuysuz, O.: Timing and climatic impact of Greenland interstadials recorded in stalagmites from northern Turkey, Geophys. Res. Lett., 36, L19707, https://doi.org/10.1029/2009GL040050, 2009.

Fleming, L. E. and Anchukaitis, K. J.: North Pacific decadal variability in the CMIP5 last millennium simulations, Clim. Dynam., 47, 3783-3801, https://doi.org/10.1007/s00382-016-30417, 2016.
Flohr, P., Fleitmann, D., Zorita, E., Sadekov, A., Cheng, H., Bosomworth, M., Edwards, L., Matthews, W., and Matthews, R.: Late Holocene droughts in the Fertile Crescent recorded in a speleothem from northern Iraq, Geophys. Res. Lett., 44, 15281536, https://doi.org/10.1002/2016GL071786, 2017.

Fluckiger, J., Dallenbach, A., Blunier, T., Stauffer, B., Stocker, T. F., Raynaud, D., and Barnola, J. M.: Variations in atmospheric $\mathrm{N}_{2} \mathrm{O}$ concentration during abrupt climatic changes, Science, 285, 227230, https://doi.org/10.1126/science.285.5425.227, 1999.

Fluckiger, J., Monnin, E., Stauffer, B., Schwander, J., Stocker, T. F., Chappellaz, J., Raynaud, D., and Barnola, J. M.: Highresolution Holocene $\mathrm{N}_{2} \mathrm{O}$ ice core record and its relationship with $\mathrm{CH}_{4}$ and $\mathrm{CO}_{2}$, Global Biogeochem. Cy., 16, 1010, https://doi.org/10.1029/2001gb001417, 2002.

Franke, J., Frank, D., Raible, C. C., Esper, J., and Broennimann, S.: Spectral biases in tree-ring climate proxies, Nat. Clim. Change, 3, 360-364, https://doi.org/10.1038/nclimate1816, 2013.

Frappier, A., Sahagian, D., González, L. A., and Carpenter, S. J.: El Niño events recorded by stalagmite carbon isotopes, Science, 298, 565, https://doi.org/10.1126/science.1076446, 2002.

Fritts, H. C.: Growth-rings of trees - their correlation with climate, Science, 154, 973, https://doi.org/10.1126/science.154.3752.973, 1966.

Fritts, H. C.: Tree Rings and Climate, Academic Press, London, New York, San Francisco, 556 pp., 1976.

Gagan, M. K., Ayliffe, L. K., Beck, J. W., Cole, J. E., Druffel, E. R. M., Dunbar, R. B., and Schrag, D. P.: New views of tropical paleoclimates from corals, Quaternary Sci. Rev., 19, 4564, https://doi.org/10.1016/s0277-3791(99)00054-2, 2000.

Gagen, M., McCarroll, D., Loader, N. J., and Robertson, I.: Stable Isotopes in Dendroclimatology: Moving Beyond "Potential", in: Dendroclimatology: Progress and Prospects, edited by: Hughes, M. K., Swetnam, T. W., and Diaz, H. F., Developments in Paleoenvironmental Research, Springer, Dordrecht, 147-172, 2011a.

Gagen, M., Zorita, E., McCarroll, D., Young, G. H. F., Grudd, H., Jalkanen, R., Loader, N. J., Robertson, I., and Kirchhefer, A.: Cloud response to summer temperatures in Fennoscandia over the last thousand years, Geophys. Res. Lett., 38, https://doi.org/10.1029/2010g1046216, 2011b.

Gallant, A. J. E., Phipps, S. J., Karoly, D. J., Mullan, A. B., and Lorrey, A. M.: Nonstationary Australasian teleconnections and implications for paleoclimate reconstructions, J. Climate, 26, 88278849, https://doi.org/10.1175/jcli-d-12-00338.1, 2013.

Gao, C. C., Robock, A., and Ammann, C.: Volcanic forcing of climate over the past 1500 years: An improved ice core-based index for climate models, J. Geophys. Res.-Atmos., 113, 15, https://doi.org/10.1029/2008jd010239, 2008.

Garreaud, R. D. and Battisti, D. S.: Interannual (ENSO) and interdecadal (ENSO-like) variability in the Southern Hemisphere tropospheric circulation, J. Climate, 12, 2113-2123, https://doi.org/10.1175/15200442(1999)012<2113:ieaiel>2.0.co;2, 1999.

Gat, J. R.: Oxygen and hydrogen isotopes in the hydrologic cycle, Annu. Rev. Earth Pl. Sc., 24, 225-262, https://doi.org/10.1146/annurev.earth.24.1.225, 1996.

Ge, Q. S., Zheng, J. Y., Hao, Z. X., Zhang, P. Y., and Wang, W. C.: Reconstruction of historical climate in China - high-resolution 
precipitation data from qing dynasty archives, B. Am. Meteorol. Soc., 86, 671, https://doi.org/10.1175/bams-86-5-671, 2005.

Ge, Q., Guo, X., Zheng, J., and Hao, Z.: Meiyu in the middle and lower reaches of the Yangtze River since 1736, Chinese Sci. Bull., 53, 107-114, https://doi.org/10.1007/s11434-007-0440-5, 2008a.

Ge, Q., Zheng, J., Tian, Y., Wu, W., Fang, X., and Wang, W.-C.: Coherence of climatic reconstruction from historical documents in China by different studies, Int. J. Climatol., 28, 1007-1024, https://doi.org/10.1002/joc.1552, 2008b.

Ge, Q., Zheng, J., Hao, Z., Liu, Y., and Li, M.: Recent advances on reconstruction of climate and extreme events in China for the past 2000 years, J. Geogr. Sci., 26, 827-854, https://doi.org/10.1007/s11442-016-1301-4, 2016.

Geil, K. L., Serra, Y. L., and Zeng, X. B.: Assessment of CMIP5 Model Simulations of the North American Monsoon System, J. Climate, 26, 8787-8801, https://doi.org/10.1175/jcli-d-1300044.1, 2013.

Gerber, S., Joos, F., Brügger, P., Stocker, T., Mann, M., Sitch, S., and Scholze, M.: Constraining temperature variations over the last millennium by comparing simulated and observed atmospheric $\mathrm{CO}_{2}$, Clim. Dynam., 20, 281-299, https://doi.org/10.1007/s00382-002-0270-8, 2003.

Gergis, J. and Ashcroft, L.: Rainfall variations in south-eastern Australia part 2: a comparison of documentary, early instrumental and palaeoclimate records, 1788-2008, Int. J. Climatol., 33, 2973-2987, https://doi.org/10.1002/joc.3639, 2013.

Gergis, J., Neukom, R., Gallant, A. J. E., and Karoly, D. J.: Australasian temperature reconstructions spanning the last millennium, J. Climate, 29, 5365-5392, https://doi.org/10.1175/JCLID-13-00781.1, 2016.

Giry, C., Felis, T., Kölling, M., Wei, W., Lohmann, G., and Scheffers, S.: Controls of Caribbean surface hydrology during the midto late Holocene: insights from monthly resolved coral records, Clim. Past, 9, 841-858, https://doi.org/10.5194/cp-9-841-2013, 2013.

Goldsmith, Y., Broecker, W. S., Xu, H., Polissar, P. J., deMenocal, P. B., Porat, N., Lan, J., Cheng, P., Zhou, W., and An, Z.: Northward extent of East Asian monsoon covaries with intensity on orbital and millennial timescales, P. Natl. Acad. Sci. USA, 114, 1817-1821, https://doi.org/10.1073/pnas.1616708114, 2017.

Gómez-Navarro, J. J., Bothe, O., Wagner, S., Zorita, E., Werner, J. P., Luterbacher, J., Raible, C. C., and Montávez, J. P.: A regional climate palaeosimulation for Europe in the period 1500-1990 Part 2: Shortcomings and strengths of models and reconstructions, Clim. Past, 11, 1077-1095, https://doi.org/10.5194/cp-111077-2015, 2015.

Gong, G. F. and Hameed, S.: The variation of moisture conditions in China during the last 2000 years, Int. J. Climatol., 11, 271-283, 1991.

González-Rouco, F., von Storch, H., and Zorita, E.: Deep soil temperature as proxy for surface air-temperature in a coupled model simulation of the last thousand years, Geophys. Res. Lett., 30, 2116, https://doi.org/10.1029/2003gl018264, 2003.

González-Rouco, J. F., Beltrami, H., Zorita, E., and von Storch, H.: Simulation and inversion of borehole temperature profiles in surrogate climates: Spatial distribution and surface coupling, Geophys. Res. Lett., 33, L01703, https://doi.org/10.1029/2005gl024693, 2006.

Goosse, H., Crespin, E., de Montety, A., Mann, M. E., Renssen, H., and Timmermann, A.: Reconstructing surface temperature changes over the past 600 years using climate model simulations with data assimilation, J. Geophys. Res.-Atmos., 115, D09108, https://doi.org/10.1029/2009JD012737, 2010.

Goosse, H., Crespin, E., Dubinkina, S., Loutre, M.-F., Mann, M. E., Renssen, H., Sallaz-Damaz, Y., and Shindell, D.: The role of forcing and internal dynamics in explaining the "Medieval Climate Anomaly", Clim. Dynam., 39, 2847-2866, https://doi.org/10.1007/s00382-012-1297-0, 2012a.

Goosse, H., Guiot, J., Mann, M. E., Dubinkina, S., and Sallaz-Damaz, Y.: The medieval climate anomaly in Europe: Comparison of the summer and annual mean signals in two reconstructions and in simulations with data assimilation, Global Planet. Change, 84-85, 35-47, https://doi.org/10.1016/j.gloplacha.2011.07.002, 2012b.

Gordon, A. L.: The marine hydrological cycle: The ocean's floods and droughts, Geophys. Res. Lett., 43, 7649-7652, https://doi.org/10.1002/2016gl070279, 2016.

Grab, S. W. and Nash, D. J.: Documentary evidence of climate variability during cold seasons in Lesotho, southern Africa, 1833-1900, Clim. Dynam., 34, 473-499, https://doi.org/10.1007/s00382-009-0598-4, 2010.

Graham, N. E., Ammann, C. M., Fleitmann, D., Cobb, K. M., and Luterbacher, J.: Support for global climate reorganization during the "Medieval Climate Anomaly", Clim. Dynam., 37, 1217 1245, https://doi.org/10.1007/s00382-010-0914-z, 2011.

Graumlich, L. J.: Response of tree growth to climatic variation in the mixed conifer and deciduous forests of the Upper Great-Lakes region, Can. J. Forest Res., 23, 133-143, https://doi.org/10.1139/x93-020, 1993.

Gray, L. J., Beer, J., Geller, M., Haigh, J. D., Lockwood, M., Matthes, K., Cubasch, U., Fleitmann, D., Harrison, G., Hood, L., Luterbacher, J., Meehl, G. A., Shindell, D., van Geel, B., and White, W.: Solar influences on climate, Rev. Geophys., 48, RG4001, https://doi.org/10.1029/2009rg000282, 2010.

Gray, S. T., Lukas, J. J., and Woodhouse, C. A.: Millenniallength records of streamflow from three major upper Colorado River tributaries, J. Am. Water Resour. As., 47, 702-712, https://doi.org/10.1111/j.1752-1688.2011.00535.x, 2011.

Griffin, D., Woodhouse, C. A., Meko, D. M., Stahle, D. W., Faulstich, H. L., Carrillo, C., Touchan, R., Castro, C. L., and Leavitt, S. W.: North American monsoon precipitation reconstructed from tree-ring latewood, Geophys. Res. Lett., 40, 954 958, https://doi.org/10.1002/grl.50184, 2013.

Griffiths, M. L., Drysdale, R. N., Gagan, M. K., Zhao, J. x., Ayliffe, L. K., Hellstrom, J. C., Hantoro, W. S., Frisia, S., Feng, Y. x., Cartwright, I., Pierre, E. S., Fischer, M. J., and Suwargadi, B. W.: Increasing Australian-Indonesian monsoon rainfall linked to early Holocene sea-level rise, Nat. Geosci., 2, 636-639, 2009.

Griffiths, M. L., Drysdale, R. N., Gagan, M. K., Frisia, S., Zhao, J.x., Ayliffe, L. K., Hantoro, W. S., Hellstrom, J. C., Fischer, M. J., Feng, Y.-X., and Suwargadi, B. W.: Evidence for Holocene changes in Australian-Indonesian monsoon rainfall from stalagmite trace element and stable isotope ratios, Earth Planet. 
Sc. Lett., 292, 27-38, https://doi.org/10.1016/j.eps1.2010.01.002, 2010.

Griffiths, M. L., Kimbrough, A. K., Gagan, M. K., Drysdale, R. N., Cole, J. E., Johnson, K. R., Zhao, J.-X., Cook, B. I., Hellstrom, J. C., and Hantoro, W. S.: Western Pacific hydroclimate linked to global climate variability over the past two millennia, Nat. Commun., 7, 11719-11719, 2016.

Guillot, D., Rajaratnam, B., and Emile-Geay, J.: Statistical paleoclimate reconstructions via Markov Random Fields, Ann. Appl. Stat., 9, 324-352, https://doi.org/10.1214/14-aoas794, 2015.

Hakim, G. J., Emile-Geay, J., Steig, E. J., Noone, D., Anderson, D. M., Tardif, R., Steiger, N., and Perkins, W. A.: The lastmillennium climate reanalysis project: framework and first results, J. Geophys. Res.-Atmos., 121, 6745-6764, https://doi.org/10.1002/2016jd024751, 2016.

Hansen, J. and Sato, M.: Greenhouse gas growth rates, P. Natl. Acad. Sci. USA, 101, 16109-16114, https://doi.org/10.1073/pnas.0406982101, 2004.

Hao, Z. X., Sun, D., and Zheng, J. Y.: East Asian monsoon signals reflected in temperature and precipitation changes over the past 300 years in the middle and lower reaches of the Yangtze River, PLoS One, 10, 11, https://doi.org/10.1371/journal.pone.0131159, 2015.

Hao, Z., Zheng, J., Zhang, X., Liu, H., Li, M., and Ge, Q.: Spatial patterns of precipitation anomalies in eastern China during centennial cold and warm periods of the past 2000 years, Int. J. Climatol., 36, 467-475, https://doi.org/10.1002/joc.4367, 2016.

Hao, Z., Geng, X., Liu, K., Liu, H., and Jingyun, Z.: Dryness and wetness variations for the past 1000 years in Guanzhong Plain, Chinese Sci. Bull., 62, 2399-2406, 2017.

Harley, G. L., Maxwell, J. T., Larson, E., Grissino-Mayer, H. D., Henderson, J., and Huffman, J.: Suwannee River flow variability $1550-2005 \mathrm{CE}$ reconstructed from a multispecies tree-ring network, J. Hydrol., 544, 438-451, https://doi.org/10.1016/j.jhydrol.2016.11.020, 2017.

Haslett, J., Whiley, M., Bhattacharya, S., Salter-Townshend, M., Wilson, S. P., Allen, J. R. M., Huntley, B., and Mitchell, F. J. G.: Bayesian palaeoclimate reconstruction, J. Roy. Stat. Soc. A Stat., 169, 395-438, https://doi.org/10.1111/j.1467985X.2006.00429.x, 2006.

Haslett, J. and Parnell, A.: A simple monotone process with application to radiocarbon-dated depth chronologies, J. Roy. Stat. Soc. C-App., 57, 399-418, https://doi.org/10.1111/j.14679876.2008.00623.x, 2008.

Hathorne, E. C., Felis, T., Suzuki, A., Kawahata, H., and Cabioch, G.: Lithium in the aragonite skeletons of massive Porites corals: a new tool to reconstruct tropical sea surface temperatures, Paleoceanography, 28, 143-152, https://doi.org/10.1029/2012pa002311, 2013.

Haug, G. H., Hughen, K. A., Sigman, D. M., Peterson, L. C., and Rohl, U.: Southward migration of the intertropical convergence zone through the Holocene, Science, 293, 1304-1308, https://doi.org/10.1126/science.1059725, 2001.

Haug, G. H., Günther, D., Peterson, L. C., Sigman, D. M., Hughen, K. A., and Aeschlimann, B.: Climate and the collapse of Maya civilization, Science, 299, 1731-1735, https://doi.org/10.1126/science.1080444, 2003.

Haywood, J. M., Jones, A., Bellouin, N., and Stephenson, D.: Asymmetric forcing from stratospheric aerosols im- pacts Sahelian rainfall, Nat. Clim. Change, 3, 660-665, https://doi.org/10.1038/nclimate1857, 2013.

Hendy, E. J., Gagan, M. K., Alibert, C. A., McCulloch, M. T., Lough, J. M., and Isdale, P. J.: Abrupt decrease in tropical Pacific Sea surface salinity at end of Little Ice Age, Science, 295, 1511-1514, https://doi.org/10.1126/science.1067693, 2002.

Hendy, E. J., Gagen, M. K., Alibert, C. A., McCulloch, M. T., Lough, J. M., and Isdale, P. J.: Kurrimine Beach, Brook Island, Britomart Reef, Great Palm Island, Lodestone Reef, Pandora Reef, Havannah Island $-\delta^{18} \mathrm{O}, \mathrm{Sr} / \mathrm{Ca}$, and U/Ca Data, available at: https://www.ncdc.noaa.gov/paleo/study/1869, accessed 10 July 2017.

Hernandez-Almeida, I., Grosjean, M., Gomez-Navarro, J. J., Larocque-Tobler, I., Bonk, A., Enters, D., Ustrzycka, A., Piotrowska, N., Przybylak, R., Wacnik, A., Witak, M., and Tylmann, W.: Resilience, rapid transitions and regime shifts: Fingerprinting the responses of Lake abiskie (NE Poland) to climate variability and human disturbance since AD 1000, Holocene, 27, 258-270, https://doi.org/10.1177/0959683616658529, 2017.

Hetzinger, S., Pfeiffer, M., Dullo, W.-C., Garbe-Schoenberg, D., and Halfar, J.: Rapid 20th century warming in the Caribbean and impact of remote forcing on climate in the northern tropical Atlantic as recorded in a Guadeloupe coral, Palaeogeogr. Palaeocl., 296, 111-124, https://doi.org/10.1016/j.palaeo.2010.06.019, 2010.

Hetzinger, S., Pfeiffer, M., Dullo, W. C., Garbe-Schoenberg, C.D., and Halfar, J.: Guadeloupe annual coral seawater $\delta^{18} \mathrm{O}$ reconstruction, PANGAEA, available at: https://doi.org/10.1594/PANGAEA.873994 (last access: March 2017), 2017.

Himmelsbach, I., Glaser, R., Schoenbein, J., Riemann, D., and Martin, B.: Reconstruction of flood events based on documentary data and transnational flood risk analysis of the Upper Rhine and its French and German tributaries since AD 1480, Hydrol. Earth Syst. Sci., 19, 4149-4164, https://doi.org/10.5194/hess-19-41492015, 2015.

Hofer, D., Raible, C. C., and Stocker, T. F.: Variations of the Atlantic meridional overturning circulation in control and transient simulations of the last millennium, Clim. Past, 7, 133-150, https://doi.org/10.5194/cp-7-133-2011, 2011.

Hoffmann, G., Werner, M., and Heimann, M.: Water isotope module of the ECHAM atmospheric general circulation model: A study on timescales from days to several years, J. Geophys. Res.Atmos., 103, 16871-16896, https://doi.org/10.1029/98jd00423, 1998.

Holmes, R. L.: Computer assisted quality control in tree ring dating and measurement, Tree-Ring Bull., 43, 69-78, 1983.

Hostetler, S. W. and Benson, L. V.: Stable isotopes of oxygen and hydrogen in the Truckee River-Pyramid Lake surface-water system. 2. A predictive model of $\delta^{18} \mathrm{O}$ and $\delta^{2} \mathrm{H}$ in Pyramid Lake, Limnol. Oceanogr., 39, 356-364, https://doi.org/10.4319/lo.1994.39.2.0356, 1994.

Hu, J., Emile-Geay, J., and Partin, J.: Correlation-based interpretations of paleoclimate data - where statistics meet past climates, Earth Planet. Sc. Lett., 459, 362-371, https://doi.org/10.1016/j.epsl.2016.11.048, 2017.

Huang, P., Xie, S.-P., Hu, K., Huang, G., and Huang, R.: Patterns of the seasonal response of tropical rainfall to global warming, Nat. Geosci., 6, 357-361, https://doi.org/10.1038/ngeo1792, 2013. 
Hughes, M. K., Wu, X. D., Shao, X. M., and Garfin, G. M.: A preliminary reconstruction of rainfall in North-Central China since AD 1600 from tree-ring density and width, Quaternary Res., 42, 88-99, https://doi.org/10.1006/qres.1994.1056, 1994.

Hurst, H. E.: Long-term storage capacity of reservoirs, T. Am. Soc. Civ. Eng., 116, 770-799, 1951.

Hurtt, G. C., Frolking, S., Fearon, M. G., Moore, B., Shevliakova, E., Malyshev, S., Pacala, S. W., and Houghton, R. A.: The underpinnings of land-use history: three centuries of global gridded land-use transitions, wood-harvest activity, and resulting secondary lands, Glob. Change Biol., 12, 1208-1229, https://doi.org/10.1111/j.1365-2486.2006.01150.x, 2006.

Huybers, K., Rupper, S., and Roe, G. H.: Response of closed basin lakes to interannual climate variability, Clim. Dynam., 46, 37093723, https://doi.org/10.1007/s00382-015-2798-4, 2016.

Huybers, P. and Curry, W.: Links between annual, Milankovitch and continuum temperature variability, Nature, 441, 329-332, https://doi.org/10.1038/nature04745, 2006.

Iles, C. E., Hegerl, G. C., Schurer, A. P., and Zhang, X. B.: The effect of volcanic eruptions on global precipitation, J. Geophys. Res.-Atmos., 118, 8770-8786, https://doi.org/10.1002/jgrd.50678, 2013.

Iles, C. E. and Hegerl, G. C.: The global precipitation response to volcanic eruptions in the CMIP5 models, Environ. Res. Lett., 9, https://doi.org/10.1088/1748-9326/9/10/104012, 2014.

Johns, T. C., Gregory, J. M., Ingram, W. J., Johnson, C. E., Jones, A., Lowe, J. A., Mitchell, J. F. B., Roberts, D. L., Sexton, D. M. H., Stevenson, D. S., Tett, S. F. B., and Woodage, M. J.: Anthropogenic climate change for 1860 to 2100 simulated with the HadCM3 model under updated emissions scenarios, Clim. Dynam., 20, 583-612, https://doi.org/10.1007/s00382-002-0296-y, 2003.

Jones, I. C. and Banner, J. L.: Estimating recharge thresholds in tropical karst island aquifers: Barbados, Puerto Rico and Guam, J. Hydrol., 278, 131-143, https://doi.org/10.1016/s00221694(03)00138-0, 2003.

Jones, P. D., Briffa, K. R., Osborn, T. J., Lough, J. M., van Ommen, T. D., Vinther, B. M., Luterbacher, J., Wahl, E. R., Zwiers, F. W., Mann, M. E., Schmidt, G. A., Ammann, C. M., Buckley, B. M., Cobb, K. M., Esper, J., Goosse, H., Graham, N., Jansen, E., Kiefer, T., Kull, C., Kuettel, M., MosleyThompson, E., Overpeck, J. T., Riedwyl, N., Schulz, M., Tudhope, A. W., Villalba, R., Wanner, H., Wolff, E., and Xoplaki, E.: High-resolution palaeoclimatology of the last millennium: a review of current status and future prospects, Holocene, 19, 3-49, https://doi.org/10.1177/0959683608098952, 2009.

Jones, M. D., Dee, S., Anderson, L., Baker, A., Bowen, G., and Noone, D. C.: Water isotope systematics: improving our palaeoclimate interpretations Introduction, Quaternary Sci. Rev., 131, 243-249, https://doi.org/10.1016/j.quascirev.2015.11.014, 2016.

Joseph, R. and Zeng, N.: Seasonally modulated tropical drought induced by volcanic aerosol, J. Climate, 24, 2045-2060, https://doi.org/10.1175/2009jcli3170.1, 2011.

Jouzel, J., Koster, R. D., Suozzo, R. J., and Russell, G. L.: Stable water isotope behavior during the last glacial maximum: A general circulation model analysis, J. Geophys. Res.-Atmos., 99, 25791-25801, https://doi.org/10.1029/94JD01819, 1994.

Jungclaus, J. H., Lorenz, S. J., Timmreck, C., Reick, C. H., Brovkin, V., Six, K., Segschneider, J., Giorgetta, M. A., Crowley, T.
J., Pongratz, J., Krivova, N. A., Vieira, L. E., Solanki, S. K., Klocke, D., Botzet, M., Esch, M., Gayler, V., Haak, H., Raddatz, T. J., Roeckner, E., Schnur, R., Widmann, H., Claussen, M., Stevens, B., and Marotzke, J.: Climate and carbon-cycle variability over the last millennium, Clim. Past, 6, 723-737, https://doi.org/10.5194/cp-6-723-2010, 2010.

Jungclaus, J. H., Bard, E., Baroni, M., Braconnot, P., Cao, J., Chini, L. P., Egorova, T., Evans, M., González-Rouco, J. F., Goosse, H., Hurtt, G. C., Joos, F., Kaplan, J. O., Khodri, M., Klein Goldewijk, K., Krivova, N., LeGrande, A. N., Lorenz, S. J., Luterbacher, J., Man, W., Meinshausen, M., Moberg, A., Nehrbass-Ahles, C., Otto-Bliesner, B. I., Phipps, S. J., Pongratz, J., Rozanov, E., Schmidt, G. A., Schmidt, H., Schmutz, W., Schurer, A., Shapiro, A. I., Sigl, M., Smerdon, J. E., Solanki, S. K., Timmreck, C., Toohey, M., Usoskin, I. G., Wagner, S., Wu, C.-Y., Yeo, K. L., Zanchettin, D., Zhang, Q., and Zorita, E.: The PMIP4 contribution to CMIP6 - Part 3: the Last Millennium, Scientific Objective and Experimental Design for the PMIP4 past1000 simulations, Geosci. Model Dev. Discuss., https://doi.org/10.5194/gmd-2016278, in review, 2016.

Kaplan, A.: Discussion of: A statistical analysis of multiple temperature proxies: are reconstructions of surface temperatures over the last 1000 years reliable?, Ann. Appl. Stat., 5, 47-51, https://doi.org/10.1214/10-aoas398m, 2011.

Karnauskas, K. B., Donnelly, J. P., and Anchukaitis, K. J.: Future freshwater stress for island populations, Nat. Clim. Change, 6, 720-725, https://doi.org/10.1038/nclimate2987, 2016.

Kay, J. E., Deser, C., Phillips, A., Mai, A., Hannay, C., Strand, G., Arblaster, J. M., Bates, S. C., Danabasoglu, G., Edwards, J., Holland, M., Kushner, P., Lamarque, J. F., Lawrence, D., Lindsay, K., Middleton, A., Munoz, E., Neale, R., Oleson, K., Polvani, L., and Vertenstein, M.: The Community Earth System Model (CESM) Large Ensemble Project a community resource for studying climate change in the presence of internal climate variability, B. Am. Meteorol. Soc., 96, 1333-1349, https://doi.org/10.1175/bams-d-13-00255.1, 2015.

Kempes, C. P., Myers, O. B., Breshears, D. D., and Ebersole, J. J.: Comparing response of Pinus edulis treering growth to five alternate moisture indices using historic meteorological data, J. Arid Environ., 72, 350-357, https://doi.org/10.1016/j.jaridenv.2007.07.009, 2008.

Knapp, P. A., Maxwell, J. T., and Soule, P. T.: Tropical cyclone rainfall variability in coastal North Carolina derived from longleaf pine (Pinus palustris Mill.): AD 1771-2014, Climatic Change, 135, 311-323, https://doi.org/10.1007/s10584015-1560-6, 2016.

Knutti, R., Furrer, R., Tebaldi, C., Cermak, J., and Meehl, G. A.: Challenges in combining projections from multiple climate models, J. Climate, 23, 2739-2758, https://doi.org/10.1175/2009JCLI3361.1, 2009.

Knutti, R., Sedláček, J., Sanderson, B. M., Lorenz, R., Fischer, E. M., and Eyring, V.: A climate model projection weighting scheme accounting for performance and interdependence, Geophys. Res. Lett., 44, 1909-1918, https://doi.org/10.1002/2016GL072012, 2017.

Konecky, B., Russell, J., Vuille, M., and Rehfeld, K.: The Indian Ocean Zonal Mode over the past millennium in observed and modeled precipitation isotopes, Quaternary Sci. Rev., 103, 1-18, https://doi.org/10.1016/j.quascirev.2014.08.019, 2014. 
Konecky, B., Russell, J., and Bijaksana, S.: Glacial aridity in central Indonesia coeval with intensified monsoon circulation, Earth Planet. Sc. Lett., 437, 15-24, https://doi.org/10.1016/j.epsl.2015.12.037, 2016.

Kurita, N.: Water isotopic variability in response to mesoscale convective system over the tropical ocean, J. Geophys. Res.-Atmos., 118, 10376-10390, https://doi.org/10.1002/jgrd.50754, 2013.

Lamarque, J.-F., Bond, T. C., Eyring, V., Granier, C., Heil, A., Klimont, Z., Lee, D., Liousse, C., Mieville, A., Owen, B., Schultz, M. G., Shindell, D., Smith, S. J., Stehfest, E., Van Aardenne, J., Cooper, O. R., Kainuma, M., Mahowald, N., McConnell, J. R., Naik, V., Riahi, K., and van Vuuren, D. P.: Historical (1850-2000) gridded anthropogenic and biomass burning emissions of reactive gases and aerosols: methodology and application, Atmos. Chem. Phys., 10, 7017-7039, https://doi.org/10.5194/acp-10-7017-2010, 2010.

Landrum, L., Otto-Bliesner, B. L., Wahl, E. R., Conley, A., Lawrence, P. J., Rosenbloom, N., and Teng, H.: Last millennium climate and its variability in CCSM4, J. Climate, 26, 1085-1111, https://doi.org/10.1175/jcli-d-11-00326.1, 2013.

Langford, S., Stevenson, S., and Noone, D.: Analysis of lowfrequency precipitation variability in CMIP5 historical simulations for southwestern North America, J. Climate, 27, 27352756, https://doi.org/10.1175/JCLI-D-13-00317.1, 2014.

Lara, A., Villalba, R., and Urrutia, R.: A 400-year tree-ring record of the Puelo River summer-fall streamflow in the Valdivian Rainforest eco-region, Chile, Climatic Change, 86, 331-356, https://doi.org/10.1007/s10584-007-9287-7, 2008.

Lean, J., Rottman, G., Harder, J., and Kopp, G.: SORCE contributions to new understanding of global change and solar variability, Sol. Phys., 230, 27-53, https://doi.org/10.1007/s11207-0051527-2, 2005.

LeGrande, A. N. and Schmidt, G. A.: Global gridded data set of the oxygen isotopic composition in seawater, Geophys. Res. Lett., 33, L12604, https://doi.org/10.1029/2006GL026011, 2006.

LeGrande, A. N. and Schmidt, G. A.: Water isotopologues as a quantitative paleosalinity proxy, Paleoceanography, 26, PA3225, https://doi.org/10.1029/2010pa002043, 2011.

LeGrande, A. N., Tsigaridis, K., and Bauer, S. E.: Role of atmospheric chemistry in the climate impacts of stratospheric volcanic injections, Nat. Geosci., 9, 652-655, https://doi.org/10.1038/ngeo2771, 2016.

Lehner, F., Raible, C. C., and Stocker, T. F.: Testing the robustness of a precipitation proxy-based North Atlantic Oscillation reconstruction, Quaternary Sci. Rev., 45, 85-94, https://doi.org/10.1016/j.quascirev.2012.04.025, 2012.

Lehner, F., Joos, F., Raible, C. C., Mignot, J., Born, A., Keller, K. M., and Stocker, T. F.: Climate and carbon cycle dynamics in a CESM simulation from 850 to 2100 CE, Earth Syst. Dynam., 6, 411-434, https://doi.org/10.5194/esd-6-411-2015, 2015.

Lehner, F., Schurer, A. P., Hegerl, G. C., Deser, C., and Froelicher, T. L.: The importance of ENSO phase during volcanic eruptions for detection and attribution, Geophys. Res. Lett., 43, 2851-2858, https://doi.org/10.1002/2016gl067935, 2016.

Lehner, F., Wahl, E. R., Wood, A. W., Blatchford, D. B., and Llewellyn, D.: Assessing recent declines in Upper Rio Grande runoff efficiency from a paleoclimate perspectiv, Geophys. Res. Lett., 44, 4124-4133, https://doi.org/10.1002/2017GL073253, 2017.
Lewis, S. C., LeGrande, A. N., Kelley, M., and Schmidt, G. A.: Water vapour source impacts on oxygen isotope variability in tropical precipitation during Heinrich events, Clim. Past, 6, 325-343, https://doi.org/10.5194/cp-6-325-2010, 2010.

Lewis, S. C. and LeGrande, A. N.: Stability of ENSO and its tropical Pacific teleconnections over the Last Millennium, Clim. Past, 11, 1347-1360, https://doi.org/10.5194/cp-11-1347-2015, 2015.

Li, J. B., Xie, S. P., Cook, E. R., Morales, M. S., Christie, D. A., Johnson, N. C., Chen, F. H., D’Arrigo, R., Fowler, A. M., Gou, X. H., and Fang, K. Y.: El Nino modulations over the past seven centuries, Nat. Clim. Change, 3, 822-826, https://doi.org/10.1038/nclimate1936, 2013.

Li, L., Schmitt, R. W., Ummenhofer, C. C., and Karnauskas, K. B.: Implications of North Atlantic Sea surface salinity for summer precipitation over the US Midwest: mechanisms and predictive value, J. Climate, 29, 3143-3159, https://doi.org/10.1175/jcli-d15-0520.1, 2016a.

Li, L., Schmitt, R. W., Ummenhofer, C. C., and Karnauskas, K. B.: North Atlantic salinity as a predictor of Sahel rainfall, Sci. Adv., 2, e1501588, https://doi.org/10.1126/sciadv.1501588, $2016 \mathrm{~b}$.

Li, J., Dodson, J., Yan, H., Zhang, D.D., Zhang, X., Xu, Q., Lee, H.F., Pei, Q., Cheng, B., Li, Ch., Ni, J., Sun, A., Lu, F., and Zong, Y.: Quantifying climatic variability in monsoonal northern China over the last 2200 years and its role in driving Chinese dynastic changes, Quaternary Sci. Rev., 159, 35-46, https://doi.org/10.1016/j.quascirev.2017.01.009, 2017.

Linsley, B. K., Wellington, G. M., and Schrag, D. P.: Decadal sea surface temperature variability in the subtropical South Pacific from 1726 to 1997 AD, Science, 290, 1145-1148, https://doi.org/10.1126/science.290.5494.1145, 2000.

Linsley, B. K., Wellington, G. M., Schrag, D. P., Ren, L., Salinger, M. J., and Tudhope, A. W.: Geochemical evidence from corals for changes in the amplitude and spatial pattern of South Pacific interdecadal climate variability over the last 300 years, Clim. Dynam., 22, 1-11, https://doi.org/10.1007/s00382-0030364-y, 2004.

Linsley, B. K., Kaplan, A., Gouriou, Y., Salinger, J., deMenocal, P. B., Wellington, G. M., and Howe, S. S.: Tracking the extent of the South Pacific Convergence Zone since the early 1600s, Geochem. Geophys. Geosyst., 7, Q05003, https://doi.org/10.1029/2005GC001115, 2006.

Linsley, B. K.: Coral derived $\delta^{18} \mathrm{O}$ seawater data from Fiji, core 1F, PANGAEA, available at: https://doi.org/10.1594/PANGAEA.874070 (last access: June 2017), 2017a.

Linsley, B. K.: Coral derived $\delta^{18} \mathrm{O}$ seawater data from Rarotonga, core 2R, PANGAEA, available at: https://doi.org/10.1594/PANGAEA.874078 (last access: June 2017), 2017b.

Liu, F., Chai, J., Wang, B., Liu, J., Zhang, X., and Wang, Z. Y.: Global monsoon precipitation responses to large volcanic eruptions, Sci. Rep.-UK, 6, 24331, https://doi.org/10.1038/srep24331, 2016.

Ljungqvist, F. C., Krusic, P. J., Sundqvist, H. S., Zorita, E., Brattstrom, G., and Frank, D.: Northern Hemisphere hydroclimate variability over the past twelve centuries, Nature, 532, 94, https://doi.org/10.1038/nature17418, 2016. 
Logan, D. C.: Known knowns, known unknowns, unknown unknowns and the propagation of scientific enquiry, J. Exp. Bot., 60, 712-714, https://doi.org/10.1093/jxb/erp043, 2009.

Lough, J. M.: Climate records from corals, WIREs Clim. Change, 1, 318-331, https://doi.org/10.1002/wcc.39, 2010.

Luterbacher, J., Xoplaki, E., Casty, C., Wanner, H., Pauling, A., Kuettel, M., Rutishauser, T., Broennimann, S., Fischer, E., Fleitmann, D., Gonzalez-Rouco, F. J., Garcia-Herrera, R., Barriendos, M., Rodrigo, F., Carlos Gonzalez-Hidalgo, J., Angel Saz, M., Gimeno, L., Ribera, P., Brunet, M., Paeth, H., Rimbu, N., Felis, T., Jacobeit, J., Duenkeloh, A., Zorita, E., Guiot, J., Tuerkes, M., Alcoforado, M. J., Trigo, R., Wheeler, D., Tett, S., Mann, M. E., Touchan, R., Shindell, D. T., Silenzi, S., Montagna, P., Camuffo, D., Mariotti, A., Nanni, T., Brunetti, M., Maugeri, M., Zerefos, C., De Zolt, S., Lionello, P., Fatima Nunes, M., Rath, V., Beltrami, H., Garnier, E., and Ladurie, E. L. R.: Mediterranean climate variability over the last centuries: a review, in: Mediterranean Climate Variability, edited by: Lionello, P., MalanotteRizzoli, P., and Boscolo, R., Developments in Earth and Environmental Sciences, Elsevier, Amsterdam, 27-148, 2006.

Luterbacher, J., Koenig, S. J., Franke, J., van der Schrier, G., Zorita, E., Moberg, A., Jacobeit, J., Della-Marta, P. M., Kuettel, M., Xoplaki, E., Wheeler, D., Rutishauser, T., Stoessel, M., Wanner, H., Brazdil, R., Dobrovolny, P., Camuffo, D., Bertolin, C., van Engelen, A., Gonzalez-Rouco, F. J., Wilson, R., Pfister, C., Limanowka, D., Nordli, O., Leijonhufvud, L., Soderberg, J., Allan, R., Barriendos, M., Glaser, R., Riemann, D., Hao, Z., and Zerefos, C. S.: Circulation dynamics and its influence on European and Mediterranean January-April climate over the past half millennium: results and insights from instrumental data, documentary evidence and coupled climate models, Climatic Change, 101, 201-234, https://doi.org/10.1007/s10584009-9782-0, 2010.

Luterbacher, J., Werner, J. P., Smerdon, J. E., FernandezDonado, L., González-Rouco, F. J., Barriopedro, D., Ljungqvist, F. C., Buentgen, U., Zorita, E., Wagner, S., Esper, J., McCarroll, D., Toreti, A., Frank, D., Jungclaus, J. H., Barriendos, M., Bertolin, C., Bothe, O., Brazdil, R., Camuffo, D., Dobrovolny, P., Gagen, M., Garica-Bustamante, E., Ge, Q., Gomez-Navarro, J. J., Guiot, J., Hao, Z., Hegerl, G. C., Holmgren, K., Klimenko, V. V., Martin-Chivelet, J., Pfister, C., Roberts, N., Schindler, A., Schurer, A., Solomina, O., von Gunten, L., Wahl, E., Wanner, H., Wetter, O., Xoplaki, E., Yuan, N., Zanchettin, D., Zhang, H., and Zerefos, C.: European summer temperatures since Roman times, Environ. Res. Lett., 11, 024001, https://doi.org/10.1088/1748-9326/11/2/024001, 2016.

MacDonald, G. M., Kremenetski, K. V., and Hidalgo, H. G.: Southern California and the perfect drought: Simultaneous prolonged drought in southern California and the Sacramento and Colorado River systems, Quatern. Int., 188, 11-23, https://doi.org/10.1016/j.quaint.2007.06.027, 2008.

MacFarling Meure, C., Etheridge, D., Trudinger, C., Steele, P., Langenfelds, R., van Ommen, T., Smith, A., and Elkins, J.: Law dome $\mathrm{CO}_{2}, \mathrm{CH}_{4}$ and $\mathrm{N}_{2} \mathrm{O}$ ice core records extended to 2000 years BP, Geophys. Res. Lett., 33, L14810, https://doi.org/10.1029/2006gl026152, 2006.
Machida, T., Nakazawa, T., Fujii, Y., Aoki, S., and Watanabe, O.: Increase in the atmospheric nitrous-oxide concentration during the last 250 years, Geophys. Res. Lett., 22, 2921-2924, https://doi.org/10.1029/95g102822, 1995.

Maher, N., McGregor, S., England, M. H., and Sen Gupta, A.: Effects of volcanism on tropical variability, Geophys. Res. Lett., 42, 6024-6033, https://doi.org/10.1002/2015gl064751, 2015.

Mankin, J. S., Smerdon, J. E., Cook, B. I., Williams, A. P., and Seager, R.: The curious case of projected 21st-century drying but greening in the American West, J. Climate, 30, 8689-8710, https://doi.org/10.1175/JCLI-D-17-0213.1, 2017.

Mann, M. E., Cane, M. A., Zebiak, S. E., and Clement, A.: Volcanic and solar forcing of the tropical Pacific over the past 1000 years, J. Climate, 18, 447-456, https://doi.org/10.1175/jcli3276.1, 2005.

Mann, M. E., Zhang, Z., Rutherford, S., Bradley, R. S., Hughes, M. K., Shindell, D., Ammann, C., Faluvegi, G., and Ni, F.: Global signatures and dynamical origins of the Little Ice Age and Medieval Climate Anomaly, Science, 326, 1256-1260, https://doi.org/10.1126/science.1177303, 2009.

Markonis, Y. and Koutsoyiannis, D.: Scale-dependence of persistence in precipitation records, Nat. Clim. Change, 6, 399-401, https://doi.org/10.1038/nclimate2894, 2016.

Marvel, K. and Bonfils, C.: Identifying external influences on global precipitation, P. Natl. Acad. Sci. USA, 110, 19301-19306, https://doi.org/10.1073/pnas.1314382110, 2013.

Masato, G., Hoskins, B. J., and Woollings, T.: Winter and summer Northern Hemisphere blocking in CMIP5 models, J. Climate, 26, 7044-7059, https://doi.org/10.1175/jcli-d-12-00466.1, 2013.

Masson-Delmotte, V., Schulz, M., Abe-Ouchi, A., Beer, J., Ganopolski, A., González Rouco, J. F., Jansen, E., Lambeck, K., Luterbacher, J., Naish, T., Osborn, T., Otto-Bliesner, B., Quinn, T., Ramesh, R., Rojas, M., Shao, X., and Timmermann, A.: Information from Paleoclimate Archives, in: Climate Change 2013 - The Physical Science Basis: Working Group I Contribution to the Fifth Assessment Report of the Intergovernmental Panel on Climate Change, edited by: Stocker, T. F., Qin, D., Plattner, G.-K., Tignor, M. B., Allen, S. K., Boschung, J., Nauels, A., Xia, Y., Bex, V., Midgley, P. M., Cambridge University Press, Cambridge, 383-464, 2013.

Matsikaris, A., Widmann, M., and Jungclaus, J.: Assimilating continental mean temperatures to reconstruct the climate of the late pre-industrial period, Clim. Dynam., 46, 3547-3566, https://doi.org/10.1007/s00382-015-2785-9, 2016.

Matthes, K., Funke, B., Andersson, M. E., Barnard, L., Beer, J., Charbonneau, P., Clilverd, M. A., Dudok de Wit, T., Haberreiter, M., Hendry, A., Jackman, C. H., Kretzschmar, M., Kruschke, T., Kunze, M., Langematz, U., Marsh, D. R., Maycock, A. C., Misios, S., Rodger, C. J., Scaife, A. A., Seppälä, A., Shangguan, M., Sinnhuber, M., Tourpali, K., Usoskin, I., van de Kamp, M., Verronen, P. T., and Versick, S.: Solar forcing for CMIP6 (v3.2), Geosci. Model Dev., 10, 2247-2302, https://doi.org/10.5194/gmd-10-2247-2017, 2017.

Maxwell, R. S., Hessl, A. E., Cook, E. R., and Pederson, N.: A multispecies tree ring reconstruction of Potomac River streamflow (950-2001), Water Resour. Res., 47, 12, https://doi.org/10.1029/2010wr010019, 2011. 
McCarroll, D. and Loader, N. J.: Stable isotopes in tree rings, Quaternary Sci. Rev., 23, 771-801, https://doi.org/10.1016/j.quascirev.2003.06.017, 2004.

McCarroll, D., Pettigrew, E., Luckman, A., Guibal, F., and Edouard, J. L.: Blue reflectance provides a surrogate for latewood density of high-latitude pine tree rings, Arct. Antarct. Alp. Res., 34, 450-453, https://doi.org/10.2307/1552203, 2002.

McConnell, M. C., Thunell, R. C., Lorenzoni, L., Astor, Y., Wright, J. D., and Fairbanks, R.: Seasonal variability in the salinity and oxygen isotopic composition of seawater from the Cariaco Basin, Venezuela: implications for paleosalinity reconstructions, Geochem. Geophy. Geosy., 10, Q06019, https://doi.org/10.1029/2008GC002035, 2009.

McGregor, S. and Timmermann, A.: The effect of explosive tropical volcanism on ENSO, J. Climate, 24, 2178-2191, https://doi.org/10.1175/2010jcli3990.1, 2011.

McGregor, H. V., Evans, M. N., Goosse, H., Leduc, G., Martrat, B., Addison, J. A., Mortyn, P. G., Oppo, D. W., Seidenkrantz, M.S., Sicre, M.-A., Phipps, S. J., Selvaraj, K., Thirumalai, K., Filipsson, H. L., and Ersek, V.: Robust global ocean cooling trend for the pre-industrial Common Era, Nat. Geosci., 8, 671, https://doi.org/10.1038/ngeo2510, 2015.

McGregor, H. V., Martrat, B., Evans, M. N., Thompson, D., Reynolds, D., Addison, J., and Participants, W.: Data, age uncertainties and ocean $\delta^{18} \mathrm{O}$ under the spotlight for Ocean2k Phase 2, PAGES Mag., 24, 44, https://doi.org/10.22498/pages.24.1.44, 2016.

Meckler, A. N., Clarkson, M. O., Cobb, K. M., Sodemann, H., and Adkins, J. F.: Interglacial hydroclimate in the tropical West Pacific through the late pleistocene, Science, 336, 1301-1304, https://doi.org/10.1126/science.1218340, 2012.

Meehl, G. A., Goddard, L., Murphy, J., Stouffer, R. J., Boer, G., Danabasoglu, G., Dixon, K., Giorgetta, M. A., Greene, A. M., Hawkins, E., Hegerl, G., Karoly, D., Keenlyside, N., Kimoto, M., Kirtman, B., Navarra, A., Pulwarty, R., Smith, D., Stammer, D., and Stockdale, T.: Decadal prediction, B. Am. Meteorol. Soc., 90, 1467-1485, https://doi.org/10.1175/2009BAMS2778.1, 2009.

Meko, D. M. and Baisan, C. H.: Pilot study of latewood-width of conifers as an indicator of variability of summer rainfall in the North American Monsoon Region, Int. J. Climatol., 21, 697-708, https://doi.org/10.1002/joc.646, 2001.

Meko, D. M. and Woodhouse, C. A.: Tree-ring footprint of joint hydrologic drought in Sacramento and Upper Colorado river basins, western USA, J. Hydrol., 308, 196-213, https://doi.org/10.1016/j.jhydrol.2004.11.003, 2005.

Meko, D. M. and Woodhouse, C. A.: Application of Streamflow Reconstruction to Water Resources Management, in: Dendroclimatology: Progress and Prospects, edited by: Hughes, M. K., Swetnam, T. W., and Diaz, H. F., Developments in Paleoenvironmental Research, Springer, Dordrecht, 231-261, 2011.

Meko, D., Cook, E. R., Stahle, D. W., Stockton, C. W., and Hughes, M. K.: Spatial patterns of tree-growth anomalies in the United-States and Southeastern Canada, J. Climate, 6, 1773-1786, https://doi.org/10.1175/15200442(1993)006<1773:spotga>2.0.co;2, 1993.

Meko, D. M., Woodhouse, C. A., Baisan, C. A., Knight, T., Lukas, J. J., Hughes, M. K., and Salzer, M. W.: Medieval drought in the upper Colorado River Basin, Geophys. Res. Lett., 34, L10705, https://doi.org/10.1029/2007g1029988, 2007.

Meko, D. M., Woodhouse, C. A., and Morino, K.: Dendrochronology and links to streamflow, J. Hydrol., 412, 200-209, https://doi.org/10.1016/j.jhydrol.2010.11.041, 2012.

Melvin, T. M. and Briffa, K. R.: A "signal-free" approach to dendroclimatic standardisation, Dendrochronologia, 26, 71-86, https://doi.org/10.1016/j.dendro.2007.12.001, 2008.

Messmer, M., Gómez-Navarro, J. J., and Raible, C. C.: Sensitivity experiments on the response of $\mathrm{Vb}$ cyclones to sea surface temperature and soil moisture changes, Earth Syst. Dynam., 8, 477-493, https://doi.org/10.5194/esd-8-477-2017, 2017.

Mikami, T.: Climatic reconstruction in historical times based on weather records, Geogr. Rev. Jpn. Ser. B, 61, 14-22, https://doi.org/10.4157/grj1984b.61.14, 1988.

Mikami, T.: Climatic variations in Japan reconstructed from historical documents, Weather, 63, 190-193, https://doi.org/10.1002/wea.281, 2008.

Milinski, S., Bader, J., Haak, H., Siongco, A. C., and Jungclaus, J. H.: High atmospheric horizontal resolution eliminates the wind-driven coastal warm bias in the southeastern tropical Atlantic, Geophys. Res. Lett., 43, 10455-10462, https://doi.org/10.1002/2016gl070530, 2016.

Miller, W. P., DeRosa, G. M., Gangopadhyay, S., and Valdes, J. B.: Predicting regime shifts in flow of the Gunnison River under changing climate conditions, Water Resour. Res., 49, 2966-2974, 2013.

Misios, S., Mitchell, D. M., Gray, L. J., Tourpali, K., Matthes, K., Hood, L., Schmidt, H., Chiodo, G., Thieblemont, R., Rozanov, E., and Krivolutsky, A.: Solar signals in CMIP-5 simulations: effects of atmosphere-ocean coupling, Q. J. Roy. Meteor. Soc., 142, 928-941, https://doi.org/10.1002/qj.2695, 2016.

Mitchell, D. M., Misios, S., Gray, L. J., Tourpali, K., Matthes, K., Hood, L., Schmidt, H., Chiodo, G., Thieblemont, R., Rozanov, E., Shindell, D., and Krivolutsky, A.: Solar signals in CMIP-5 simulations: the stratospheric pathway, Q. J. Roy. Meteor. Soc., 141, 2390-2403, https://doi.org/10.1002/qj.2530, 2015.

Moerman, J. W., Cobb, K. M., Adkins, J. F., Sodemann, H., Clark, B., and Tuen, A. A.: Diurnal to interannual rainfall delta O-18 variations in northern Borneo driven by regional hydrology, Earth Planet. Sc. Lett., 369, 108-119, https://doi.org/10.1016/j.eps1.2013.03.014, 2013.

Moerman, J. W., Cobb, K. M., Partin, J. W., Meckler, A. N., Carolin, S. A., Adkins, J. F., Lejau, S., Malang, J., Clark, B., and Tuen, A. A.: Transformation of ENSOrelated rainwater to dripwater delta O-18 variability by vadose water mixing, Geophys. Res. Lett., 41, 7907-7915, https://doi.org/10.1002/2014g1061696, 2014.

Moreno, A., Valero-Garcés, B. L., González-Sampériz, P., and Rico, M.: Flood response to rainfall variability during the last 2000 years inferred from the Taravilla Lake record (Central Iberian Range, Spain), J. Paleolimnol., 40, 943-961, https://doi.org/10.1007/s10933-008-9209-3, 2008.

Mozny, M., Brazdil, R., Dobrovolny, P., Trnka, M., Potopova, V., Hlavinka, P., Bartosova, L., Zahradnicek, P., Stepanek, P., and Zalud, Z.: Drought reconstruction based on grape harvest dates for the Czech Lands, 1499-2012, Clim. Res., 70, 119-132, https://doi.org/10.3354/cr01423, 2016. 
Nash, D. J. and Grab, S. W.: "A sky of brass and burning winds": documentary evidence of rainfall variability in the Kingdom of Lesotho, Southern Africa, 1824-1900, Climatic Change, 101, 617-653, https://doi.org/10.1007/s10584-009-9707-y, 2010.

Nash, D. J., Pribyl, K., Klein, J., Neukom, R., Endfield, G. H., Adamson, G. C. D., and Kniveton, D. R.: Seasonal rainfall variability in southeast Africa during the nineteenth century reconstructed from documentary sources, Climatic Change, 134, 605619, https://doi.org/10.1007/s10584-015-1550-8, 2016.

Neukom, R., Luterbacher, J., Villalba, R., Kuettel, M., Frank, D., Jones, P. D., Grosjean, M., Esper, J., Lopez, L., and Wanner, H.: Multi-centennial summer and winter precipitation variability in southern South America, Geophys. Res. Lett., 37, L14708, https://doi.org/10.1029/2010g1043680, 2010.

Neukom, R., Gergis, J., Karoly, D. J., Wanner, H., Curran, M., Elbert, J., González-Rouco, F., Linsley, B. K., Moy, A. D., Mundo, I., Raible, C. C., Steig, E. J., van Ommen, T., Vance, T., Villalba, R., Zinke, J., and Frank, D.: Inter-hemispheric temperature variability over the past millennium, Nat. Clim. Change, 4 , 362-367, https://doi.org/10.1038/nclimate2174, 2014.

Neukom, R., Rohrer, M., Calanca, P., Salzmann, N., Huggel, C., Acuña, D., Christie, D. A., and Morales, M. S.: Facing unprecedented drying of the Central Andes? Precipitation variability over the period AD 1000-2100, Environ. Res. Lett., 10, 084017, https://doi.org/10.1088/1748-9326/10/8/084017, 2015.

NOAA: GPCC Global Precipitation Climatology Centre, available at: https://www.esrl.noaa.gov/psd/data/gridded/data.gpcc. html, last access: October 2017.

NOAA: GPCP Version 2.3 Combined Precipitation Data Set, available at: https://www.esrl.noaa.gov/psd/data/gridded/data.gpcp. html, last access: October 2017.

Nurhati, I. S., Cobb, K. M., Charles, C. D., and Dunbar, R. B.: Late 20th century warming and freshening in the central tropical Pacific, Geophys. Res. Lett., 36, L21606, https://doi.org/10.1029/2009GL040270, 2009.

Nurhati, I. S., Cobb, K. M., Charles, C. D., and Dunbar, R. B.: Correction to "Late 20th century warming and freshening in the central tropical Pacific", Geophys. Res. Lett., 38, L24707, https://doi.org/10.1029/2011gl049972, 2011a.

Nurhati, I. S., Cobb, K. M., and Di Lorenzo, E.: Decadal-scale SST and salinity variations in the Central Tropical Pacific: signatures of natural and anthropogenic climate change, J. Climate, 24, 3294-3308, https://doi.org/10.1175/2011JCLI3852.1, 2011 b.

Nurhati, I. S., Cobb, K. M., and Di Lorenzo, E.: Palmyra Island Coral 110 Year Sr/Ca SST and $\delta^{18} \mathrm{O}_{\mathrm{sw}}$, available at: http://www. ncdc.noaa.gov/paleo/study/10373, accessed 23 May 2016.

Oglesby, R., Feng, S., Hu, Q., and Rowe, C.: The role of the Atlantic Multidecadal Oscillation on medieval drought in North America: synthesizing results from proxy data and climate models, Global Planet. Change, 84-85, 56-65, https://doi.org/10.1016/j.gloplacha.2011.07.005, 2012.

Ortega, P., Lehner, F., Swingedouw, D., Masson-Delmotte, V., Raible, C. C., Casado, M., and Yiou, P.: A model-tested North Atlantic Oscillation reconstruction for the past millennium, Nature, 523, 71, https://doi.org/10.1038/nature14518, 2015.

Osborn, T. J. and Hulme, M.: Development of a relationship between station and grid-box rainday frequencies for climate model evaluation, J. Cli- mate, 10, 1885-1908, https://doi.org/10.1175/1520 0442(1997)010<1885:doarbs>2.0.co;2, 1997.

Oster, J. L., Ibarra, D. E., Winnick, M. J., and Maher, K.: Steering of westerly storms over western North America at the Last Glacial Maximum, Nat. Geosci., 8, 201-205, https://doi.org/10.1038/ngeo2365, 2015.

Otto-Bliesner, B. L., Hewitt, C. D., Marchitto, T. M., Brady, E., Abe-Ouchi, A., Crucifix, M., Murakami, S., and Weber, S. L.: Last Glacial Maximum ocean thermohaline circulation: PMIP2 model intercomparisons and data constraints, Geophys. Res. Lett., 34, L12706, https://doi.org/10.1029/2007GL029475, 2007.

Otto-Bliesner, B. L., Russell, J. M., Clark, P. U., Liu, Z., Overpeck, J. T., Konecky, B., deMenocal, P., Nicholson, S. E., He, F., and Lu, Z.: Coherent changes of southeastern equatorial and northern African rainfall during the last deglaciation, Science, 346, 1223-1227, https://doi.org/10.1126/science.1259531, 2014

Otto-Bliesner, B. L., Brady, E. C., Fasullo, J., Jahn, A., Landrum, L., Stevenson, S., Rosenbloom, N., Mai, A., and Strand, G.: CLIMATE VARIABILITY AND CHANGE SINCE 850 CE An Ensemble Approach with the Community Earth System Model, B Am. Meteorol. Soc., 97, 735-754, https://doi.org/10.1175/bamsd-14-00233.1, 2016.

Overpeck, J. T., Webb, T., and Prentice, I. C.: Quantitative interpretation of fossil pollen spectra: Dissimilarity coefficients and the method of modern analogs, Quaternary Res., 23, 87-108, https://doi.org/10.1016/0033-5894(85)90074-2, 1985.

PAGES2k Consortium: A global multiproxy database for temperature reconstructions of the Common Era, Sci. data, 4, 170088, https://doi.org/10.1038/sdata.2017.88, 2017.

PAGES 2k Consortium, Ahmed, M., Anchukaitis, K. J., Asrat, A., Borgaonkar, H. P., Braida, M., Buckley, B. M., Buntgen, U., Chase, B. M., Christie, D. A., Cook, E. R., Curran, M. A. J., Diaz, H. F., Esper, J., Fan, Z.-X., Gaire, N. P., Ge, Q., Gergis, J., González-Rouco, J. F., Goosse, H., Grab, S. W., Graham, N., Graham, R., Grosjean, M., Hanhijarvi, S. T., Kaufman, D. S., Kiefer, T., Kimura, K., Korhola, A. A., Krusic, P. J., Lara, A., Lezine, A.-M., Ljungqvist, F. C., Lorrey, A. M., Luterbacher, J., Masson-Delmotte, V., McCarroll, D., McConnell, J. R., McKay, N. P., Morales, M. S., Moy, A. D., Mulvaney, R., Mundo, I. A., Nakatsuka, T., Nash, D. J., Neukom, R., Nicholson, S. E., Oerter, H., Palmer, J. G., Phipps, S. J., Prieto, M. R., Rivera, A., Sano, M., Severi, M., Shanahan, T. M., Shao, X., Shi, F., Sigl, M., Smerdon, J. E., Solomina, O. N., Steig, E. J., Stenni, B., Thamban, M., Trouet, V., Turney, C. S. M., Umer, M., van Ommen, T., Verschuren, D., Viau, A. E., Villalba, R., Vinther, B. M., von Gunten, L., Wagner, S., Wahl, E. R., Wanner, H., Werner, J. P., White, J. W. C., Yasue, K., and Zorita, E.: Continental-scale temperature variability during the past two millennia, Nat. Geosci., 6, 339-346, https://doi.org/10.1038/ngeo1797, 2013.

PAGES 2k-PMIP3 group: Continental-scale temperature variability in PMIP3 simulations and PAGES $2 \mathrm{k}$ regional temperature reconstructions over the past millennium, Clim. Past, 11, 16731699, https://doi.org/10.5194/cp-11-1673-2015, 2015.

Palmer, J. G., Cook, E. R., Turney, C. S. M., Allen, K., Fenwick, P., Cook, B. I., O’Donnell, A., Lough, J., Grierson, P., and Baker, P.: Drought variability in the eastern Australia and New Zealand summer drought atlas (ANZDA, CE 1500-2012) modulated by 
the Interdecadal Pacific Oscillation, Environ. Res. Lett., 10, 124002, https://doi.org/10.1088/1748-9326/10/12/124002, 2015.

Partin, J. W., Cobb, K. M., Adkins, J. F., Clark, B., and Fernandez, D. P.: Millennial-scale trends in west Pacific warm pool hydrology since the Last Glacial Maximum, Nature, 449, 452-455, 2007.

Partin, J. W., Jenson, J. W., Banner, J. L., Quinn, T. M., Taylor, F. W., Sinclair, D., Hardt, B., Lander, M. A., Bell, T., Miklavic, B., Jocson, J. M. U., and Taborosi, D.: Relationship between modern rainfall variability, cave dripwater, and stalagmite geochemistry in Guam, USA, Geochem. Geophy. Geosy., 13, Q03013, https://doi.org/10.1029/2011gc003930, 2012.

Partin, J. W., Quinn, T. M., Shen, C. C., Emile-Geay, J., Taylor, F. W., Maupin, C. R., Lin, K., Jackson, C. S., Banner, J. L., Sinclair, D. J., and Huh, C. A.: Multidecadal rainfall variability in South Pacific Convergence Zone as revealed by stalagmite geochemistry, Geology, 41, 1143-1146, https://doi.org/10.1130/G34718.1, 2013.

Partin, J. W., Konecky, B., and Iso2k Project Members: Iso2k: a community-driven effort to develop a global database of paleowater isotopes covering the past two millennia., Eos Trans. AGU, Fall Meet. Suppl., 2015.

Pauling, A., Luterbacher, J., Casty, C., and Wanner, H.: Five hundred years of gridded high-resolution precipitation reconstructions over Europe and the connection to large-scale circulation, Clim. Dynam., 26, 387-405, https://doi.org/10.1007/s00382005-0090-8, 2006.

Pausata, F. S. R., Battisti, D. S., Nisancioglu, K. H., and Bitz, C. M.: Chinese stalagmite $\delta^{18} \mathrm{O}$ controlled by changes in the Indian monsoon during a simulated Heinrich event, Nat. Geosci., 4, 474-480, 2011.

Pausata, F. S. R., Karamperidou, C., Caballero, R., and Battisti, D. S.: ENSO response to high-latitude volcanic eruptions in the Northern Hemisphere: the role of the initial conditions, Geophys. Res. Lett., 43, 8694-8702, https://doi.org/10.1002/2016gl069575, 2016.

Pederson, N., Cook, E. R., Jacoby, G. C., Peteet, D. M., and Griffin, K. L.: The influence of winter temperatures on the annual radial growth of six northern range margin tree species, Dendrochronologia, 22, 7-29, https://doi.org/10.1016/j.dendro.2004.09.005, 2004.

Pederson, G. T., Gray, S. T., Woodhouse, C. A., Betancourt, J. L., Fagre, D. B., Littell, J. S., Watson, E., Luckman, B. H., and Graumlich, L. J.: The unusual nature of recent snowpack declines in the North American Cordillera, Science, 333, 332-335, https://doi.org/10.1126/science.1201570, 2011.

Peterson, T. C. and Vose, R. S.: An overview of the global historical climatology network temperature database, B. Am. Meteorol. Soc., 78, 2837-2849, https://doi.org/10.1175/15200477(1997)078<2837:aootgh>2.0.co;2, 1997.

Peyron, O., Guiot, J., Cheddadi, R., Tarasov, P., Reille, M., de Beaulieu, J.-L., Bottema, S., and Andrieu, V.: Climatic reconstruction in Europe for $18000 \mathrm{yr}$ B. P. from pollen data, Quaternary Res., 49, 183-196, https://doi.org/10.1006/qres.1997.1961, 1998.

Pfister, C., Brazdil, R., Glaser, R., Barriendos, M., Camuffo, D., Deutsch, M., Dobrovolny, P., Enzi, S., Guidoboni, E., Kotyza, O., Militzer, S., Racz, L., and Rodrigo, F. S.: Documentary evidence on climate in sixteenth-century Europe, Climatic Change, 43, 55-110, https://doi.org/10.1023/a:1005540707792, 1999.

Pfister, C., Luterbacher, J., Wanner, H., Wheeler, D., Brazdil, R., Ge, Q., Hao, Z., Moberg, A., Grab, S. W., and Rosario del Prieto, M.: Documentary evidence as climate proxies, White Paper written for the Proxy Uncertainty Workshop in Trieste, PAGES, Bern, Switzerland, 2008.

Phillips, A. S., Deser, C., and Fasullo, J.: Evaluating modes of variability in climate models, EOS Trans. AGU, 95, 453-455, https://doi.org/10.1002/2014EO490002, 2014.

Phipps, S. J., McGregor, H. V., Gergis, J., Gallant, A. J. E., Neukom, R., Stevenson, S., Ackerley, D., Brown, J. R., Fischer, M. J., and van Ommen, T. D.: Paleoclimate data-model comparison and the role of climate forcings over the past 1500 years, J. Climate, 26, 6915-6936, https://doi.org/10.1175/JCLID-12-00108.1, 2013.

Pinot, S., Ramstein, G., Harrison, S. P., Prentice, I. C., Guiot, J., Stute, M., and Joussaume, S.: Tropical paleoclimates at the Last Glacial Maximum: comparison of Paleoclimate Modeling Intercomparison Project (PMIP) simulations and paleodata, Clim. Dynam., 15, 857-874, https://doi.org/10.1007/s003820050318, 1999.

Piovano, E., Córdoba, F., and Stutz, S.: Limnogeology in Southern South America: an overview, Lat. Am. J. Sedimentol. Basin Res., 21, 65-75, 2014.

Polyak, V. J., Cokendolpher, J. C., Norton, R. A., and Asmerom, Y.: Wetter and cooler late Holocene climate in the southwestern United States from mites preserved in stalagmites, Geology, 29, 643-646, https://doi.org/10.1130/00917613(2001)029<0643:WACLHC>2.0.CO;2, 2001.

Pongratz, J., Raddatz, T., Reick, C. H., Esch, M., and Claussen, M.: Radiative forcing from anthropogenic land cover change since AD 800, Geophys. Res. Lett., 36, L02709, https://doi.org/10.1029/2008gl036394, 2009.

Predybaylo, E., Stenchikov, G. L., Wittenberg, A. T., and Zeng, F.: Impacts of a Pinatubo-size volcanic eruption on ENSO, J. Geophys. Res.-Atmos., 122, 925-947, https://doi.org/10.1002/2016jd025796, 2017.

Pulwarty, R. S., Jacobs, K. L., and Dole, R. M.: The Hardest Working River: Drought and Critical Water Problems in the Colorado River Basin, Drought and Water Crises: Science, Technology, and Management Issues, CRC Press, Boca Raton, FL, 86, 249285, 2005.

Qian, W., Hu, Q., Zhu, Y., and Lee, D. K.: Centennial-scale dry-wet variations in East Asia, Clim. Dynam., 21, 77-89, https://doi.org/10.1007/s00382-003-0319-3, 2003.

Raible, C. C., Casty, C., Luterbacher, J., Pauling, A., Esper, J., Frank, D. C., Buentgen, U., Roesch, A. C., Tschuck, P., Wild, M., Vidale, P.-L., Schaer, C., and Wanner, H.: Climate variabilityobservations, reconstructions, and model simulations for the Atlantic-European and Alpine region from 1500-2100 AD, Climatic Change, 79, 9-29, https://doi.org/10.1007/s10584-0069061-2, 2006.

Raible, C. C., Lehner, F., González-Rouco, J. F., and FernándezDonado, L.: Changing correlation structures of the Northern Hemisphere atmospheric circulation from 1000 to 2100 AD, Clim. Past, 10, 537-550, https://doi.org/10.5194/cp-10-5372014, 2014. 
Raible, C. C., Bazrenbold, O., and Gomez-Navarro, J. J.: Drought indices revisited - improving and testing of drought indices in a simulation of the last two millennia for Europe, Tellus A, 69, 1287492, https://doi.org/10.1080/16000870.2017.1296226, 2017.

Ramsey, C. B.: Deposition models for chronological records, Quaternary Sci. Rev., 27, 42-60, https://doi.org/10.1016/j.quascirev.2007.01.019, 2008.

Rao, M. P., Cook, B. I., Cook, E. R., D’Arrigo, R. D., Krusic, P. J., Anchukaitis, K. J., LeGrande, A. N., Buckley, B. M., Davi, N. K., Leland, C., and Griffin, K. L.: European and Mediterranean hydroclimate responses to tropical volcanic forcing over the last millennium, Geophys. Res. Lett., 44, 51045112, https://doi.org/10.1002/2017GL073057, 2017.

Rasbury, M. and Aharon, P.: ENSO-controlled rainfall variability records archived in tropical stalagmites from the mid-ocean island of Niue, South Pacific, Geochem. Geophy. Geosy., 7, Q07010, https://doi.org/10.1029/2005gc001232, 2006.

Ren, L., Linsley, B. K., Wellington, G. M., Schrag, D. P., and Hoegh-Guldberg, O.: Deconvolving the $\delta^{18} \mathrm{O}$ seawater component from subseasonal coral $\delta^{18} \mathrm{O}$ and $\mathrm{Sr} / \mathrm{Ca}$ at Rarotonga in the southwestern subtropical Pacific for the period 1726 to 1997, Geochim. Cosmochim. Ac., 67, 1609-1621, https://doi.org/10.1016/s0016-7037(02)00917-1, 2003.

Renwick, J. A. and Wallace, J. M.: Relationships between North Pacific wintertime blocking, El Nino, and the PNA pattern, Mon. Weather Rev., 124, 2071-2076, https://doi.org/10.1175/15200493(1996)124<2071:rbnpwb>2.0.co;2, 1996.

Rice, J. L., Woodhouse, C. A., and Lukas, J. J.: Science and decision making: water management and tree-ring data in the western United States, J. Am. Water Resour. As., 45, 1248-1259, https://doi.org/10.1111/j.1752-1688.2009.00358.x, 2009.

Richey, J. N. and Sachs, J. P.: Precipitation changes in the western tropical Pacific over the past millennium, Geology, 44, 671-674, https://doi.org/10.1130/g37822.1, 2016.

Risi, C., Bony, S., Vimeux, F., and Jouzel, J.: Correction to "Water-stable isotopes in the LMDZ4 general circulation model: Model evaluation for present-day and past climates and applications to climatic interpretations of tropical isotopic records", J. Geophys. Res.-Atmos., 115, D24123, https://doi.org/10.1029/2010JD015242, 2010.

Robock, A. and Liu, Y.: The volcanic signal in GoddardInstitute-for-Space-Studies - 3-dimensional model simulations, J. Climate, 7, 44-55, https://doi.org/10.1175/15200442(1994)007<0044:tvsigi>2.0.co;2, 1994.

Robock, A. and Mao, J. P.: The volcanic signal in surface-temperature observations, J. Climate, 8, 1086-1103, https://doi.org/10.1175/15200442(1995)008<1086:tvsist>2.0.co;2, 1995.

Ropelewski, C. F. and Halpert, M. S.: North-American precipitation and temperature patterns associated with the El Nino Southern Oscillation (ENSO), Mon. Weather Rev., 114, 2352-2362, https://doi.org/10.1175/15200493(1986)114<2352:napatp>2.0.co;2, 1986.

Rozanski, K., Araguás-Araguás, L., and Gonfiantini, R.: Isotopic patterns in modern global precipitation, in: Climate Change in Continental Isotopic Records, American Geophysical Union, Washington, D.C., https://doi.org/10.1029/GM078p0001, 1-36, 1993.
Sachs, J. P., Sachse, D., Smittenberg, R. H., Zhang, Z., Battisti, D. S., and Golubic, S.: Southward movement of the Pacific intertropical convergence zone AD 1400-1850, Nat. Geosci., 2, 519-525, 2009.

Saurer, M., Kress, A., Leuenberger, M., Rinne, K. T., Treydte, K. S., and Siegwolf, R. T. W.: Influence of atmospheric circulation patterns on the oxygen isotope ratio of tree rings in the Alpine region, J. Geophys. Res.-Atmos., 117, D05118, https://doi.org/10.1029/2011jd016861, 2012.

Scheff, J. and Frierson, D. M. W.: Robust future precipitation declines in CMIP5 largely reflect the poleward expansion of model subtropical dry zones, Geophys. Res. Lett., 39, https://doi.org/10.1029/2012g1052910, 2012.

Schmidt, G. A.: Error analysis of paleosalinity calculations, Paleoceanography, 14, 422-429, https://doi.org/10.1029/1999pa900008, 1999.

Schmidt, G. A., Bigg, G. R., and Rohling, E. J.: Global Seawater Oxygen-18 Database - v1.21, available at: https://data.giss.nasa. gov/o18data/ (last access: October 2017), 1999.

Schmidt, G. A., LeGrande, A. N., and Hoffmann, G.: Water isotope expressions of intrinsic and forced variability in a coupled ocean-atmosphere model, J. Geophys. Res.-Atmos., 112, D10103, https://doi.org/10.1029/2006JD007781, 2007.

Schmidt, G. A., Jungclaus, J. H., Ammann, C. M., Bard, E., Braconnot, P., Crowley, T. J., Delaygue, G., Joos, F., Krivova, N. A., Muscheler, R., Otto-Bliesner, B. L., Pongratz, J., Shindell, D. T., Solanki, S. K., Steinhilber, F., and Vieira, L. E. A.: Climate forcing reconstructions for use in PMIP simulations of the last millennium (v1.0), Geosci. Model Dev., 4, 33-45, https://doi.org/10.5194/gmd-4-33-2011, 2011.

Schmidt, G. A., Jungclaus, J. H., Ammann, C. M., Bard, E., Braconnot, P., Crowley, T. J., Delaygue, G., Joos, F., Krivova, N. A., Muscheler, R., Otto-Bliesner, B. L., Pongratz, J., Shindell, D. T., Solanki, S. K., Steinhilber, F., and Vieira, L. E. A.: Climate forcing reconstructions for use in PMIP simulations of the Last Millennium (v1.1), Geosci. Model Dev., 5, 185-191, https://doi.org/10.5194/gmd-5-185-2012, 2012.

Schmidt, G. A., Annan, J. D., Bartlein, P. J., Cook, B. I., Guilyardi, E., Hargreaves, J. C., Harrison, S. P., Kageyama, M., LeGrande, A. N., Konecky, B., Lovejoy, S., Mann, M. E., Masson-Delmotte, V., Risi, C., Thompson, D., Timmermann, A., Tremblay, L.B., and Yiou, P.: Using palaeo-climate comparisons to constrain future projections in CMIP5, Clim. Past, 10, 221-250, https://doi.org/10.5194/cp-10-221-2014, 2014.

Schneider, D. P., Ammann, C. M., Otto-Bliesner, B. L., and Kaufman, D. S.: Climate response to large, high-latitude and low-latitude volcanic eruptions in the Community Climate System Model, J. Geophys. Res.-Atmos., 114, D15101, https://doi.org/10.1029/2008jd011222, 2009.

Schneider, U., Becker, A., Finger, P., Meyer-Christoffer, A., Ziese, M., and Rudolf, B.: GPCC's new land surface precipitation climatology based on quality-controlled in situ data and its role in quantifying the global water cycle, Theor. Appl. Climatol., 115, 15-40, https://doi.org/10.1007/s00704-013-0860-x, 2014.

Schneider, L., Smerdon, J. E., Pretis, F., Hartl-Meier, C., and Esper, J.: A new archive of large volcanic events over the past millennium derived from reconstructed summer temperatures, 
Environ. Res. Lett., 12, 094005, https://doi.org/10.1088/17489326/aa7a1b, 2017.

Scholz, D. and Hoffmann, D. L.: StalAge - an algorithm designed for construction of speleothem age models, Quat. Geochronol., 6, 369-382, https://doi.org/10.1016/j.quageo.2011.02.002, 2011.

Scholz, D., Hoffmann, D. L., Hellstrom, J., and Ramsey, C. B.: A comparison of different methods for speleothem age modelling, Quat. Geochronol., 14, 94-104, https://doi.org/10.1016/j.quageo.2012.03.015, 2012.

Schurer, A. P., Hegerl, G. C., Mann, M. E., Tett, S. F. B., and Phipps, S. J.: Separating forced from chaotic climate variability over the past millennium, J. Climate, 26, 6954-6973, https://doi.org/10.1175/jcli-d-12-00826.1, 2013.

Seager, R.: The turn of the century North American drought: global context, dynamics, and past analogs, J. Climate, 20, 5527-5552, https://doi.org/10.1175/2007jcli1529.1, 2007.

Seager, R., Harnik, N., Robinson, W. A., Kushnir, Y., Ting, M., Huang, H. P., and Velez, J.: Mechanisms of ENSO-forcing of hemispherically symmetric precipitation variability, Q. J. Roy. Meteor. Soc., 131, 1501-1527, https://doi.org/10.1256/qj.04.96, 2005.

Self, S., Rampino, M. R., Zhao, J., and Katz, M. G.: Volcanic aerosol perturbations and strong El Nino events: No general correlation, Geophys. Res. Lett., 24, 1247-1250, https://doi.org/10.1029/97g101127, 1997.

Seppälä, A. and Clilverd, M. A.: Energetic particle forcing of the Northern Hemisphere winter stratosphere: comparison to solar irradiance forcing, Front. Phys., 2, https://doi.org/10.3389/fphy.2014.00025, 2014.

Shapiro, A. I., Schmutz, W., Rozanov, E., Schoell, M., Haberreiter, M., Shapiro, A. V., and Nyeki, S.: A new approach to the long-term reconstruction of the solar irradiance leads to large historical solar forcing, Astron. Astrophys., 529, 8, https://doi.org/10.1051/0004-6361/201016173, 2011.

Sharma, S., Magnuson, J. J., Batt, R. D., Winslow, L. A., Korhonen, J., and Aono, Y.: Direct observations of ice seasonality reveal changes in climate over the past 320-570 years, Sci. Reports, 6, 25061, https://doi.org/10.1038/srep25061, 2016.

Sheffield, J., Barrett, A. P., Colle, B., Fernando, D. N., Fu, R., Geil, K. L., Hu, Q., Kinter, J., Kumar, S., Langenbrunner, B., Lombardo, K., Long, L. N., Maloney, E., Mariotti, A., Meyerson, J. E., Mo, K. C., Neelin, J. D., Nigam, S., Pan, Z. T., Ren, T., Ruiz-Barradas, A., Serra, Y. L., Seth, A., Thibeault, J. M., Stroeve, J. C., Yang, Z., and Yin, L.: North American climate in CMIP5 experiments. Part I: Evaluation of historical simulations of continental and regional climatology, J. Climate, 26, 92099245, https://doi.org/10.1175/jcli-d-12-00592.1, 2013.

Shen, C., Wang, W.-C., Peng, Y., Xu, Y., and Zheng, J.: Variability of summer precipitation over Eastern China during the last millennium, Clim. Past, 5, 129-141, https://doi.org/10.5194/cp5-129-2009, 2009.

Shen, C.-C., Wu, C.-C., Cheng, H., Edwards, R. L., Hsieh, Y.T., Gallet, S., Chang, C.-C., Li, T.-Y., Doan Dinh, L., Kano, A., Hori, M., and Spoetl, C.: High-precision and high-resolution carbonate Th-230 dating by MC-ICP-MS with SEM protocols, Geochim. Cosmochim. Ac., 99, 71-86, https://doi.org/10.1016/j.gca.2012.09.018, 2012.

Shen, C.-C., Lin, K., Duan, W., Jiang, X., Partin, J. W., Edwards, R. L., Cheng, H., and Tan, M.: Testing the an- nual nature of speleothem banding, Sci. Rep.-UK, 3, 2633, https://doi.org/10.1038/srep02633, 2013.

Shindell, D. T., Schmidt, G. A., Mann, M. E., and Faluvegi, G.: Dynamic winter climate response to large tropical volcanic eruptions since 1600, J. Geophys. Res.-Atmos., 109, D05104, https://doi.org/10.1029/2003jd004151, 2004.

Shindell, D. T., Faluvegi, G., Miller, R. L., Schmidt, G. A., Hansen, J. E., and Sun, S.: Solar and anthropogenic forcing of tropical hydrology, Geophys. Res. Lett., 33, L24706, https://doi.org/10.1029/2006gl027468, 2006.

Shuman, B., Henderson, A. K., Colman, S. M., Stone, J. R., Fritz, S. C., Stevens, L. R., Power, M. J., and Whitlock, C.: Holocene lake-level trends in the Rocky Mountains, USA, Quaternary Sci. Rev., 28, 1861-1879, https://doi.org/10.1016/j.quascirev.2009.03.003, 2009.

Sigl, M., Winstrup, M., McConnell, J. R., Welten, K. C., Plunkett, G., Ludlow, F., Buentgen, U., Caffee, M., Chellman, N., Dahl-Jensen, D., Fischer, H., Kipfstuhl, S., Kostick, C., Maselli, O. J., Mekhaldi, F., Mulvaney, R., Muscheler, R., Pasteris, D. R., Pilcher, J. R., Salzer, M., Schuepbach, S., Steffensen, J. P., Vinther, B. M., and Woodruff, T. E.: Timing and climate forcing of volcanic eruptions for the past 2500 years, Nature, 523, 543, https://doi.org/10.1038/nature14565, 2015.

Smerdon, J. E.: Climate models as a test bed for climate reconstruction methods: pseudoproxy experiments, WIREs Clim. Change, 3, 63-77, https://doi.org/10.1002/wcc.149, 2012.

Smerdon, J. E. and Pollack, H. N.: Reconstructing Earth's surface temperature over the past 2000 years: the science behind the headlines, WIREs Clim. Change, 7, 746-771, https://doi.org/10.1002/wcc.418, 2016.

Smerdon, J. E., Cook, B. I., Cook, E. R., and Seager, R.: Bridging past and future climate across paleoclimatic reconstructions, observations, and models: a hydroclimate case study, J. Climate, 28, 3212-3231, https://doi.org/10.1175/jcli-d-14-00417.1, 2015.

Smerdon, J. E., Luterbacher, J., and Phipps, S. J.: Hydro2k: integrating proxy data and models for insights into past and future hydroclimate, PAGES Mag., 24, 45, https://doi.org/10.22498/pages.24.1.45, 2016.

Sperber, K., Annamalai, H., Kang, I. S., Kitoh, A., Moise, A., Turner, A., Wang, B., and Zhou, T.: The Asian summer monsoon: an intercomparison of CMIP5 vs. CMIP3 simulations of the late 20th century, Clim. Dynam., 41, 2711-2744, https://doi.org/10.1007/s00382-012-1607-6, 2013.

St. George, S.: An overview of tree-ring width records across the Northern Hemisphere, Quaternary Sci. Rev., 95, 132-150, https://doi.org/10.1016/j.quascirev.2014.04.029, 2014.

St. George, S., Meko, D. M., and Cook, E. R.: The seasonality of precipitation signals embedded within the North American Drought Atlas, Holocene, 20, 983-988, https://doi.org/10.1177/0959683610365937, 2010.

St. George, S. and Ault, T. R.: The imprint of climate within Northern Hemisphere trees, Quaternary Sci. Rev., 89, 1-4, https://doi.org/10.1016/j.quascirev.2014.01.007, 2014.

Stager, J. C., Ruzmaikin, A., Conway, D., Verburg, P., and Mason, P. J.: Sunspots, El Nino, and the levels of Lake Victoria, East Africa, J. Geophys. Res.-Atmos., 112, D15106, https://doi.org/10.1029/2006jd008362, 2007.

Stahle, D. W.: Useful strategies for the development of tropical treering chronologies, IAWA J., 20, 249-253, 1999. 
Stahle, D. W., Cleaveland, M. K., Blanton, D. B., Therrell, M. D., and Gay, D. A.: The Lost Colony and Jamestown droughts, Science, 280, 564-567, https://doi.org/10.1126/science.280.5363.564, 1998.

Stahle, D. W., Cleaveland, M. K., Grissino-Mayer, H. D., Griffin, R. D., Fye, F. K., Therrell, M. D., Burnette, D. J., Meko, D. M., and Diaz, J. V.: Cool- and warm-season precipitation reconstructions over western New Mexico, J. Climate, 22, 3729-3750, https://doi.org/10.1175/2008jcli2752.1, 2009.

Steiger, N. and Smerdon, J.: A pseudoproxy assessment of data assimilation for reconstructing the atmosphere-ocean dynamics of hydroclimate extremes, Clim. Past Discuss., https://doi.org/10.5194/cp-2017-69, in review, 2017.

Steiger, N. J., Hakim, G. J., Steig, E. J., Battisti, D. S., and Roe, G. H.: Assimilation of time-averaged pseudoproxies for climate reconstruction, J. Climate, 27, 426-441, https://doi.org/10.1175/jcli-d-12-00693.1, 2014.

Steinhilber, F., Beer, J., and Froehlich, C.: Total solar irradiance during the Holocene, Geophys. Res. Lett., 36, L19704, https://doi.org/10.1029/2009g1040142, 2009.

Stephans, C. L., Quinn, T. M., Taylor, F. W., and Corrège, T.: Assessing the reproducibility of coral-based climate records, Geophys. Res. Lett., 31, L18210, https://doi.org/10.1029/2004GL020343, 2004.

Stephens, G. L., L'Ecuyer, T., Forbes, R., Gettelman, A., Golaz, J.C., Bodas-Salcedo, A., Suzuki, K., Gabriel, P., and Haynes, J.: Dreary state of precipitation in global models, J. Geophys. Res.Atmos., 115, D24211, https://doi.org/10.1029/2010jd014532, 2010.

Stevenson, S., Powell, B. S., Merrifield, M. A., Cobb, K. M., Nusbaumer, J., and Noone, D.: Characterizing seawater oxygen isotopic variability in a regional ocean modeling framework: implications for coral proxy records, Paleoceanography, 30, 15731593, https://doi.org/10.1002/2015PA002824, $2015 \mathrm{a}$.

Stevenson, S., Timmermann, A., Chikamoto, Y., Langford, S., and DiNezio, P.: Stochastically generated North American megadroughts, J. Climate, 28, 1865-1880, https://doi.org/10.1175/jcli-d-13-00689.1, 2015b.

Stevenson, S., Otto-Bliesner, B., Fasullo, J., and Brady, E.: "El Niño Like" hydroclimate responses to last millennium volcanic eruptions, J. Climate, 29, 2907-2921, https://doi.org/10.1175/JCLID-15-0239.1, 2016.

Stevenson, S., Fasullo, J., Otto-Bliesner, B. L., Tomas, R., and Gao, C. C.: Role of eruption season in reconciling model and proxy responses to tropical volcanism, P. Natl. Acad. Sci. USA, 114, 1822-1826, https://doi.org/10.1073/pnas.1612505114, 2017.

Stockton, C. W. and Jacoby, G. C.: Long-Term Surface-Water Supply and Streamflow Trends in the Upper Colorado River Basin, Lake Powell Res. Proj. Bull. 18, Natl. Sci. Found., Arlington, VA, 1976.

Stokes, M. A. and Smiley, T. L.: An Introduction to Tree-Ring Dating, University of Chicago Press, Chicago, Illinois, USA, 1968.

Stuiver, M. and Braziunas, T. F.: Modeling atmospheric ${ }^{14} \mathrm{C}$ influences and ${ }^{14} \mathrm{C}$ ages of marine samples to $10000 \mathrm{BC}$, Radiocarbon, 35, 137-189, https://doi.org/10.1017/S0033822200013874, 1993.

Sturm, C., Zhang, Q., and Noone, D.: An introduction to stable water isotopes in climate models: benefits of forward proxy modelling for paleoclimatology, Clim. Past, 6, 115-129, https://doi.org/10.5194/cp-6-115-2010, 2010.

Suess, H. E.: The radiocarbon record in tree rings of the last 8000 years, Radiocarbon, 22, 200-209, 1980.

Swann, A. L. S., Hoffman, F. M., Koven, C. D., and Randerson, J. T.: Plant responses to increasing $\mathrm{CO}_{2}$ reduce estimates of climate impacts on drought severity, P. Natl. Acad. Sci. USA, 113, 10019-10024, https://doi.org/10.1073/pnas.1604581113, 2016.

Teal, L. R., Bulling, M. T., Parker, E. R., and Solan, M.: Global patterns of bioturbation intensity and mixed depth of marine soft sediments, Aquat. Biol., 2, 207-218, 2008.

Terray, L., Corre, L., Cravatte, S., Delcroix, T., Reverdin, G., and Ribes, A.: Near-surface salinity as nature's rain gauge to detect human influence on the tropical water cycle, J. Climate, 25, 958977, https://doi.org/10.1175/JCLI-D-10-05025.1, 2011.

Tharammal, T., Bala, G., and Noone, D.: Impact of deep convection on the isotopic amount effect in tropical precipitation, J. Geophys. Res.-Atmos., 122, 1505-1523, https://doi.org/10.1002/2016JD025555, 2017.

Thompson, D. M., Ault, T. R., Evans, M. N., Cole, J. E., and EmileGeay, J.: Comparison of observed and simulated tropical climate trends using a forward model of coral $\delta^{18} \mathrm{O}$, Geophys. Res. Lett., 38, L14706, https://doi.org/10.1029/2011gl048224, 2011.

Thomson, D. J.: Spectrum estimation and harmonic-analysis, Proc. IEEE, 70, 1055-1096, https://doi.org/10.1109/proc.1982.12433, 1982.

Tierney, J. E., Oppo, D. W., Rosenthal, Y., Russell, J. M., and Linsley, B. K.: Coordinated hydrological regimes in the IndoPacific region during the past two millennia, Paleoceanography, 25, PA1102, https://doi.org/10.1029/2009PA001871, 2010.

Tierney, J. E., Smerdon, J. E., Anchukaitis, K. J., and Seager, R.: Multidecadal variability in East African hydroclimate controlled by the Indian Ocean, Nature, 493, 389-392, https://doi.org/10.1038/nature11785, 2013.

Tierney, J. E., Abram, N. J., Anchukaitis, K. J., Evans, M. N., Giry, C., Kilbourne, K. H., Saenger, C. P., Wu, H. C., and Zinke, J.: Tropical sea surface temperatures for the past four centuries reconstructed from coral archives, Paleoceanography, 30, 226-252, https://doi.org/10.1002/2014PA002717, 2015a.

Tierney, J. E., Ummenhofer, C. C., and deMenocal, P. B.: Past and future rainfall in the Horn of Africa, Sci. Adv., 1, e1500682e1500682, https://doi.org/10.1126/sciadv.1500682, 2015b.

Tierney, J. E., Smerdon, J., Anchukaitis, K. J., and Seager, R.: East African 675 Year MCEOF Hydroclimatic Lake Proxy Data Synthesis, available at: https://www.ncdc.noaa.gov/paleo-search/ study/13686, last access: October 2017.

Tingley, M. P., Craigmile, P. F., Haran, M., Li, B., Mannshardt, E., and Rajaratnam, B.: Piecing together the past: statistical insights into paleoclimatic reconstructions, Quaternary Sci. Rev., 35, 122, https://doi.org/10.1016/j.quascirev.2012.01.012, 2012.

Todd, B., Macdonald, N., Chiverrell, R. C., Caminade, C., and Hooke, J. M.: Severity, duration and frequency of drought in SE England from 1697 to 2011, Clim. Change, 121, 673-687, https://doi.org/10.1007/s10584-013-0970-6, 2013.

Tolwinski-Ward, S. E., Evans, M. N., Hughes, M. K., and Anchukaitis, K. J.: An efficient forward model of the climate controls on interannual variation in tree-ring width, Clim. Dy- 
nam., 36, 2419-2439, https://doi.org/10.1007/s00382-010-0945$5,2011$.

Toohey, M., Stevens, B., Schmidt, H., and Timmreck, C.: Easy Volcanic Aerosol (EVA v1.0): an idealized forcing generator for climate simulations, Geosci. Model Dev., 9, 4049-4070, https://doi.org/10.5194/gmd-9-4049-2016, 2016.

Touchan, R., Xoplaki, E., Funkhouser, G., Luterbacher, J., Hughes, M. K., Erkan, N., Akkemik, U., and Stephan, J.: Reconstructions of spring/summer precipitation for the Eastern Mediterranean from tree-ring widths and its connection to large-scale atmospheric circulation, Clim. Dynam., 25, 75-98, https://doi.org/10.1007/s00382-005-0016-5, 2005.

Touchan, R., Anchukaitis, K. J., Meko, D. M., Sabir, M., Attalah, S., and Aloui, A.: Spatiotemporal drought variability in northwestern Africa over the last nine centuries, Clim. Dynam., 37, 237252, https://doi.org/10.1007/s00382-010-0804-4, 2011.

Touchan, R., Anchukaitis, K. J., Shishov, V. V., Sivrikaya, F., Attieh, J., Ketmen, M., Stephan, J., Mitsopoulos, I., Christou, A., and Meko, D. M.: Spatial patterns of eastern Mediterranean climate influence on tree growth, Holocene, 24, 381-392, https://doi.org/10.1177/0959683613518594, 2014.

Trauth, M. H.: TURBO2: A MATLAB simulation to study the effects of bioturbation on paleoceanographic time series, Comput. Geosci., 61, 1-10, https://doi.org/10.1016/j.cageo.2013.05.003, 2013.

Treble, P., Shelley, J. M. G., and Chappell, J.: Comparison of high resolution sub-annual records of trace elements in a modern (1911-1992) speleothem with instrumental climate data from southwest Australia, Earth Planet. Sc. Lett., 216, 141-153, https://doi.org/10.1016/S0012-821X(03)00504-1, 2003.

Trenberth, K. E. and Dai, A.: Effects of Mount Pinatubo volcanic eruption on the hydrological cycle as an ana$\log$ of geoengineering, Geophys. Res. Lett., 34, L15702, https://doi.org/10.1029/2007gl030524, 2007.

Treydte, K. S., Schleser, G. H., Helle, G., Frank, D. C., Winiger, M., Haug, G. H., and Esper, J.: The twentieth century was the wettest period in northern Pakistan over the past millennium, Nature, 440, 1179-1182, https://doi.org/10.1038/nature04743, 2006.

Treydte, K., Frank, D., Esper, J., Andreu, L., Bednarz, Z., Berninger, F., Boettger, T., D’Alessandro, C. M., Etien, N., Filot, M., Grabner, M., Guillemin, M. T., Gutierrez, E., Haupt, M., Helle, G., Hilasvuori, E., Jungner, H., KalelaBrundin, M., Krapiec, M., Leuenberger, M., Loader, N. J., Masson-Delmotte, V., Pazdur, A., Pawelczyk, S., Pierre, M., Planells, O., Pukiene, R., Reynolds-Henne, C. E., Rinne, K. T., Saracino, A., Saurer, M., Sonninen, E., Stievenard, M., Switsur, V. R., Szczepanek, M., Szychowska-Krapiec, E., Todaro, L., Waterhouse, J. S., Weigl, M., and Schleser, G. H.: Signal strength and climate calibration of a European treering isotope network, Geophys. Res. Lett., 34, L24302, https://doi.org/10.1029/2007gl031106, 2007.

Truebe, S. A., Ault, T. R., Cole, J. E., A Forward Model of Cave Dripwater $\delta^{18} \mathrm{O}$ and Application to Speleothem Records, IOP Conf. Series: Earth and Environmental Science, 9, 012022, https://doi.org/10.1088/1755-1315/9/1/012022, 2010.

Urrutia, R. B., Lara, A., Villalba, R., Christie, D. A., Le Quesne, C., and Cuq, A.: Multicentury tree ring reconstruction of annual streamflow for the Maule River watershed in south central Chile, Water Resour. Res., 47, W06527, https://doi.org/10.1029/2010wr009562, 2011.

van der Schrier, G., Jones, P. D., and Briffa, K. R.: The sensitivity of the PDSI to the Thornthwaite and Penman-Monteith parameterizations for potential evapotranspiration, J. Geophys. Res.Atmos., 116, D03106, https://doi.org/10.1029/2010jd015001, 2011.

Verschuren, D., Laird, K. R., and Cumming, B. F.: Rainfall and drought in equatorial east Africa during the past 1100 years, Nature, 403, 410-414, 2000.

Vieira, L. E. A. and Solanki, S. K.: Evolution of the solar magnetic flux on time scales of years to millenia, Astron. Astrophys., 509, 13, https://doi.org/10.1051/0004-6361/200913276, 2010.

Vieira, L. E. A., Solanki, S. K., Krivova, N. A., and Usoskin, I.: Evolution of the solar irradiance during the Holocene, Astron. Astrophys., 531, https://doi.org/10.1051/0004-6361/201015843, 2011.

Voelker, S. L., Meinzer, F. C., Lachenbruch, B., Brooks, J. R., and Guyette, R. P.: Drivers of radial growth and carbon isotope discrimination of bur oak (Quercus macrocarpa Michx.) across continental gradients in precipitation, vapour pressure deficit and irradiance, Plant Cell Environ., 37, 766-779, https://doi.org/10.1111/pce.12196, 2014.

Vuille, M. and Werner, M.: Stable isotopes in precipitation recording South American summer monsoon and ENSO variability - observations and model results. Climate Dyn., 25, 401-413, https://doi.org/10.1007/s00382-005-0049-9, 2005.

Vuille, M., Werner, M., Bradley, R. S., Keimig, F.: Stable isotopes in precipitation in the Asian monsoon region. J. Geophys. Res., 110, D23108, https://doi.org/10.1029/2005JD006022, 2005a.

Vuille, M., Werner, M., Bradley, R. S., Chan, R. S., and Keimig, F.: Stable isotopes in East African precipitation record Indian Ocean Zonal mode. Geophys. Res. Lett., 32, L21705, https://doi.org/10.1029/2005GL023876, 2005b.

Wahl, E. R., Diaz, H. F., Smerdon, J. E., and Ammann, C. M.: Late winter temperature response to large tropical volcanic eruptions in temperate western North America: relationship to ENSO phases, Global Planet. Change, 122, 238-250, https://doi.org/10.1016/j.gloplacha.2014.08.005, 2014.

Wahl, E., Diaz, H., Vose, R., and Gross, W.: Multicentury Evaluation of Recovery from Strong Precipitation Deficits in California, J. Climate, 30, 6053-6063, https://doi.org/10.1175/JCLI-D-160423.1, 2017.

Wang, Y. J., Cheng, H., Edwards, R. L., An, Z. S., Wu, J. Y., Shen, C. C., and Dorale, J. A.: A high-resolution absolute-dated late pleistocene monsoon record from Hulu Cave, China, Science, 294, 2345-2348, https://doi.org/10.1126/science.1064618, 2001.

Wang, Y. M., Lean, J. L., and Sheeley, N. R.: Modeling the sun's magnetic field and irradiance since 1713, Astrophys. J., 625, 522-538, https://doi.org/10.1086/429689, 2005.

Wang, X., Auler, A. S., Edwards, R. L., Cheng, H., Ito, E., Wang, Y., Kong, X., and Solheid, M.: Millennial-scale precipitation changes in southern Brazil over the past 90,000 years, Geophys. Res. Lett., 34, L23701, https://doi.org/10.1029/2007GL031149, 2007.

Wang, C., Zhang, L., Lee, S.-K., Wu, L., and Mechoso, C. R.: A global perspective on CMIP5 climate model biases, Nat. Clim. 
Change, 4, 201-205, https://doi.org/10.1038/nclimate2118, 2014a.

Wang, J., Emile-Geay, J., Guillot, D., Smerdon, J. E., and Rajaratnam, B.: Evaluating climate field reconstruction techniques using improved emulations of real-world conditions, Clim. Past, 10, 119, https://doi.org/10.5194/cp-10-1-2014, 2014b.

Wang, J., Emile-Geay, J., Guillot, D., McKay, N. P., and Rajaratnam, B.: Fragility of reconstructed temperature patterns over the Common Era: Implications for model evaluation, Geophys. Res. Lett., 42, 7162-7170, https://doi.org/10.1002/2015gl065265, 2015.

Wegmann, M., Broennimann, S., Bhend, J., Franke, J., Folini, D., Wild, M., and Luterbacher, J.: Volcanic influence on European summer precipitation through monsoons: possible cause for "Years without Summer", J. Climate, 27, 3683-3691, https://doi.org/10.1175/jcli-d-13-00524.1, 2014.

Weigel, A. P., Knutti, R., Liniger, M. A., and Appenzeller, C.: Risks of model weighting in multimodel climate projections, J. Climate, 23, 4175-4191, https://doi.org/10.1175/2010JCLI3594.1, 2010.

Werner, J. P. and Tingley, M. P.: Technical Note: Probabilistically constraining proxy age-depth models within a Bayesian hierarchical reconstruction model, Clim. Past, 11, 533-545, https://doi.org/10.5194/cp-11-533-2015, 2015.

Wetter, O., Pfister, C., Weingartner, R., Luterbacher, J., Reist, T., and Troesch, J.: The largest floods in the High Rhine basin since 1268 assessed from documentary and instrumental evidence, Hydrolog. Sci. J., 56, 733-758, https://doi.org/10.1080/02626667.2011.583613, 2011.

Wetter, O., Pfister, C., Werner, J. P., Zorita, E., Wagner, S., Seneviratne, S. I., Herget, J., Gruenewald, U., Luterbacher, J., Alcoforado, M.-J., Barriendos, M., Bieber, U., Brazdil, R., Burmeister, K. H., Camenisch, C., Contino, A., Dobrovolny, P., Glaser, R., Himmelsbach, I., Kiss, A., Kotyza, O., Labbe, T., Limanowka, D., Litzenburger, L., Nordl, O., Pribyl, K., Retso, D., Riemann, D., Rohr, C., Siegfried, W., Soderberg, J., and Spring, J.-L.: The year-long unprecedented European heat and drought of 1540-a worst case, Climatic Change, 125, 349-363, https://doi.org/10.1007/s10584-014-1184-2, 2014.

Widmann, M., Goosse, H., van der Schrier, G., Schnur, R., and Barkmeijer, J.: Using data assimilation to study extratropical Northern Hemisphere climate over the last millennium, Clim. Past, 6, 627-644, https://doi.org/10.5194/cp-6-627-2010, 2010.

Wigley, T. M. L., Briffa, K. R., and Jones, P. D.: On the average value of correlated time-series, with applications in dendroclimatology and hydrometeorology, J. Clim. Appl. Meteorol., 23, 201-213, https://doi.org/10.1175/15200450(1984)023<0201:otavoc>2.0.co;2, 1984.

Williams, A. P., Michaelsen, J., Leavitt, S. W., and Still, C. J.: Using tree rings to predict the response of tree growth to climate change in the continental United States during the twenty-first century, Earth Interact., 14, 1-20, https://doi.org/10.1175/2010EI362.1, 2010.

Williams, A. P., Funk, C., Michaelsen, J., Rauscher, S. A., Robertson, I., Wils, T. H. G., Koprowski, M., Eshetu, Z., and Loader, N. J.: Recent summer precipitation trends in the Greater Horn of Africa and the emerging role of Indian Ocean sea surface temperature, Clim. Dynam., 39, 2307-2328, https://doi.org/10.1007/s00382-011-1222-y, 2012.
Wils, T. H. G., Robertson, I., Eshetu, Z., Koprowski, M., Sass-Klaassen, U. G. W., Touchan, R., and Loader, N. J.: Towards a reconstruction of Blue Nile baseflow from Ethiopian tree rings, Holocene, 20, 837-848, https://doi.org/10.1177/0959683610365940, 2010.

Wilson, R., Cook, E., D’Arrigo, R., Riedwyl, N., Evans, M. N., Tudhope, A., and Allan, R.: Reconstructing ENSO: the influence of method, proxy data, climate forcing and teleconnections, J. Quaternary Sci., 25, 62-78, https://doi.org/10.1002/jqs.1297, 2010.

Wilson, R., Rao, R., Rydval, M., Wood, C., Larsson, L.-A., and Luckman, B. H.: Blue Intensity for dendroclimatology: the BC blues: a case study from British Columbia, Canada, Holocene, 24, 1428-1438, https://doi.org/10.1177/0959683614544051, 2014.

Wilson, R., Anchukaitis, K., Briffa, K. R., Buentgen, U., Cook, E., D’Arrigo, R., Davi, N., Esper, J., Frank, D., Gunnarson, B., Hegerl, G., Helama, S., Klesse, S., Krusic, P. J., Linderholm, H. W., Myglan, V., Osborn, T. J., Rydval, M., Schneider, L., Schurer, A., Wiles, G., Zhang, P., and Zorita, E.: Last millennium Northern Hemisphere summer temperatures from tree rings: Part I: The long term context, Quaternary Sci. Rev., 134, 1-18, https://doi.org/10.1016/j.quascirev.2015.12.005, 2016.

Winter, A., Miller, T., Kushnir, Y., Sinha, A., Timmermann, A., Jury, M. R., Gallup, C., Cheng, H., and Edwards, R. L.: Evidence for 800 years of North Atlantic multi-decadal variability from a Puerto Rican speleothem, Earth Planet. Sc. Lett., 308, 23-28, https://doi.org/10.1016/j.epsl.2011.05.028, 2011.

Winter, A., Zanchettin, D., Miller, T., Kushnir, Y., Black, D., Lohmann, G., Burnett, A., Haug, G. H., Estrella-Martinez, J., Breitenbach, S. F. M., Beaufort, L., Rubino, A., and Cheng, H.: Persistent drying in the tropics linked to natural forcing, Nat. Commun., 6, 7627, https://doi.org/10.1038/ncomms8627, 2015.

Wise, E. K. and Dannenberg, M. P.: Persistence of pressure patterns over North America and the North Pacific since AD 1500, Nat. Commun., 5, 6, https://doi.org/10.1038/ncomms5912, 2014.

Wittenberg, A. T.: Are historical records sufficient to constrain ENSO simulations?, Geophys. Res. Lett., 36, L12702, https://doi.org/10.1029/2009GL038710, 2009.

Woodhouse, C. A. and Lukas, J. J.: Drought, tree rings and water resource management in Colorado, Can. Water Resour. J., 31, 297-310, 2006.

Woodhouse, C. A. and Lukas, J. J.: Multi-century tree-ring reconstructions of Colorado streamflow for water resource planning, Climatic Change, 78, 293-315, https://doi.org/10.1007/s10584006-9055-0, 2006.

Woodhouse, C. A., Gray, S. T., and Meko, D. M.: Updated streamflow reconstructions for the Upper Colorado River Basin, Water Resour. Res., 42, 16, https://doi.org/10.1029/2005wr004455, 2006.

Xoplaki, E., Fleitmann, D., Luterbacher, J., Wagner, S., Haldon, J. F., Zorita, E., Telelis, I., Toreti, A., and Izdebski, A.: The Medieval Climate Anomaly and Byzantium: A review of the evidence on climatic fluctuations, economic performance and societal change, Quaternary Sci. Rev., 136, 229-252, https://doi.org/10.1016/j.quascirev.2015.10.004, 2016.

Xu, H., Lan, J., Sheng, E., Liu, B., Yu, K., Ye, Y., Shi, Z., Cheng, P., Wang, X., Zhou, X., and Yeager, K. M.: Hydroclimatic contrasts 
over Asian monsoon areas and linkages to tropical Pacific SSTs, Sci. Rep.-UK, 6, https://doi.org/10.1038/srep33177, 2016.

Yan, Z., Ye, D., and Wang, C.: Climatic jumps in the flood/drought historical chronology of central China, Clim. Dynam., 6, 153160, 1992.

Yao, S. Y.: The geographical distribution of floods and droughts in Chinese history, 206 B. C.-A. D. 1911, The Far Eastern Quarterly, 2, 357-378, https://doi.org/10.2307/2049242, 1943.

Yi, L., Yu, H., Ge, J., Lai, Z., Xu, X., Qin, L., and Peng, S.: Reconstructions of annual summer precipitation and temperature in north-central China since $1470 \mathrm{AD}$ based on drought/flood index and tree-ring records, Climatic Change, 110, 469-498, https://doi.org/10.1007/s10584-011-0052-6, 2012.

Yoshimori, M., Stocker, T. F., Raible, C. C., and Renold, M.: Externally forced and internal variability in ensemble climate simulations of the Maunder Minimum, J. Climate, 18, 4253-4270, https://doi.org/10.1175/jcli3537.1, 2005.

Yoshimori, M., Raible, C. C., Stocker, T. F., and Renold, M.: On the interpretation of low-latitude hydrological proxy records based on Maunder Minimum AOGCM simulations, Clim. Dynam., 27, 493-513, https://doi.org/10.1007/s00382-006-0144-6, 2006.

Young, G. H. F., McCarroll, D., Loader, N. J., and Kirchhefer, A. J.: A 500-year record of summer near-ground solar radiation from tree-ring stable carbon isotopes, Holocene, 20, 315324, https://doi.org/10.1177/0959683609351902, 2010.

Zanchettin, D., Timmreck, C., Graf, H. F., Rubino, A., Lorenz, S., Lohmann, K., Krüger, K., and Jungclaus, J. H.: Bi-decadal variability excited in the coupled ocean-atmosphere system by strong tropical volcanic eruptions, Clim. Dynam., 39, 419-444, https://doi.org/10.1007/s00382-011-1167-1, 2012.

Zanchettin, D., Bothe, O., Graf, H. F., Lorenz, S. J., Luterbacher, J., Timmreck, C., and Jungclaus, J. H.: Background conditions influence the decadal climate response to strong volcanic eruptions, J. Geophys. Res.-Atmos., 118, 4090-4106, https://doi.org/10.1002/jgrd.50229, 2013a.

Zanchettin, D., Rubino, A., Matei, D., Bothe, O., and Jungclaus, J. H.: Multidecadal-to-centennial SST variability in the MPI-ESM simulation ensemble for the last millennium, Clim. Dynam., 40, 1301-1318, https://doi.org/10.1007/s00382-0121361-9, 2013b.

Zanchettin, D., Bothe, O., Lehner, F., Ortega, P., Raible, C. C., and Swingedouw, D.: Reconciling reconstructed and simulated features of the winter Pacific/North American pattern in the early 19th century, Clim. Past, 11, 939-958, https://doi.org/10.5194/cp-11-939-2015, 2015.

Zanchettin, D., Khodri, M., Timmreck, C., Toohey, M., Schmidt, A., Gerber, E. P., Hegerl, G., Robock, A., Pausata, F. S. R., Ball, W. T., Bauer, S. E., Bekki, S., Dhomse, S. S., LeGrande, A. N., Mann, G. W., Marshall, L., Mills, M., Marchand, M., Niemeier, U., Poulain, V., Rozanov, E., Rubino, A., Stenke, A., Tsigaridis, K., and Tummon, F.: The Model Intercomparison Project on the climatic response to Volcanic forcing (VolMIP): experimental design and forcing input data for CMIP6, Geosci. Model Dev., 9, 2701-2719, https://doi.org/10.5194/gmd-9-2701-2016, 2016.

Zanchettin, D.: Aerosol and solar irradiance effects on decadal climate variability and predictability, Current Climate Change Reports, 3, 150-162, https://doi.org/10.1007/s40641-017-0065-y, 2017.
Zappa, G., Shaffrey, L. C., and Hodges, K. I.: The ability of CMIP5 models to simulate North Atlantic extratropical cyclones, J. Climate, 26, 5379-5396, https://doi.org/10.1175/jcli-d-12-00501.1, 2013.

Zhang, P. Y.: Climate Change in China During Historical Times, Shandong Science and Technology Press, Jinan, China, 1996.

Zhang, J. and Crowley, T. J.: Historical climate records in China and reconstruction of past climates, J. Climate, 2, 833-849, https://doi.org/10.1175/15200442(1989)002<0833:hcrica>2.0.co;2, 1989.

Zhang, P. Y. and Gong, G. F.: Ancient precipitation records in China, World Meteorol. Org. Bull., 29, 7-11, 1980.

Zhang, D. and Liu, Y.: A new approach to the reconstruction of temporal rainfall sequences from 1724-1904 Qing Dynasty weather records from Beijing, Quaternary Sci., 22, 199-208, 2002.

Zhang, D. and Wang, P. K.: A study on Meiyu activity of eighteenth century in the lower Yangtze Region, Sci. China Ser. B, 34, 1237-1245, 1991.

Zhang, D. E., Liu, C. Z., and Jiang, J. M.: Reconstruction of six regional dry/wet series and their abrupt changes during the last 1000 years in east China, Quaternary Sci., 1, 1-11, 1997.

Zhang, D., Li, X., and Liang, Y.: Supplement of yearly charts of dryness/wetness in China for the last 500-year period, 1993-2000, J. Appl. Meteorol. Sci., 14, 379-389, 2003.

Zhang, D., Liu, Y., Liang, Y., and Li, J.: Reconstruction of annual and seasonal precipitation series of Nanjing, Suzhou and Hangzhou during the 18th century, Quaternary Sci., 25, 121-128, 2005.

Zhang, P., Cheng, H., Edwards, R. L., Chen, F., Wang, Y., Yang, X., Liu, J., Tan, M., Wang, X., Liu, J., An, C., Dai, Z., Zhou, J., Zhang, D., Jia, J., Jin, L., and Johnson, K. R.: A test of climate, sun, and culture relationships from an 1810-year Chinese cave record, Science, 322, 940-942, https://doi.org/10.1126/science.1163965, 2008.

Zhang, T., Simelton, E., Huang, Y., and Shi, Y.: A Bayesian assessment of the current irrigation water supplies capacity under projected droughts for the 2030s in China, Agr. Forest Meteorol., 178, 56-65, https://doi.org/10.1016/j.agrformet.2012.06.002, 2013.

Zheng, J. Y., Hao, Z. X., and Ge, Q. S.: Variation of precipitation for the last 300 years over the middle and lower reaches of the Yellow River, Sci. China Ser. D, 48, 2182-2193, https://doi.org/10.1360/03yd0392, 2005.

Zheng, J., Wang, W. C., Ge, Q., Man, Z., and Zhang, P.: Precipitation variability and extreme events in eastern China during the past 1500 years, Terr. Atmos. Ocean. Sci., 17, 579-592, https://doi.org/10.3319/TAO.2006.17.3.579(A), 2006.

Zheng, J. Y., Ge, Q. S., Hao, Z. X., Liu, H. L., Man, Z. M., Hou, Y. J., and Fang, X. Q.: Paleoclimatology proxy recorded in historical documents and method for reconstruction on climate change, Quaternary Sci., 34, 1186-1196, 2014.

Zinke, J., Pfeiffer, M., Timm, O., Dullo, W. C., Kroon, D., and Thomassin, B. A.: Mayotte coral reveals hydrological changes in the western Indian Ocean between 1881 and 1994, Geophys. Res. Lett., 35, L23707, https://doi.org/10.1029/2008g1035634, 2008.

Zinke, J., Pfeiffer, M., Timm, O., Dullo, W. C., Kroon, D., and Thomassin, B. A.: Mayotte - coupled $\mathrm{Sr} / \mathrm{Ca}$ and $\delta^{18} \mathrm{O}$ data, available at: http://www.ncdc.noaa.gov/paleo/study/8606, last access: 23 May 2016. 